\title{
The Cyclical Behavior of Unemployment and Wages under Information Frictions*
}

\author{
Camilo Morales-Jiménez ${ }^{\dagger}$ \\ Federal Reserve Board
}

\begin{abstract}
This Version: February 1, 2017
Latest Version: Click HERE
\end{abstract}

\begin{abstract}
I propose a new mechanism for sluggish wages based on workers' noisy information about the state of the economy. Wages do not respond immediately to a positive aggregate shock because workers do not (yet) have enough information to demand higher wages. This increases firms' incentives to post more vacancies, which makes unemployment volatile and sensitive to aggregate shocks. The model is robust to two major criticisms of existing theories of sluggish wages and volatile unemployment: flexibility of wages for new hires and pro-cyclicality of the opportunity cost of employment. Calibrated to U.S. data, the model explains $70 \%$ of unemployment volatility.
\end{abstract}

*I am especially grateful to Boragan Aruoba, Luminita Stevens, John Haltiwanger, and John Shea for their valuable suggestions and support. I would also like to thank Katherine Abraham, Pablo Cuba-Borda, Sebnem Kalemli-Ozcan, Ethan Kaplan, Felipe Saffie, Marisol Rodriguez-Chatruc, Loukas Karabarbounis, Ellen McGrattan, Ryan Michaels, Iourii Manovskii and seminar participants at the University of Maryland, University of Pennsylvania, University of Minnesota and Federal Reserve Bank of Philadelphia for valuable suggestions and helpful comments. The views expressed in this paper are solely the responsibility of the author and should not be interpreted as reflecting the views of the Board of Governors of the Federal Reserve System or of anyone else associated with the Federal Reserve System.

${ }^{\dagger}$ Contact: cmoralesjimenez@frb.gov 


\section{Introduction}

Search and matching models are an appealing way to study fluctuations in the labor market, as they define unemployment in a manner that is consistent with statistical agencies' convention and describe in an attractive way the functioning of the labor market, how firms and workers are matched and how wages are negotiated. ${ }^{1}$ However, Shimer (2005) points out the low volatility of unemployment predicted by the standard search and matching model, hence giving rise to a large body of literature studying the amplifying effects of sluggish wages. This approach to the Shimer Puzzle has been criticized in recent years on the basis that, empirically, wages for new hires exhibit little rigidity while the opportunity cost of employment is pro-cyclical. ${ }^{2}$ In this paper, I propose a new mechanism for sluggish wages based on workers' noisy information about the state of the economy that is robust to the aforementioned critiques and that generates business cycle dynamics for unemployment and wages that are consistent with the empirical evidence. ${ }^{3}$

In my model, wages for new hires are flexible, but wages do not adjust immediately to the true state of the economy because agents learn slowly about aggregate shocks. This delayed adjustment in wages increases firms' incentives to expand employment, making unemployment volatile and sensitive to aggregate shocks. My model is able to explain $70 \%$ of overall unemployment volatility and generates wage semi-elasticities with respect to the unemployment rate of around $-3 \%$ for new hires.

The model presented in this paper is in many respects similar to a standard RBC model with search and matching in the labor market. I introduce heterogeneous firms and assume that they differ in their permanent total factor productivity (TFP) levels, which are public information. Hence, in equilibrium, the most productive firms are larger and pay higher wages. In order to distinguish between new hires coming from unemployment and job changers, I assume that workers search on the job for better-paid jobs. However, the most important distinction in this model versus the existing literature is that workers (households) face information frictions regarding aggregate

\footnotetext{
${ }^{1}$ Rogerson and Shimer (2010) assess in more detail how models with search frictions have shaped our understanding of aggregate labor market outcomes.

${ }^{2}$ For example, Rudanko (2009) shows in a model with long-term contracts that wage rigidity does not increase unemployment volatility as long as wages for new hires are flexible. Mortensen and Nagypal (2007) argue that the literature has overemphasized the need for sticky wages to increase unemployment volatility in the standard model of Mortensen and Pissarides (1994) and highlight three other features that could help explain the Shimer puzzle: (1) low elasticity of the matching function with respect to vacancies, (2) low value for the flow opportunity cost of employment (FOCE), and (3) strong feedback from the job-finding rate to wages. Similarly, Pissarides (2009) critiques the assumption of sticky wages based on empirical evidence that wages for new hires (job changers or new hires coming from unemployment) are more pro-cyclical than are wages for existing workers (e.g. Beaudry \& DiNardo, 1991; Bils 1985; Haefke, Sonntag \& van Rens 2013; Shin, 1994).

${ }^{3}$ Even though this paper focuses on labor market fluctuations, whether sticky wages are a source of fluctuations over the business cycle is not only of interest for labor economics. For example, Christiano, Eichenbaum, Evans (2005) and Smets and Wouters (2007) find that nominal wage stickiness is one of the most important frictions for understanding macroeconomic dynamics under nominal shocks.
} 
conditions. In particular, the only source of aggregate uncertainty is aggregate TFP, which is not directly observed by workers. Instead, workers form expectations based on a public and noisy signal that they receive each period. This information structure implies that TFP shocks are only partially perceived by workers, who slowly learn about aggregate conditions as time goes by. This information friction affects the decisions of households and workers including those related with consumption and saving. Firms and workers negotiate wages each period. Workers negotiate wages based on their beliefs about the aggregate state of the economy. Hence, after a positive productivity shock, wages remain relatively constant because workers do not immediately possess the proper information to demand higher wages, which generates sluggish wages within jobs. In other words, if productivity increases at time $t$, the wage demanded by workers at firm $j$ at time $t$ will not be very different from the wage that workers demanded at firm $j$ at time $t-1$.

The persistence in wages within jobs increases firms' incentives to hire workers in an expansion, as they get to keep a larger fraction of the match surplus. However, in equilibrium, the highpaying/most-productive firms hire proportionally more new workers than the low-paying/lessproductive firms in response to a positive productivity shock. This differential response is because there is a significant increase in job-to-job flows as a consequence of the increase in employment, which reduces the average duration of a match for less productive firms and therefore the value of an additional worker. Given that firms have to pay a cost for recruiting new workers, low-wage less-productive firms end up paying this cost more frequently than more productive firms. ${ }^{4} \mathrm{In}$ addition, an increase in aggregate TFP reduces the pool of unemployment, which makes it more difficult for low-paying firms to find new workers but doesn't significantly affect high-wage firms, as they rely more on the pool of employed searchers to fill a vacancy.

I also find in my model that high-paying firms tend to exhibit more "flexible" wages in the sense that their wages increase more during expansions. This result is a direct consequence of the differential employment growth rate. An increase in consumption and employment at firm $j$ increases the opportunity cost of employment at that firm because workers would prefer to enjoy more free time. ${ }^{5}$ In an expansion, high-paying firms have to offer higher wages in to compensate their workers not only for the increase in consumption but also for the larger increase of employment. ${ }^{6}$ However, in an expansion, low-paying firms do not have to increase their wages as much as high-paying firms because, even though consumption increases, employment at low-paying firms is

\footnotetext{
${ }^{4}$ For example, Davis, Faberman, and Haltiwanger (2013) find a large heterogeneity in hires, separations and vacancy duration across firms. In addition, they find that firms with higher employment growth have higher vacancy yields.

${ }^{5}$ Following Chodorow-Reich and Karabarbounis (2014), the FOCE in my model is the sum of two components: (1) foregone unemployment benefits and (2) the foregone value of non-working activities in terms of consumption. Hence, the faster firm $j$ grows, the larger the opportunity cost of employment for its employees, as the foregone value of non-working activities in terms of consumption increases.

${ }^{6}$ Notice that an increase in consumption makes the value of non-working activities rise in terms of consumption.
} 
expanding at a lower rate. Hence, even though wages within jobs adjust slowly to the true state of the economy, the average wage for new hires exhibits a large response to productivity shocks on impact because a new hire faces more and better-paying job opportunities in an expansion than in a recession.

I calibrate my model using U.S. data for the period 1979 to 2015. To address the cyclicality of wages for job stayers versus new hires, I use the Current Population Survey (CPS) and IPUMS-CPS (Flood, King, Ruggles \& Warren, 2015) microdata to compute the average wage for all workers, job changers, and new hires from unemployment controlling for individual characteristics (e.g. Solon, Barsky \& Parker, 1994; Haefke, Sonntag \& van Rens, 2013; Muller, 2012). ${ }^{7}$ These series show that job changers earn a lower wage than the average worker in the economy but a larger wage than new hires from unemployment, suggesting that unemployed workers are more likely to find a job at low paying jobs and move up the job ladder. However, I find low wage semi-elasticities with respect to the unemployment rate using these wage series: $-0.27 \%$ for all workers, $-0.57 \%$ for job changers, and $-1.66 \%$ for new employees. Only the latter semi-elasticity is statistically significant.

The model calibrated to the U.S. economy is able to generate a large volatility in labor market quantities (unemployment, vacancies, vacancy-unemployment ratio), and relatively low volatility in wages and consumption as in the data. Also, my model generates wage semi-elasticities with respect to the unemployment rate of around $-3 \%$ for new hires, and $-1 \%$ for all workers, which is similar to the estimate of Pissarides (2009) and larger than the estimates of Hagedorn and Manovskii (2013) and Gertler, Huckfeldt, and Trigari (2014). Even though most of the wage cyclicality in my model is driven by the differential growth rate between high and low-paying firms, I show that my model generates differential net job flows that are consistent with the empirical evidence presented by Haltiwanger, Hyatt and McEntarfer (2015). These moments (volatility, wage semi-elasticities, differential growth rates) are not a target in my calibration.

I use the University of Michigan Surveys of Consumers to test the main prediction of this paper: Wages should increase when workers are more optimistic about economic conditions. I show that wage growth is positively correlated with workers' expectations at monthly and quarterly frequencies. However, this relationship is only statistically significant at quarterly frequencies. I estimate that a 1 standard deviation increase in my measure of workers expectations is associated with a $0.35 \%, 0.63 \%$ and $0.48 \%$ increase in the average wage for all workers, new employees, and job changers, respectively. Also, I find no significant correlation between unemployment and output expectations from the Survey of Professional Forecasters and wages.

In the extensions of the model, I show that wage dynamics depend on workers' expectations while hiring decisions depend on firms beliefs as long as firms' information set includes workers' expectations. Assuming that firms face information frictions makes unemployment responses larger

\footnotetext{
${ }^{7}$ Henceforth, I will refer to new hires from unemployment as "new employees."
} 
or smaller than in my benchmark model depending on specific assumptions. I present three variations of my benchmark model that generate very different unemployment dynamics, but in all cases, wages display a hump-shaped response to aggregate shocks because wage demands change as workers learn about aggregate economic conditions.

Finally, I propose a method for solving heterogeneous agents models with information frictions by combining Reiter's method (Reiter, 2009) and the Kalman filter and may be of interest in its own right. First, I show that the vector of state variables only needs to include the last $\mathcal{T}$ realization of the aggregate shocks in order to keep track of agents' expectations, where $\mathcal{T}$ is a large integer. Then, the law of motion for the economy (based on which agents form expectations) can be found by smoothly adjusting the agents' perceived law of motion with the law of generated by those agents' beliefs.

The rest of this paper is organized as follows. I relate my paper with existing literature in section 2. I present my model in section 3 and explain the numerical computation of it in section 4. Section 5 presents quantitative analysis, and I test the main implication of my model using survey data in section 6 . In section 7 , I discuss some alternative issues and extensions, and section 8 concludes.

\section{Related Literature}

Evidence on Information Frictions: My assumption about information frictions finds empirical support in Coibion and Gorodnichenko (2012) who compute forecast errors made by professional forecasters, consumers, and firms. They document that forecast errors are not consistent with the predictions of a model with perfect information. Rather, they find that forecast errors follow a mean-reverting process with a quarterly persistence between 0.8 and 0.9 . According to their results, the behavior of forecast errors is more consistent with a model in which agents receive noisy signals about aggregate conditions, as I assume in this paper. In addition, Carroll (2003) formulates and finds evidence in favor of a model in which consumers have a larger degree of information rigidity than other agents. Similarly, Roberts (1998) finds evidence of non-rational expectations in survey data, and Branch (2004) argues that surveys reject the rational expectation hypothesis not because agents use an ad hoc expectation rule, but rather because agents optimally decide not to use a more complicated expectation (predictor) function.

Evidence on Differential Growth Rate: Using employer-employee data for the United States, Kahn and McEntarfer (2014) find that employment at high-wage firms is more sensitive to the business cycle. According to their estimates, the differential employment growth rate (high minus low-paying firms) is negatively correlated with the unemployment rate, and this difference is not driven by a more cyclically-sensitive product demand for high-paying firms or because high- 
wage firms suffer more from earnings rigidities. Hence, a decline in unemployment is associated with a larger increase in employment at high-wage firms. In addition, they find that during a downturn, the distribution of new matches shifts toward low-paying firms, whose separation rate declines more than high-paying firms because of the reduction in job-to-job transitions. Therefore, even though employment changes are more cyclical at high-paying firms, gross worker flows are more cyclical at low-paying firms. Using employer-employee data for the United States., Haltiwanger et al. (2015) find that job-to-job flows do reallocate workers from lower-paying to higher-paying firms and that this reallocation is highly pro-cyclical. They find that net employment growth for high-wage firms is substantially greater in times of low unemployment compared with low-wage firms, which is driven by net poaching from low-wage to high wage firms. Similarly, Moscarini and Postel-Vinay (2012) find that employment growth is more negatively correlated with the unemployment rate at large high-paying firms than at small low-paying firms. Moreover, they find that this fact holds mainly within, not across, sectors and states. In an earlier paper, Moscarini and Postel-Vinay (2008) using different data sources, conclude that "following a positive aggregate shock to labor demand, wages respond little on impact and start rising when firms run out of cheap unemployed hires and start competing to poach and to retain employed workers" (p, 2). Hence, wages increase for two reasons: workers are paid progressively more, and workers move to higher-paying firms. ${ }^{8}$

Contribution: This work builds on the literature that addresses the Shimer puzzle (Shimer, 2005; Constain \& Reiter, 2008) by studying the amplifying effects of sluggish wages on job creation. ${ }^{9}$ This literature is large and includes: Blanchard and Gali (2010); Christiano, Eichenbaum and Trabandt (2016); Elsby (2009); Gertler and Trigari (2009); Hall (2005); Kennan (2009); Menzio (2005); and Venkateswaran (2013). My paper differs in at least three aspects with respect to this literature. First, I propose a new mechanism for sticky wages based on workers who face information frictions regarding aggregate variables. This mechanism, in contrast to the previous literature, does not rely on any assumption about the persistence of aggregate shocks (Menzio, 2005) or the distribution of firms (Kennan, 2009). ${ }^{10}$ In contrast to Venkateswaran (2013), I show

\footnotetext{
${ }^{8}$ Similarly, there is a large literature that points out the existence of sectoral wage differences for the United States and differences in the cyclical behavior of employment across sectors. Some examples are: Abraham and Katz (1986), Davis and Haltiwanger (1991), Haisken-DeNew and Schmidt (1995), Horrace and Oaxaga (2001), Juhn, Muphy, and Pierce (1993), Krueger and Summer (1988), Rielly and Zanchi (2003), Barlevy (2001), Okun (1973), McLaughlin and Bils (2001). In this paper, I abstract from sector wage premiums because: (1) in my empirical exercise, I control for sector fix effects and (2) according to Moscarini and Postel-Vinay (2012), the differential growth rate between high and low paying firms holds mainly within, not across, sectors.

${ }^{9}$ There are alternative sources of fluctuations that increase unemployment volatility that are not studied in this paper. For example, den Haan, Ramy, and Watson (2000) show that endogenous job destruction increases the response of unemployment to productivity shocks, and Carlsson and Westermark (2015) point out that sticky wages for job stayers may increase the strength of this channel. Similarly, recent literature has pointed out that sticky wages for job stayers may increase the unemployment volatility if firms face financial frictions (Schoefer, 2015) or if labor effort is variable (Bils, Chang \& Kim, 2014), even though sticky wages for continuing workers do not directly affect vacancy decisions in their models.

${ }^{10}$ Menzio (2005) and Kennan (2009) derive endogenous sticky wages based on firms that have private information
} 
that assuming that firms face information frictions does not generate sticky wages but can amplify the unemployment response to productivity shocks. ${ }^{11}$ As in Menzio (2005) and Kennan (2009), what drives sticky wages in my model is the fact that workers are willing to work for wages that do not adjust to the true state of the economy. That is, it is not enough to explain why firms offer wages that are very persistent — workers need to be willing to accept them.

Second, my model is able to generate significant unemployment volatility in spite of the procyclicality of the FOCE. According to Chodorow-Reich and Karabarbounis (2014), the FOCE is very procyclical, which weakens or breaks down the results of influential papers such as Hall and Milgrom (2008) and Hagedorn and Manovskii (2008). ${ }^{12}$ This point is also related to the argument of Brugemann and Moscarini (2010) that assuming rent rigidities (wages in excess of the value of unemployment) can account for at most $20 \%$ of the volatility in the job-finding rate. In this paper, even though the FOCE is procyclical, I still find significant responses of labor market quantities to shocks because of the timing of the model and the real part of the information friction. Given that households make consumption and saving decisions based on the same information friction, investment (capital accumulation) absorbs most of the shock in the initial periods, which prevents consumption and the FOCE from increasing. Hence, even though the FOCE eventually rises, it takes time because workers (not firms) have information frictions regarding aggregate variables.

Third, this paper looks at the distributional implications of productivity shocks. I show how and why high-wage firms expand employment the most during an expansion and how this mechanism generates different wage dynamics across firms. In this paper, even though the information friction is the same for all agents, wages at low-paying firms are less sensitive to the business cycle than wages at high-paying firms.

This paper is also related to the literature about information frictions. My model is close in spirit to Lucas (1972), in which agents' inability to distinguish between aggregate and idiosyncratic shocks generates money non-neutrality. Following Angeletos and La'O (2012), the information friction presented in this paper has both a nominal and a real part. That is, noisy information about aggregate conditions affects not only price (wage) decisions but also real allocations (saving, consumption). As previously explained, the real part of the information friction plays an important role in explaining the dynamics of the model. Even though this information structure seems exogenous, paying limited attention to aggregate shocks is a standard result in the rational inattention

about their labor productivity. In Menzio (2005), aggregate shocks cannot be very persistent. Otherwise, workers would demand higher wages. In Kennan's model, the standard deviation of idiosyncratic productivity cannot be large.

${ }^{11}$ Venkateswaran (2013) assumes firms that face information frictions regarding aggregate variables. In his model, after a positive productivity shock, firms do not offer higher wages because they partially attribute aggregate shocks to idiosyncratic conditions, which makes firms post more vacancies.

${ }^{12}$ The critique in Chodorow-Reich and Karabarbounis (2014) extends to all papers that assume a fixed and therefore acyclical FOCE, including Menzio (2005) and Kennan (2009). 
literature that started with Sims (2003). For example, Mackowiak and Wiederhold (2009) present a model in which agents optimally decide to receive a noisy signal about aggregate conditions, as I assume in this paper, because acquiring information is costly. Similarly, Acharya (2014) and Reis (2006a, 2006b) show that agents optimally decide to update their information set sporadically when they face a cost of acquiring and processing information.

Finally, this paper is related to the literature that studies the cyclicality of wages over the business cycle. Many studies conclude that the degree of wage cyclicality is small, based in part on empirical evidence suggesting that nominal wages adjust, on average, every four quarters in the United States (e.g. Kahn, 1997; Barattieri, Basu \& Gottschalk, 2014). ${ }^{13,14}$ However, Pissarides (2009) argues that vacancy decisions depend only on the wage for new hires and points out that the wage semi-elasticity with respect to the unemployment rate for new hires is around -3\%, compared with a semi-elasticity of $-1 \%$ for job stayers. The Pissarides critique has been recently challenged by Gertler et al. (2014), who argue that the evidence presented by Pissarides is based only on job changers. Using Survey of Income Participation Program (SIPP) data, Gertler et al (2014) do not find that wages for new workers are more procyclical than wages for job stayers. They find that the wage semi-elasticity for job changers with respect to the unemployment rate is $-1.7 \%$, which they argue is driven by changes in match quality. ${ }^{15}$ Whether wages for new hires are more procyclical than wages for existing workers is still an open question and is beyond the scope of this paper. ${ }^{16}$ Nevertheless, I use CPS and IPUMS-CPS microdata in order to construct the average wage for all workers and new hires (adjusted for individual characteristics) and assess the predictions of my model. It is worth noting that in my model wages for new hires are flexible and I show that my model is able to reproduce a wage semi-elasticity with respect to the unemployment rate of around $-3 \%$ for new hires, and $-1 \%$ for all workers, which is not a target in my calibration. ${ }^{17}$ Hence, this paper points out that wage flexibility for new hires does not imply that wages adjust immediately to the true state of the economy.

\footnotetext{
${ }^{13}$ For example, Christiano et al (2013) argue that a "successful model must have the property that wages are relatively insensitive to the aggregate state of the economy" (p, 3). Similary, Abraham and Haltiwanger (1995) find that the relation between aggregate wages and output does not always seem to be contemporaneous. They conclude that it is not possible to say whether real aggregate wages are procyclical and that in general the cyclicality is small.

${ }^{14}$ In contrast to other countries, there is no seasonal pattern in wage adjustments in the United States. Le Bihan, Montornes and Heckel (2012), Lunnemann and Wintr (2009), and Sigurdsson and Sigurdardottir (2011) present evidence of nominal wage adjustment for France, Luxembourg and Iceland that exhibits seasonal patterns.

${ }^{15}$ They do not find that wages for job changers are more procyclical than wages for job stayers when they include match fixed effects.

${ }^{16}$ For example, Hines, Hoynes, and Krueger (2001) argue that much of the cyclicality of wages estimated by Solon, et al (1994) comes from weighting the data by hours worked.

${ }^{17}$ Based on their empirical results, Gertler et al (2014) build a model in which the wage elasticity of job changers is driven by changes in match quality. Menzio and Shi (2011) also present a model in which job to job transitions are driven by random match quality.
} 


\section{Theoretical Framework}

The model presented in this section is, in many aspects, similar to a standard real business cycle model with search and matching in the labor market as in Andolfatto (1996) and Merz (1995). I introduce job changers in this model by assuming that there is a distribution of productivity across firms that induces a distribution of wages in the economy. The main difference of my model with respect to the relevant literature is that workers face information frictions about aggregate conditions. As in Lucas (1972), workers form expectations about current aggregate economic conditions based on noisy signals.

\subsection{Model Overview}

There are two types of agents in this economy: Households and firms. There is a representative household in the economy made up of a continuum of workers that supplies capital and labor to firms and owns all firms in the economy. The household derives utility from consumption and leisure and discounts future utility at rate $\beta$. Capital is supplied in a perfectly competitive market at the capital rental rate $r$ and depreciates at rate $\delta_{k}$, while labor supply is subject to search frictions. I assume complete consumption insurance, which implies that workers seek to maximize income for the household. A worker can be employed or unemployed at each point in time. Unemployed workers receive unemployment compensation $b$ and are matched with a firm with probability $q$. Employed workers are separated from their job with exogenous probability $\delta_{h}$, in which case they must spend at least one period in unemployment before they can be matched with another firm. Employed workers can search on the job. An employed worker is matched with another firm with probability $\bar{i} \cdot q$, where $\bar{i}$ is the search intensity of employed workers relative to unemployed workers and is fixed. However, employed workers only change jobs if they find a firm that offers an equal or better continuation value, which translates into equal or better wages in equilibrium.

There is a continuum of firms indexed by $j$ with mass normalized to 1 . All firms produce a homogeneous good that is sold in a competitive market to the household and can be used for consumption or capital accumulation. A priori the only difference among firms is their (permanent) TFP level, which is denoted by $a_{j}$. Without loss of generality, I assume that $a_{j}$ is increasing in $j$. Hence, $a_{x} \geq a_{y}$ for all $x \geq y$. As in Moscarini and Postel-Vinay (2013), the most productive firms pay higher wages and are larger in equilibrium. ${ }^{18}$ Firms produce with capital $k_{j}$ and labor $h_{j}$, and

\footnotetext{
${ }^{18}$ While there is evidence in favor of a positive relationship between firm size and wages (e.g. Brown \& Medoff, 1989; Moscarini \& Postel-Vinay, 2008), there is also evidence indicating that firm age is as well important for understanding differences in cyclical behavior across firms (e.g. Haltiwanger, Jarmin \& Miranda 2013; Fort, Haltiwanger, Jarmin, \& Miranda 2013). In particular, Haltiwanger et al. (2015) point out the importance of classifying firms by wage instead of size. This paper abstracts from firm entry and exit. Hence, even though in my paper larger firms
} 
firms' output is denoted by $y_{j}=e^{a_{j}+a} k_{j}^{\alpha} h_{j}^{1-\alpha}$, where $a$ stands for aggregate TFP, which is common to all firms. At the beginning of each period, firms rent capital and open new vacancies, $v_{j}$. A vacancy is matched with a worker with probability $\tilde{q}$. If a vacancy is matched with an unemployed worker, the vacancy is filled with probability 1 . However, if a vacancy is matched with an employed worker, the vacancy is filled only if the worker is coming from a less productive firm. As is standard, new workers (filled vacancies) become productive in the subsequent period. To avoid biasing my results in favor of high-wage firms, I assume a hiring cost of the form $\frac{\kappa}{1+\chi}\left(\tilde{q}_{j} v_{j}\right)^{1+\chi}$, where $\chi>0$ and $\tilde{q}_{j}$ is the job filling rate for firm $j .{ }^{19}$

The total number of matches in the economy $m(v, s)$ is an increasing function in the total number of vacancies $\left(v=\int_{0}^{1} v_{j} d j\right)$ and the total number of job searchers $\left(s=u+\int_{0}^{1}\left(1-\delta_{h}\right) \bar{i} h_{j} d j\right)$, where $u=1-\int_{0}^{1} h_{j} d j$ is the number of unemployed workers. Following the literature, $m(v, s)$ is assumed to be homogeneous of degree 1 . Hence, $q=m(\theta, 1)$ and $\tilde{q}=m\left(1, \theta^{-1}\right)$ where $\theta=v / s$ is labor market tightness.

Firms and workers negotiate wages, $w_{j}$, each period in order to split the expected match surplus according to a simple game: Firms make a wage offer that can be accepted or rejected, and in the latter case workers make a take-it-or-leave-it offer to firms with exogenous probability $\vartheta$. Hence, in steady state, $\vartheta$ is the fraction of the match surplus that goes to workers.

The only source of aggregate uncertainty is aggregate TFP $a$, which follows an AR(1) process. However, $a$ is not directly observed by workers in this economy. Instead, every period there is a public and noisy signal $\hat{a}$ about the current level of aggregate TFP. This signal, which is observed by workers and firms, is common knowledge. Based on the expectations derived from this signal, workers make wage demands (in a sense that will be explained below) and the household makes consumption/savings decisions. Even though workers do not perfectly observe aggregate TFP, the idiosyncratic TFP level $a_{j}$ for each firm is public information. In the benchmark model, firms have perfect information about aggregate productivity. ${ }^{20}$

The timing of the model each period is as follows: (1) aggregate TFP is realized; (2) the public signal is received and workers form expectations; (3) wages are negotiated; (4) firms rent capital are more productive and pay higher wages, it is possible to think about the firm's size in the long run. However, I expect my results to be robust to firm entry and exit since firm size does not affect my mechanism.

${ }^{19}$ Assuming a vacancy posting cost instead would disproportionally affect low-wage firms, as they have to post even more vacancies in expansions as a consequence of a larger decline in their job filling rate. However, in the context of this model, assuming a hiring cost function does not imply that vacancy decisions do not depend on labor market conditions. On the contrary, job-to-job transitions induce changes in the separation rate within firms that significantly influence the value of a new vacancy. Pissarides (2009) argues that hiring costs are a plausible assumption and discusses how assuming a hiring rather than vacancy costs may change the results in the standard model. However, I show that my calibrated model with perfect information does not do a good job matching the unemployment and wage dynamics observed in the data. In contrast, Gertler and Trigari (2009) and Gertler et al. (2014) assume a quadratic cost of adjusting employment to ensure a determinate equilibrium. I prefer a hiring cost over a cost of adjusting employment, as a hiring cost does not bias my results in favor of high-wage firms.

${ }^{20}$ In section 7.3, I discuss this assumption in more detail. 
and post vacancies; (5) production takes place, and factors are paid; (6) the household makes a consumption decision based on the beliefs derived from the signal $\hat{a} ;(7)$ a fraction $\left(1-\delta_{h}\right) \bar{i} q$ of employed workers at firm $j$ is matched with another firm, and a fraction $q$ of unemployed workers finds a new job; (8) a fraction $\left(1-\delta_{h}\right) \bar{i} q F_{j}$ of employed workers leaves firm $j$ to join another firm, where $F_{j}$ is the probability for firm $j$ 's employees of being matched with a firm with higher $a_{j}$.

\subsection{Household}

There is a representative household made up of a continuum of members with mass normalized to $1 .^{21}$ The household is the owner of all firms in the economy, and it supplies capital and labor to firms. Capital is supplied in a perfectly competitive market at the rental rate $r$, while labor supply is subject to search frictions. I assume complete consumption insurance, which implies that workers seek to maximize income for the household. Consumption and savings decisions are made at the household level, but household members make their decisions based on the same information set $\mathcal{I}_{h}$. Throughout this paper, $E_{\mathcal{I}_{h}}[x]$ is the expected value of $x$ conditional on the information set $\mathcal{I}_{h}$, and $E[x]$ is the expectation conditional on perfect information.

\subsubsection{Consumption and Saving}

Consumption and savings decision are made at the household level to maximize the life-time utility function

$$
\mathbb{U}(\omega, \Omega)=\frac{c^{1-\sigma}}{1-\sigma}-\Psi \frac{\tilde{h}^{1+\eta}}{1+\eta}+\beta E\left[\mathbb{U}\left(\omega^{\prime}, \Omega^{\prime}\right)\right]
$$

subject to the budget constraint (2), the aggregation of labor (3), and a perceived law of motion for the economy (4):

$$
\begin{aligned}
c+k^{\prime} & \leq\left(r+1-\delta_{k}\right) k+\int_{0}^{1} w_{j} h_{j} d j+\int_{0}^{1} \pi_{j} d j+b \cdot u-T \\
\tilde{h} & =\left(\int_{0}^{1} h_{j}^{1+\xi} d j\right)^{\frac{1}{1+\xi}} \\
\Omega^{\prime} & =\lambda^{h}(\Omega)
\end{aligned}
$$

where' denotes next period's value. $\omega=\left\{k,\left\{h_{j}\right\}_{j=0}^{1}, \mathcal{I}_{h}\right\}$ is the vector of state variables for the representative household, and $\Omega$ is a vector that summarizes the aggregate state of the economy. $c$ is consumption, $k$ is capital, $w_{j}$ is the wage paid by firm $j$, and $\pi_{j}$ stands for firm $j$ 's profits.

\footnotetext{
${ }^{21}$ For expositional purposes, I derive in this section the value of employment and unemployment based on the model assumptions. For a detailed derivation of these value functions as in Merz (1995) and Andolfatto (1996), see appendix D.
} 
$u=\int_{0}^{1}\left(1-h_{j}\right) d j$ is the total number of unemployed workers, and $b$ is unemployment compensation, which is financed by lump sum taxes $(T=b \cdot u)$. Parameter $\xi$ in (3) governs the elasticity of substitution between $h_{x}$ and $h_{y}$ for all $x \neq y .{ }^{22}$ The household and its members form expectations based on their information set $\mathcal{I}_{h}$ and on a perceived law of motion for the economy $\left(\lambda^{h}(\cdot)\right)$. Therefore, the problem for the household is given by:

$$
\begin{array}{cl}
\max _{c, k^{\prime}} & E_{\mathcal{I}_{h}}\{\mathbb{U}(\omega, \Omega)\} \\
& \text { s.t. }
\end{array}
$$

Hence, the first order condition for consumption:

$$
c^{-\sigma}=\beta E_{\mathcal{I}_{h}}\left[\left(1-\delta+r^{\prime}\right) c^{-\sigma}\right]
$$

It is worth noting that the consumption decision is also affected by information frictions because the expectation in equation (5) is conditional on the information set $\mathcal{I}_{h}$. In other words, information frictions affect not only the wage bargaining process as described in section 3.5, but also real allocations. ${ }^{23}$ To the extent that aggregate shocks are partially perceived, the household will respond to productivity innovations by accumulating capital in an attempt to smooth consumption through time. As a result, the marginal disutility of labor (in terms of consumption) does not increase, which prevents wages from going up. This mechanism will be clear in section 3.5.

\subsubsection{Workers}

A worker can be employed or unemployed at each point in time. Unemployed workers receive unemployment compensation $b$ and are matched with a firm with probability $q$. Conditional on a match, a worker is matched with firm $j$ with probability $\left(\frac{v_{j}}{v}\right)$, where $v$ is the total number of vacancies in the economy and $v_{j}$ stands for firm $j$ 's vacancies. Hence, the value of unemployment $U(\omega, \Omega)$ is given by:

$$
U(\omega, \Omega)=b+E\left\{Q\left((1-q) \cdot U\left(\omega^{\prime}, \Omega^{\prime}\right)+q \cdot \int_{0}^{1} W_{x}\left(\omega^{\prime}, \Omega^{\prime}\right) \frac{v_{x}}{v} d x\right)\right\}
$$

where $Q=\beta\left(\frac{c^{\prime}}{c}\right)^{-\sigma}$ is the stochastic discount factor between this period and the next period

\footnotetext{
${ }^{22}$ We can interpret this parameter as follows: firms and workers are located uniformly on a circle, and firms hire workers who are closer to them. As firms increase in size, they have to attract workers who are farther away, which implies that workers have to spend more time commuting, which reduces their utility level.

${ }^{23}$ Following the terminology of Angeletos and La'O (2012), the information friction is real because it affects both prices and real allocations.
} 
and $W_{j}(\omega, \Omega)$ is the value of employment at firm $j$. Meanwhile, employed workers are separated from their job with exogenous probability $\delta_{h}$, in which case they have to spend at least one period in unemployment before they can be matched with another firm. I assume that employed workers can search on the job and are matched with another firm with probability $\bar{i} q$. However, I assume that employed workers only change jobs if they find a firm that offers an equal or better continuation value. Throughout this paper, I refer to jobs that deliver an equal or greater continuation value as better jobs. ${ }^{24}$ Hence, the value of employment at firm $j$ is given by:

$$
\begin{aligned}
W_{j}(\omega, \Omega)= & w_{j}-\Psi \frac{\tilde{h}^{\eta-\xi}}{c^{-\sigma}} h_{j}^{\xi} \\
& +E\left\{Q \left(\left(1-\delta_{h}\right)(1-\bar{i} q) W_{j}\left(\omega^{\prime}, \Omega^{\prime}\right)\right.\right. \\
& +\left(1-\delta_{h}\right) \bar{i} q \int_{0}^{1} \max \left\{W_{j}\left(\omega^{\prime}, \Omega^{\prime}\right), W_{x}\left(\omega^{\prime}, \Omega^{\prime}\right)\right\} \frac{v_{x}}{v} d x \\
& \left.\left.+\delta_{h} U\left(\omega^{\prime}, \Omega^{\prime}\right)\right)\right\}
\end{aligned}
$$

The first line in equation (7) is the net flow income of a worker employed at firm $j$. The second term $\left(\Psi \frac{\tilde{h}^{\eta-\xi}}{c^{-\sigma}} h_{j}^{\xi}\right)$ is the value of non-working activities (or the marginal disutility of labor) in terms of consumption, which is derived from the household's utility function (1). The second line in equation (7) says that with probability $\left(1-\delta_{h}\right)(1-\bar{i} q)$ a worker is not exogenously separated from firm $j$ and is not matched with another firm. The third line captures that with probability $\left(1-\delta_{h}\right) \bar{i} q$ a worker is not exogenously separated from firm $j$, is matched with another firm, and picks the firm that gives her the higher continuation value. Finally, with probability $\delta_{h}$ a worker becomes unemployed.

Given that only weakly better jobs are accepted, $\max \left\{W_{j}(\omega, \Omega), W_{x}(\omega, \Omega)\right\}=W_{x}(\omega, \Omega) \forall x \geq j$. Therefore, combining equations (6) and (7):

$$
\begin{aligned}
\left(W_{j}(\omega, \Omega)-U(\omega, \Omega)\right)= & w_{j}-z_{j} \\
& +E\left\{Q \left(\left(1-\delta_{h}\right)\left(1-\bar{i} q F_{j}\right)\left(W_{j}\left(\omega^{\prime}, \Omega^{\prime}\right)-U\left(\omega^{\prime}, \Omega^{\prime}\right)\right)\right.\right. \\
& +\left(1-\delta_{h}\right) \bar{i} q F_{j}\left(\tilde{W}_{j}\left(\omega^{\prime}, \Omega^{\prime}\right)-U\left(\omega^{\prime}, \Omega^{\prime}\right)\right) \\
& \left.\left.-q\left(\bar{W}\left(\omega^{\prime}, \Omega^{\prime}\right)-U\left(\omega^{\prime}, \Omega^{\prime}\right)\right)\right)\right\}
\end{aligned}
$$

Following Hall and Milgrom (2008), I define $z_{j}$ as the flow-opportunity cost of employment for firm $j . F_{j}$ is the probability of finding a weakly better job than $j, \tilde{W}_{j}\left(\omega^{\prime}, \Omega^{\prime}\right)$ is the expected value of the new job for job changers leaving firm $j$, and $\bar{W}\left(\omega^{\prime}, \Omega^{\prime}\right)$ is the expected value of a new job

\footnotetext{
${ }^{24}$ As explained in section 3.3, firms with higher idiosyncratic productivity pay higher wages.
} 
for unemployed workers. These terms in turn satisfy:

$$
\begin{aligned}
z_{j} & =b+\Psi \frac{\tilde{h}^{\eta-\xi}}{c^{-\sigma}} h_{j}^{\xi} \\
F_{j} & =\int_{j}^{1} \frac{v_{x}}{v} d x \\
\tilde{W}_{j}\left(\omega^{\prime}, \Omega^{\prime}\right) & =\int_{j}^{1} W_{x}\left(\omega^{\prime}, \Omega^{\prime}\right)\left(\frac{v_{x}}{\int_{j}^{1} v_{y} d y}\right) d x \\
\bar{W}\left(\omega^{\prime}, \Omega^{\prime}\right) & =\int_{0}^{1} W_{x}\left(\omega^{\prime}, \Omega^{\prime}\right) \frac{v_{x}}{v} d x
\end{aligned}
$$

Notice that the net value of employment $\left(W_{j}(\omega, \Omega)-U(\omega, \Omega)\right)$ is a decreasing function in $z_{j}$ and therefore in consumption. An increase in consumption makes $z_{j}$ go up and reduces the net value of employment. As a consequence, wages must increase when consumption increases in order to compensate workers for the decline in the value of employment.

Chorodow-Reich and Karabarbounis (2014) find empirically that the FOCE $\left(z_{j}\right)$ is pro-cyclical and conclude that this procyclicality undermines the results of previous papers attempting to solve the unemployment volatility puzzle. A similar point is made by Brugemann and Moscarini (2010), who argue that rent rigidity, defined as the fraction of wages that does not depend on $z_{j}$, can account for at most $20 \%$ of the volatility in the job-finding rate. However, notice that in this paper information frictions reduce the sensitivity of $z_{j}$ to productivity shocks. As explained above, to the extent that aggregate shocks are partially perceived, the household will respond to positive productivity innovations by accumulating capital in an attempt to smooth consumption through time, which prevents $z_{j}$ from increasing.

It is worth noticing that equations (8) and (9) explain why high paying firms are more sensitive to aggregate shocks than low paying firms in this model. Since high-paying firms are larger in equilibrium, the $\operatorname{FOCE}\left(z_{j}\right)$ is an increasing function in $j$ and, as a consequence, so is $\frac{z_{j}}{p_{j}}$. Hagedorn and Manovskii (2008) show that larger values of $z$, relative to $p$, imply larger percentage changes in the value of a filled vacancy in response to changes in labor productivity, leading to larger fluctuations in vacancy posting and employment. Given that $z_{j}$ is increasing in firm size, we should also expect high paying firms to have more volatile wages than low paying firms. There are alternative explanations for the high sensitive of high paying firms to the business cycle. For example, high paying firms may face a very cyclical demand or a high wage rigidity. However, Kahn and McEntarfer (2014) find that high paying firms do not have a more cyclical demand than low paying firm. They also find that high paying firm have a larger drop in wage rigidity during recessions than low paying firms. Nonetheless, the underlying source of this differential comicality is not important for the results of this paper. 
Finally, notice that the expectations in equations (6), (7) and (8) are not conditional on the household's information set $\mathcal{I}_{h}$. Instead, the expectations are conditional on perfect information because equations (6) and (7) describe what a worker will actually receive in expectation and not what workers expect to receive. However, workers will have to form expectations about $W_{j}(\omega, \Omega)$ and $U(\omega, \Omega)$ to negotiate wages, as described in section 3.5.

\section{$3.3 \quad$ Firms}

There is a continuum of firms indexed by $j$ with a mass normalized to 1 . Firms produce with capital and labor, and their output can be used for consumption or for capital accumulation. At the beginning of each period, firms rent capital and open new vacancies, $v$. A vacancy is matched with a worker with probability $\tilde{q}$. As is standard in the literature, a filled vacancy becomes productive in the subsequent period. However, not all matches become productive. If a vacancy is matched with a worker who is currently employed at a better job, the match is dissolved. Hence, denoting $\tilde{q}^{u}$ as the probability of filling a vacancy with an unemployed worker and $\tilde{q}_{j}^{c}$ as the probability of filling a vacancy with a job changer, the job filling rate for firm $j\left(\tilde{q}_{j}\right)$ is given by:

$$
\begin{aligned}
& \tilde{q}_{j}=\tilde{q}^{u}+\tilde{q}_{j}^{c} \\
& \tilde{q}^{u}=\tilde{q} \cdot\left(\frac{u}{s}\right) \\
& \tilde{q}_{j}^{c}=\tilde{q} \cdot\left(\int_{0}^{j} \frac{\left(1-\delta_{h}\right) \bar{i} h_{x}}{s} d x\right)
\end{aligned}
$$

Notice that $\tilde{q}^{u}$ is the same for all firms. By contrast, the job filling rate varies across firms even though the probability of a match $(\tilde{q})$ is the same for all firms. $\tilde{q}_{j}^{c}$ and $\tilde{q}_{j}$ are higher for the most productive firms. As a consequence, low-productivity firms rely more on the pool of unemployed workers. Hence, in an expansion, low-wage firms find it more difficult to fill a vacancy and to retain a worker than high-wage firms. 
The problem for firm $j$ is given by:

$$
\begin{aligned}
\Pi_{j}\left(\omega_{f}, \Omega\right) & =\max _{v_{j}, k_{j}} \pi_{j}+E\left[Q \Pi_{j}\left(\omega_{f}^{\prime}, \Omega^{\prime}\right)\right] \\
\text { s.t. } & \\
\pi_{j} & =y_{j}-w_{j} h_{j}-r k_{j}-\frac{\kappa}{1+\chi}\left(\tilde{q}_{j} v_{j}\right)^{1+\chi} \\
y_{j} & =e^{a_{j}+a} k_{j}^{\alpha} h_{j}^{1-\alpha} \\
h_{j}^{\prime} & =\left(1-\delta_{h}\right)\left(1-\bar{i} q F_{j}\right) h_{j}+\tilde{q}_{j} v_{j} \\
\Omega^{\prime} & =\lambda^{f}(\Omega) \\
v_{j}, \quad k_{j} & \geq 0
\end{aligned}
$$

where $a$ stands for aggregate TFP, which is common to all firms. $\omega_{f}=\left\{h_{j}\right\}$ is the vector of state variables for firm $j$, and equation (20) is the perceived law of motion for the economy. Denoting marginal labor productivity by $p_{j}=(1-\alpha) e^{a_{j}+a} k_{j}^{\alpha} h_{j}^{-\alpha}$, the first order conditions with respect to $v_{j}$ and $k_{j}$ are given by:

$$
\begin{array}{lll}
v_{j}:-\kappa\left(\tilde{q}_{j} v_{j}\right)^{\chi}+E\left[Q \cdot J_{j}^{\prime}\left(\omega_{f}^{\prime}, \Omega^{\prime}\right)\right] & \leq 0 \\
k_{j}: p_{j}\left(\frac{h_{j}}{k_{j}}\right)\left(\frac{\alpha}{1-\alpha}\right)-r & & =0
\end{array}
$$

where $J_{j}\left(\omega_{j}, \Omega\right)$ is the firm's value of an additional worker, or the continuation value of a filled vacancy:

$$
\begin{aligned}
& J_{j}\left(\omega_{f}, \Omega\right)=\frac{\partial \prod_{j}\left(\omega_{f}, \Omega\right)}{\partial h_{j}} \\
& J_{j}\left(\omega_{f}, \Omega\right)=p_{j}-w_{j}+E\left[Q \cdot\left(1-\delta_{h}\right)\left(1-\bar{i} q F_{j}\right) \cdot J_{j}\left(\omega_{f}^{\prime}, \Omega^{\prime}\right)\right]
\end{aligned}
$$

Notice that even though the exogenous separation rate $\delta_{h}$ is the same for all firms, the total separation rate varies across firms. If we define $\delta_{h j}=1-\left(1-\delta_{h}\right)\left(1-\bar{i} q_{t} F_{j}\right)$ as firm $j$ 's total separation rate, we can see that low-wage (less-productive) firms have higher separation rates. Given that $F_{j}$ is lower for more productive firms, $\delta_{h j}$ is also lower for the most productive firms. Note that even though I am not assuming a cost per vacancy posted, labor market conditions affect the value of a new vacancy through the firm specific separation rate $\delta_{h j}$. I will show that low-wage firms experience a larger increase in separations (quits) in expansions than high-wage firms. Hence, the value of a new worker increases less for less-productive firms in expansions. 


\subsection{Information Sets}

I assume that workers (households) face information frictions in the sense that they do not perfectly know the current value of aggregate TFP $(a)$, which is the only source of aggregate uncertainty. I assume that there is a public signal $(\hat{a})$, based on which workers form expectations. I assume that this public signal is also observed by firms, so that workers' beliefs are common knowledge. The public signal and aggregate productivity are related as follows:

$$
\hat{a}=a+n
$$

where $n$ is the noise of the signal. The aggregate TFP $(a)$ and the noise $(n)$ are assumed to follow two independent $\mathrm{AR}(1)$ processes. I interpret the autocorrelation in this noise as waves of optimism or pessimism:

$$
\begin{array}{ll}
a^{\prime}=\rho_{a} \cdot a+e_{a}^{\prime} ; & e_{a} \sim N\left(0, \varsigma_{a}\right) \\
n^{\prime}=\rho_{n} \cdot n+e_{n}^{\prime} ; & e_{n} \sim N\left(0, \varsigma_{n}\right)
\end{array}
$$

To formally define the equilibrium of this economy and find the solution of this model, I assume that workers can perfectly observe the state of the economy with a lag of $\mathcal{T}$ periods where $\mathcal{T}$ is a large integer. Hence, the information set for the representative household is given by:

$$
\mathcal{I}_{h}=\left\{\hat{a}^{\mathcal{T}}, \Omega_{-\mathcal{T}}\right\}
$$

where $\hat{a}^{\mathcal{T}}$ represents the last $\mathcal{T}$ realizations of $n$, and $\Omega_{-\mathcal{T}}$ is the value of the vector $\Omega \mathcal{T}$ periods ago. This information set does not mean that the representative household does not perceive new productivity shocks at all. On the contrary, workers form expectations about current and future economic conditions based on Bayes' rule and this information set to make their decisions. This assumption about information implies that aggregate shocks are partially perceived by workers, who learn slowly about productivity innovations as time elapses while simultaneously continuing to receive positive or negative signals. Hence, if workers do not have enough information to conclude that the economy is in an expansionary path, they will not demand higher wages. Further, partial perception of aggregate shocks causes $c$ and $z_{j}$ to become more persistent, another avenue through which wage increases are muted somewhat. 


\subsection{Wages}

I assume that wages are completely flexible and are negotiated at the start of every period according to a simple game, through which firms and workers bargain over the match surplus $\left(S_{j}\right)$ :

$$
S_{j}=J_{j}\left(\omega_{f}, \Omega\right)+W_{j}(\omega, \Omega)-U(\omega, \Omega)
$$

Notice that $w_{j}$ appears in functions $J_{j}\left(\omega_{f}, \Omega\right)$ and $W_{j}(\omega, \Omega)$ in accordance with equations $(25)$ and $(7)$. However, because $w_{j}$ is an endogenous variable, it is not written as an argument for these functions. ${ }^{25}$ For expositional purposes, I will abuse notation slightly in this section and define functions $\vec{J}_{j}\left(w, \omega_{f}, \Omega\right)$ and $\vec{W}_{j}(w, \omega, \Omega)$ as:

$$
\begin{aligned}
\vec{J}_{j}\left(w, \omega_{f}, \Omega\right)= & p_{j}-w+E\left[Q \cdot\left(1-\delta_{h}\right)\left(1-\bar{i} q F_{j}\right) \cdot J_{j}\left(\omega_{f}^{\prime}, \Omega^{\prime}\right)\right] \\
\vec{W}_{j}(w, \omega, \Omega)= & w-\Psi \frac{\tilde{h}^{\eta-\xi}}{c^{-\sigma}} h_{j}^{\xi} \\
& +E\left\{Q \left(\left(1-\delta_{h}\right)(1-\bar{i} q F j) W_{j}\left(\omega^{\prime}, \Omega^{\prime}\right)\right.\right. \\
& \left.\left.+\left(1-\delta_{h}\right) \bar{i} q F_{j} \tilde{W}_{j}\left(\omega^{\prime}, \Omega^{\prime}\right)+\delta_{h} U\left(\omega^{\prime}, \Omega^{\prime}\right)\right)\right\}
\end{aligned}
$$

Function $\vec{J}_{j}\left(w, \omega_{f}, \Omega\right)$ can be interpreted as the value of a filled vacancy for an arbitrary wage $w . \vec{W}_{j}(w, \omega, \Omega)$ is interpreted similarly. ${ }^{26}$ As a consequence, functions $\vec{J}_{j}\left(w, \omega_{f}, \Omega\right)$ and $J_{j}\left(w, \omega_{f}, \Omega\right)$ are related as follows:

$$
\begin{aligned}
& J\left(\omega_{f}, \Omega\right)=\vec{J}_{j}\left(w_{j}, \omega_{f}, \Omega\right) \\
& W(\omega, \Omega)=\vec{W}_{j}\left(w_{j}, \omega, \Omega\right)
\end{aligned}
$$

where $w_{j}$ is the wage that will result from equilibrium.

\subsubsection{Wage Negotiation}

Wages in this economy are negotiated according to the following game: (1) The firm offers a wage $x$ to the worker. (2) The worker observes the firm's offer. Upon acceptance, the game ends with payoffs of $\vec{W}_{j}(x, \omega, \Omega)-U(\omega, \Omega)$ to the worker and $\vec{J}_{j}\left(x, \omega_{f}, \Omega\right)$ to the firm. (3) If the worker rejects the firm's offer, the match is destroyed with exogenous probability $1-\vartheta$ (with payoffs to

\footnotetext{
${ }^{25}$ In contrast, the match surplus is independent of $w_{j}$.

${ }^{26}$ Notice that I do not index $w$ in equations (31) and (32) by firms $j$ in order to distinguish between an arbitrary wage $w$ and the equilibrium wage $w_{j}$. On the other hand, notice that the match surplus does not depend on $w$ :

$$
\vec{J}_{j}\left(w, \omega_{f}, \Omega\right)+\vec{W}_{j}(w, \omega, \Omega)-U(\omega, \Omega) \equiv J_{j}\left(\omega_{f}, \Omega\right)+W_{j}(\omega, \Omega)-U(\omega, \Omega)=S_{j}
$$
}


both agents of 0); otherwise, the worker demands a wage $y$. (4) The firm observes this demand. Upon acceptance, the game ends with payoffs of $\vec{W}_{j}(y, \omega, \Omega)-U(\omega, \Omega)$ for worker and $\vec{J}_{j}\left(y, \omega_{f}, \Omega\right)$ for firm. If the firm rejects the worker's offer, the game ends with payoffs of zero for both agents. The extensive-from representation of this game is given in Figure 1.

\subsubsection{Equilibrium Wage and Discussion}

Even though this model assumes information frictions, an important benchmark is the case in which all agents have perfect information. In this spirit, the following lemma establishes the equilibrium of this game under perfect information, which will be used to compare the results under information frictions.

Lemma 1. If all agents in the economy have complete and perfect information, the following strategy profiles constitute the unique sub-game perfect Nash equilibrium of this game:

- For the worker:

- To accept only wage offers greater than or equal to $x^{*}$ where $\vec{W}_{j}\left(x^{*}, \omega, \Omega\right)-U(\omega, \Omega)=$ $\vartheta \cdot S_{j}$

- To demand a wage equal to $y^{*}$ such that $\vec{W}_{j}\left(y^{*}, \omega, \Omega\right)-U(\omega, \Omega)=S_{j}$ and $\vec{J}_{j}\left(y^{*}, \omega_{f}, \Omega\right)=$ 0.

- For the firm:

- To offer $x^{*}$.

- To accept only wage demands that are less than or equal to $y^{*}$.

Proof. See Appendix C.1

Hence, under perfect information, the solution to this game coincides with the solution to the Nash-bargaining game when the worker's bargaining power is equal to $\vartheta$. Therefore, I will call $\vartheta$ the long-term bargaining power of workers.

Now, before characterizing the solution to this game with information frictions, the following lemmas tell us that, in equilibrium, firms cannot credibly communicate the true state of the economy to the workers.

Lemma 2. Suppose that agents are information-constrained as described in section 3.4. If there is an equilibrium in which firms' strategy is to reveal the aggregate state of the economy, the best strategy for firms is the same strategy described in Lemma 1.

Proof. See Appendix C.2 
Lemma 3. If agents in the economy are information-constrained as described in section 3.4, then in equilibrium, firms do not follow a strategy in which they perfectly reveal the true state of the economy.

Proof. See Appendix C.3

Even though Lemmas 2 and 3 do not characterize the solution to this game, they make clear that a solution in which firms reveal the true state of the economy is not possible. The intuition is simple: firms have incentives to lie. Firms will always be tempted to tell workers that aggregate productivity is lower than it actually is, so wages can be lower. As a consequence, workers do not rely on firms' offer to form expectations about aggregate conditions. Before defining the solution for this game with information frictions, I make the following assumption:

Assumption 1. For all realizations of $a$ and $n$,

$$
\vec{J}_{j}\left(x^{* *}, \omega_{f}, \Omega\right) \geq 0
$$

where $x^{* *}$ is such that:

$$
E_{\mathcal{I}_{h}}\left[\vec{W}_{j}\left(x^{* *}, \omega, \Omega\right)-U(\omega, \Omega)\right]=\vartheta \cdot E_{\mathcal{I}_{h}}\left[S_{j}\right]
$$

That is, if both parties agree upon a wage $x^{* *}$ such that, according to the worker's information set, a fraction $\vartheta$ of the match surplus goes to the worker, the firm still gets a positive payoff for all realizations of the true productivity and the signal. I check that this assumption holds in my calibration (section 7.1). Next, the following lemma presents the solution to this game.

Lemma 4. If agents in the economy are information-constrained as described in section 3.4, the following strategy profiles constitute a Perfect Bayesian Nash equilibrium that satisfies the intuitive criterion:

- For the worker:

- To accept only wage offers greater than or equal to $x^{* *}$ where:

$$
E_{\mathcal{I}_{h}}\left[\vec{W}_{j}\left(x^{* *}, \omega, \Omega\right)-U(\omega, \Omega)\right]=\vartheta \cdot E_{\mathcal{I}_{h}}\left[S_{j}\right]
$$

- To demand a wage equal to $y^{* *}$ such that:

$$
E_{\mathcal{I}_{h}}\left[\vec{W}_{j}\left(y^{* *}, \omega, \Omega\right)-U(\omega, \Omega)\right]=E_{\mathcal{I}_{h}}\left[S_{j}\right]
$$

- For the firm: 
- To offer $x^{* *}$.

- To accept only wage demands that are less than or equal to $\tilde{y}^{* *}$ such that $\vec{J}_{j}\left(\tilde{y}^{* *}, \omega_{f}, \Omega\right)=$ 0.

Proof. See Appendix C.4

Notice that in equilibrium, wages are a function of what workers would have demanded if given the chance, even though they do not get to make such a wage demand in equilibrium. If firms anticipate that workers will ask for a fraction $X$ of their perceived match surplus, they will offer a wage such that workers get $\vartheta \cdot X$ of the match surplus. Notice that this result is common in the literature. In the classical paper of Rubinstein (1982), there are no counter-offers in equilibrium because the first player to move makes an offer that takes into account what the other player would get in the second stage of the game. Similarly, Hall and Milgrom (2008) and Christiano et al. (2016) assume that wages are negotiated according to an alternating wage offer game. In those papers, there are no counter-offers in equilibrium because firms compensate workers for what they would get if they had the chance to make a counter-offer. ${ }^{27}$ In this sense, this set-up introduces information frictions in a tractable way, and the solution under perfect information of this game is the same as the Nash bargaining solution with workers' bargaining power equal to $\vartheta$.

Regarding the solution with information frictions, Lemma 4 is an important result for this paper. Given that firms have incentives to lie about true productivity (Lemma 3), workers will only use their own information set to assess wage offers. Hence, wage demands will be based on information frictions. To the extent that aggregate TFP shocks are partially perceived, wage demands will be less sensitive to aggregate conditions because workers' expectations are smoother than aggregate shocks. Consequently, wages will be more sluggish under information frictions. Notice that assuming that firms face the same information friction would not affect the solution to this game and therefore would not directly affect how sensitive wages are to productivity shocks.

\subsection{Equilibrium}

We can now characterize the vector that describes the aggregate state of the economy as $\Omega=$ $\left\{k,\left\{h_{j}\right\}_{j=0}^{1}, a^{\mathcal{T}}, n^{\mathcal{T}}\right\}$. As before, $a^{\mathcal{T}}$ and $n^{\mathcal{T}}$ refer to the last $\mathcal{T}$ realizations of $a$ and $n$, respectively. ${ }^{28}$

Definition 1. A recursive competitive equilibrium for this economy is a list of functions $\{\mathbb{U}(\omega, \Omega)$, $\left.W_{j}(\omega, \Omega), U(\omega, \Omega), \Pi_{j}\left(\omega_{f}, \Omega\right), J_{j}\left(\omega_{f}, \Omega\right)\right\}$ [Value Functions], $\left\{\left\{w_{j}(\Omega)\right\}_{j=0}^{1}, Q(\Omega), r(\Omega)\right\}$ [Prices], $\left\{h_{j}\left(\omega_{f}, \Omega\right), k_{j}\left(\omega_{f}, \Omega\right), v_{j}\left(\omega_{f}, \Omega\right), \pi_{j}\left(\omega_{f}, \Omega\right), \tilde{W}_{j}(\omega, \Omega), z_{j}(\Omega)\right\}_{j=0}^{1}, \bar{W}(\omega, \Omega), c(\omega, \Omega), k(\omega, \Omega), y(\Omega)$,

\footnotetext{
${ }^{27}$ Similarly, Matejka and McKay (2012) derive a model in which goods' prices are determined by consumers' beliefs when they face information frictions and firms have perfect information.

${ }^{28}$ Section 4 and Appendix G describe the solution method in more detail.
} 
$s(\Omega), \theta(\Omega)\}\left[\right.$ Allocations], $\left\{\left\{\tilde{q}_{j}(\Omega), \tilde{q}_{j}^{c}(\Omega), F_{j}(\Omega)\right\}_{j=0}^{1}, q(\Omega), q^{u}(\Omega)\right\}$ [Probabilities], and $\left\{\lambda, \lambda^{f}, \lambda^{c}\right\}[$ Law of motion] such that given a law of motion for $\{\hat{a}, a, n\}$ [Exogenous variables]

- The representative household and workers optimize: Taking as given prices, probabilities and a perceived law of motion for the economy $(4), c(\omega, \Omega), k^{\prime}(\omega, \Omega)$, satisfy optimality conditions (5) and the household's budget constraint (2).

- Firms optimize: Taking as given prices, probabilities and a perceived law of motion for the economy (20), $v_{j}\left(\omega_{f}, \Omega\right), k_{j}\left(\omega_{f}, \Omega\right)$, and $h_{j}\left(\omega_{f}, \Omega\right)$ satisfy optimality conditions (22), (23) and the law of motion for $h_{j}(70)$.

- Wages and the stochastic discount factor: Wages are a solution to wage bargaining game 3.5.1 and the stochastic discount factor is consistent with $Q(\Omega)=\beta\left(\frac{c\left(\omega^{\prime}, \Omega^{\prime}\right)}{c(\omega, \Omega)}\right)^{-\sigma}$.

- Consistency of value functions: Value functions $\mathbb{U}(\omega, \Omega), W_{j}(\omega, \Omega), U(\omega, \Omega), \Pi_{j}\left(\omega_{f}, \Omega\right)$, and $J_{j}\left(\omega_{f}, \Omega\right)$ are consistent with equations (1), (7), (6), (16), and (25).

- Beliefs: At each point in time, workers' beliefs are determined by their information set $\mathcal{I}_{h}$, their perceived law of motion for the economy (4), and Bayes' rule.

- Law of motion: The decision rules of households and firms imply a law of motion for the economy $(\lambda)$ that is consistent with the household's and firms' perceived law of motion: $\lambda^{f}=$ $\lambda^{h}=\lambda$.

- Probabilities: Probabilities $\tilde{q}_{j}(\Omega), \tilde{q}_{j}^{c}(\Omega), F_{j}(\Omega), q^{u}(\Omega)$, and $q(\Omega)$ are consistent with equation (13), (15), (10), (14) and $q(\Omega)=m(v(\Omega), s(\Omega)) / s(\Omega)$.

- Allocations: $\pi_{j}\left(\omega_{f}, \Omega\right), y_{j}\left(\omega_{f}, \Omega\right), z_{j}(\Omega), \tilde{W}_{j}(\omega, \Omega), \bar{W}(\omega, \Omega)$ and $\theta(\Omega)$ are consistent with equations (17), (18), (9), (11), (12), and $\theta(\Omega)=\left(\frac{v(\Omega)}{s(\Omega)}\right)$.

- Aggregation: $v, Y, s, u$, and $k$ are consistent with:

$$
\begin{aligned}
& v(\Omega)=\int_{0}^{1} v_{j}\left(\omega_{f}, \Omega\right) d j \\
& y(\Omega)=\int_{0}^{1} y_{j}\left(\omega_{f}, \Omega\right) d j \\
& s(\Omega)=u(\Omega)+\int_{0}^{1} \bar{i} h_{j}\left(\omega_{f}, \Omega\right) d j \\
& u(\Omega)=\int_{0}^{1}\left(1-h_{j}\left(\omega_{f}, \Omega\right)\right) d j \\
& k(\Omega)=\int_{0}^{1} k_{j}\left(\omega_{f}, \Omega\right) d j
\end{aligned}
$$


- Exogenous variables: a, $\hat{a}$, and $n$ evolve according to equations (26), (27) and (28).

Appendix E presents the equations that describe the equilibrium of this economy.

\section{Computation}

To compute the solution to this model numerically, it is important to find and determine a law of motion for the economy, based on which the household forms expectations and makes decisions. This task may not be simple for a large vector $\Omega$, given a distribution of firms and workers. Another challenge is that the vector of state variables should incorporate a set of variables that capture agents' beliefs, which could include prior beliefs about $\Omega$ or lags of the vector of state variables. This could not only increase significantly the size of the vector of state variables but also may require the computation of higher order expectations (expectations of agents' expectations).

Hence, I propose a procedure that combines the solution method for heterogeneous agent models developed by Reiter (2009) and the Kalman filter. In particular, the law of motion for the aggregate economy will be linear (Reiter method), which will allow me to form expectations using the Kalman filter. I show in Appendix G that I can keep track of agents' expectations by keeping track of the last $\mathcal{T}$ realizations of the aggregate shocks in the economy, where $\mathcal{T}$ is a "large" integer. ${ }^{29}$ Hence, to solve the model with noisy signals, you only need to include the last $\mathcal{T}$ realizations of the aggregate shocks as state variables. ${ }^{30}$

In more detail, the Reiter method solves heterogeneous agent models by taking a first-order approximation of the model around the deterministic steady state of the economy. ${ }^{31}$ Assume that the following system of equations describes the equilibrium of the economy:

$$
f\left(\Omega, \Omega^{\prime}, \Upsilon, \Upsilon^{\prime}, \mathbb{E}\right)=0
$$

where $\Upsilon$ is the vector of endogenous variables of the economy and $\mathbb{E}$ is the vector of exogenous shocks. The Reiter method then finds the solution in three steps:

1. A finite representation of the economy is provided by discretizing the distribution of agents.

2. The deterministic steady state of the economy is found by imposing $\mathbb{E}=0$ and finding the solution to:

$$
f^{*}=f\left(\Omega^{*}, \Omega^{*}, \Upsilon^{*}, \Upsilon^{*}, 0\right)=0
$$

\footnotetext{
${ }^{29} \mathcal{T}$ is large enough if $\tilde{\mathcal{T}}>>\mathcal{T}$ generates almost the same results. In my calibration, I find that $\mathcal{T}=100$ was more than enough.

${ }^{30}$ Notice that vector $\Omega$ in the equilibrium definition in section 3.6 included the last $\mathcal{T}$ realization of the aggregate shocks.

${ }^{31}$ For a detailed application of the Reiter method, see Costain and Nakov (2011).
} 
3. The model is linearized numerically around the steady state, which yields the system of linear equations:

$$
f_{1}^{*}\left(\Omega-\Omega^{*}\right)+f_{2}^{*}\left(\Omega^{\prime}-\Omega^{*}\right)+f_{3}^{*}\left(\Upsilon-\Upsilon^{*}\right)+f_{4}^{*}\left(\Upsilon^{\prime}-\Upsilon^{*}\right)+f_{5}^{*} \mathbb{E}=0
$$

where $f_{i}^{*}$ is the partial derivative of (38) with respect to its $i$-th argument. This system is solved using a standard method such as Sims (2002) or Klein (2000).

Hence, the Reiter method induces a law of motion for the economy of the form:

$$
\begin{aligned}
& \Omega^{\prime}=\mathbb{F} \Omega+\mathbb{E} \\
& \Upsilon=\mathbb{G} \Omega
\end{aligned}
$$

where $\mathbb{F}$ and $\mathbb{G}$ are matrices of coefficients. Therefore, the law of motion for the economy is described by $\lambda=\{\mathbb{F}, \mathbb{G}\}$. The challenge for a model with information frictions comes from the fact that the law of motion $\lambda$ is derived from a perceived law of motion $\lambda^{h}$, which in equilibrium has to be equal to the actual law of motion $\lambda$.

I exploit the linearity of the Reiter method and proceed as follows: ${ }^{32}$

1. Define a tolerance level.

2. Guess a linear law of motion for the economy $\lambda^{h\{1\}}=\left\{\mathbb{F}^{h\{1\}}, \mathbb{G}^{h\{1\}}\right\}$. A good initial guess may be the law of motion of the model under perfect information.

3. Let the household form expectations based on this guess and the Kalman filter. Appendix $\mathrm{G}$ explains how to compute these expectations.

4. Find the solution of the model using the Reiter method, which is given by a new law of motion $\lambda^{\{1\}}=\left\{\mathbb{F}^{\{1\}}, \mathbb{G}^{\{1\}}\right\}$.

5. If the maximum difference between $\lambda^{h\{1\}}$ and $\lambda^{\{1\}}$ is less than the predetermined tolerance level, stop and conclude that $\lambda^{h\{1\}}=\lambda$. Otherwise, update the household's perceived law of motion as follows:

$$
\lambda^{h\{n+1\}}=d \cdot \lambda^{h\{n\}}+(1-d) \cdot \lambda^{\{n\}} ; \quad 0<d<1
$$

where $d$ is a fraction that determines how smoothly the guess is updated.

6. Go back to step 3.

\footnotetext{
${ }^{32}$ The linearity of the model makes the model tractable as I can compute expectations based on a linear filter. Otherwise, I would need to use non-linear filters (such as the particle filter), which would substantially increase the complexity of the problem for a large vector $\Omega$.
} 


\section{Quantitative Analysis}

I assess the model's predictions using quarterly data for the United States for the period 1979 to 2015. I present business cycle statistics for the quarterly time series (seasonally adjusted) of unemployment, vacancies, output, consumption, investment, aggregate TFP, and real wages (deflated by CPI) for new employees, job changers, and all workers. I take the quarterly average of series that are available monthly. Following Shimer (2005), all variables are HP-filtered in logs with a smoothing parameter of $10^{5} .^{33}$

Unemployment is the total number of unemployed people from the CPS. Vacancies are the composite help-wanted index computed by Barnichon (2010a). Output is real output in the nonfarm business sector. Aggregate productivity is measured as the Solow residual, which is available and updated on the Federal Reserve Bank of San Francisco's website. Consumption consists of nondurable goods and services. Finally, investment is real gross private domestic investment. I include investment as a variable of interest because the effect of the information friction on investment plays an important role in my model.

Given the debate about the cyclicality of wages, I use the CPS and IPUMS-CPS (Flood et al., 2015) microdata to construct the average hourly wage for three group of workers: all workers, new employees, and job changers. In order to compute these wages, I follow Muller (2012) and Haefke et al. (2013) who also used the CPS microdata to construct similar series. The series presented in this paper are the coefficients of time fixed effects in Mincer equations controlling for education, a fourth order polynominal in experience, gender, race, marital status, state, 10 occupation dummies and 14 industry dummies. Since 1994, the CPS has asked individuals whether they still work at the same job as in the previous month, making it possible to identify job changers. However, it is not possible to identify job-to-job transitions prior to that year. Hence, the sample period for the average wage for job changers is 1994-2015. Figure 10a plots these wage series along with the average hourly earnings of production and nonsupervisory employees (red line) for comparison, and Appendix F provides more details about the methodology that I follow to construct these wage series.

Based on the series reported in Figure 10a, we can see that, on average, new hires from unemployment and job changers earn a wage that is $12.6 \%$ and $3.7 \%$ lower than the average worker, respectively, suggesting that workers who were previously unemployed usually get employed at low paying jobs and move up the job ladder. Notice that these differences in wages cannot be explained by education, experience, gender, race, marital status, state, occupation, or industry, as those variables were included in the Mincer equation.

Table 1 presents unconditional business cycle statistics for the U.S. economy. As has been

\footnotetext{
${ }^{33}$ In general my results are not very sensitive to this parameter.
} 
previously documented in the literature, unemployment is one of the most volatile series (e.g. Shimer, 2005; Costain \& Reiter, 2008). Unemployment is 10 times more volatile than TFP, and 8 times more volatile than output, in contrast to consumption, whose standard deviation is almost as large as that of TFP. Vacancies and the vacancy-unemployment ratio are also highly volatile as their standard deviations are $19.5 \%$ and $37.5 \%$, respectively, in comparison with $2.3 \%$ and $1.6 \%$ for output and TFP, respectively. Investment also fluctuates a lot over the business cycle. Even though it is not as volatile as unemployment or vacancies, the standard deviation of investment is 4.5 times larger than that of output. In contrast, wages are not very volatile. The standard deviations of the average wage of all workers $\left(w^{a}\right)$, new hires from unemployment $\left(w^{u}\right)$, and job changers $\left(w^{c}\right)$ are $2.1 \%, 3.4 \%$ and $2.4 \%$ respectively. Also, it is noteworthy that wages are the less persistent and less correlated series with unemployment and output.

\subsection{Parameterization}

I calibrate this model to a monthly frequency and compute quarterly averages of the model generated series in order to compare my model results with the U.S. data. I borrow the values for the intertemporal elasticity of substitution $(\sigma)$, the inverse of the Frisch elasticity $(\eta)$, and the output elasticity of labor $(\alpha)$ from previous literature and set these parameters equal to $1,0.5$, and 0.33 , respectively. ${ }^{34}$ Following the literature, I set $\vartheta$ equal to 0.5 , which implies equal bargaining power for workers and firms in steady state. The unemployment benefit $b$ is set to 0.041 following the evidence presented by Chodorow-Reich and Karabarbounis (2014). ${ }^{35}$ I set $\delta$ and $\beta$ so that the annual depreciation rate is equal to $10 \%$ and the annual interest rate is equal to $5 \%$ in steady state.

Given firm heterogeneity in this model, it is important to have a matching function that guarantees that all matching probabilities are between 0 and 1 , which is not the case for the widely used Cobb-Douglas function. Hence, I follow den Han, Ramey and Watson (2000) and Hagedorn and Manovskii (2008) and assume the following function:

$$
m(s, v)=\frac{s v}{\left(s^{l}+v^{l}\right)^{\frac{1}{l}}}
$$

I choose the parameter $l$ so that the job-finding probability $(q)$ is equal to 0.27 in steady state,

\footnotetext{
${ }^{34}$ Peterman (2013) reviews the Frisch elasticities used in macro models (between 2 and 4) and estimates an elasticity for macro studies between 2.9 and 3.1, which implies a value of 0.33 for $\eta$. In order to have a similar value to the standard literature, I set $\eta=0.5$, but a lower value would make the results of this paper stronger, as $z_{j}$ would become less cyclical.

${ }^{35}$ Chodorow-Reich and Karabarbounis (2014) estimate that unemployment benefits are $21.5 \%$ of the marginal labor productivity. However, when adjusted by eligibility, claims and take up costs, $b$ declines to 0.041. Given that I will have a distribution of labor productivity, I take a conservative approach, and I set $b$ to $0.041 \%$ of the mode marginal labor productivity, which is equal to 1.
} 
which implies an average duration of unemployment equal to 15 weeks consistent with evidence for the US economy. The exogenous separation rate $\delta_{h}$ is set such that the unemployment rate is equal to $5.5 \%$ in steady state.

I discretize the distribution for $a_{j}$ into 101 points, and I calibrate it such that marginal labor productivity $\left(p_{j}\right)$ is distributed according to a truncated normal between $[p, \infty)$ with a mode equal to 1 and standard deviation equal to 0.6, which is consistent with Long, Dziczek, Luria and Wiarda (2008). ${ }^{36}$ In order to guarantee a positive match surplus in equilibrium for all firms, I set $p$ equal to 0.4 , which is 10 times larger than $b$.

I calibrate the disutility of labor parameter $\Psi$ such that the average of the ratio $\frac{z_{j}}{p_{j}}$ across firms is equal to 0.72 , which is consistent with the value found by Hall and Milgrom (2008). ${ }^{37}$ The value for $\bar{i}$ is calibrated such that the number of job changers per month in steady state is equal to $2.5 \%$ of the total population, which is consistent with the estimates of Fallick and Fleischman (2004).

I use parameters $\xi$ and $\chi$ to target some moments of the wage and size distribution across firms for the United States. Kahn and McEntarfer (2014) present the average monthly earnings across firms for each wage quintile, which are reproduce in Table 2. According to this table, a worker employed at a firm in the highest wage quintile earns, on average, 3.61 times more than a worker employed at a firm in the lowest wage quintile. I calibrate $\xi$ to match this moment in order to capture the curvature of the wage distribution. On the other hand, Table 3 presents statistics for the distribution of firm size based on the Business Dynamics Statistics from 1977 to 2014. I calibrate parameter $\chi$ to target the average size of firms with 100 to 249 employees as a fraction of the average size of the smallest firms. ${ }^{38}$ Figure 2 plots these distributions in steady state.

Finally, the persistence of aggregate TFP is set equal to $0.95^{1 / 3}$ and the standard deviation calibrated to match the standard deviation of TFP presented in Table 1. Following Coibion and Gorodnichenko (2012), $\frac{\varsigma_{n}}{\varsigma_{a}}$ is set to 2 and $\rho_{n}$ is calibrated such that the perception error has a quarterly persistence of $0.8 .{ }^{39}$ Table 4 summarizes the aforementioned calibration parameters and their sources when appropriate.

\footnotetext{
${ }^{36}$ Hence, everything is term of the mode (marginal) labor productivity across firms. Given that the distribution of employment is not uniform in equilibrium, the median productivity across firms is not equal to the median productivity across workers.

${ }^{37}$ There is an extensive debate surrounding the value of the FOCE $(z)$ in the literature, with parameterizations ranging from 0.4 (e.g. Shimer, 2005) to 0.955 (e.g. Hagedorn and Manovskii, 2008). A value around 0.72 is less controversial than these extremes.

${ }^{38}$ Given that average size increases drastically at the end of the distribution, I do not target the average size of the largest firms

${ }^{39}$ Perception error IS defined as aggregate TFP - perceived aggregate TFP.
} 


\subsection{Model Results}

\subsubsection{Steady State}

Before turning to the dynamics, I first present Figure 3, which illustrates the role of heterogeneous firms in this model. Panel 3a plots the distribution of idiosyncratic TFP across firms $\left(f\left(a_{j}\right)\right)$ and the marginal labor productivity associated with each $a_{j}$, and panel $3 \mathrm{~b}$ shows the wage rate $\left(w_{j}\right)$ and the probability of finding a better job conditional on a match for employed workers $\left(F_{j}\right)$. We can see that the most productive firms have higher marginal labor productivity and as a consequence pay higher wages. Panel 3c shows the average firm size as a function of the firm's labor productivity $p$ (solid black line), and the distributions of employment (dashed line). In particular, the dashed black line in panel 3c plots the fraction of workers who are currently employed in a firm with labor productivity equal to $p_{j}$. As in Moscarini and Postel-Vinay (2013) the most productive firms are larger in equilibrium, and therefore the distribution of employment is shifted to the right in comparison with the distribution for $p$ (solid red line).

Panel $3 d$ plots the separation rate $\left(\delta_{h j}\right)$ and the job filling rate $\left(\tilde{q}_{j}\right)$ associated with each level of marginal labor productivity. Because employed workers only accept jobs that pay a higher wage and unemployed workers always accept a job offer, the most productive firms have a higher job filling rate and a lower separation rate than less-productive firms. Also, low-paying firms rely more on the pool of unemployment while high-wage firms find most of their new hires from the pool of employment. Hence, it is not surprising that the labor productivity distribution of new employees is shifted to the left relative to the productivity distribution for job changers (panel 3e) — new workers are more likely to find a job at a low-paying firm, in contrast to job changers, who are poached by the most productive firms.

In panel 3f, we can also see that the distribution of overall employment is even more shifted to the right than the distribution of job changers, as the most productive firms have a low separation rate in equilibrium. In other words, a firm at the right tail of the productivity distribution has a higher job filling rate but also a lower separation rate than a firm at the middle of the distribution. Hence, a very productive firm does not have to post as many vacancies as a firm that is in the middle of the distribution.

Based on these distributions, Table 5 reports the average wage for different types of workers as a fraction of the average wage for all workers in the economy. The average wage for job stayers is higher than the average wage for any other group because high-paying firms have the lowest separation rate, which gives a higher weight to employed workers at those firms. In contrast, the average wage for new employees is the lowest among these groups of workers. As explained earlier, new employees are more likely to find a job at a low-paying firm. These results are consistent with Figure 10a, which shows that, on average, job changers earn a higher wage than new employees 
but a lower wage than the average worker in the economy. Even though the model does a good job matching the wage and size distribution in the economy, the average wage for new employees generated by my model is lower than in the data (0.701 versus 0.874 ).

\subsubsection{Responses to Productivity Shocks}

Next, Figures 4 and 5 plot the Impulse Response Functions (IRFs) of the aggregate variables of this model to a $1 \%$ increase in aggregate TFP (solid black lines). In order to decipher the role of information frictions, I simultaneously plot the IRFs generated by a calibrated model in which agents have perfect information (dashed lines). In addition, Figure 6 plots the IRFs for firms located at the 20th, 40th, 50th, 60th, and 80th percentiles of the wage distribution weighted by employment.

Based on these figures, we can see the role of information frictions in amplifying the unemployment response to productivity shocks. Because TFP shocks are partially perceived by workers, wages are less sensitive to aggregate productivity innovations (Figure 4). In particular, the assumed information friction has two reinforcing effects on wages. First, workers' expectations are highly sluggish. Hence, in a boom, workers do not demand a large increase in wages because they do not have enough information to conclude that the economy has entered an expansionary path. Second, given workers' beliefs, consumption does not change significantly on impact, so that a large fraction of the increase in aggregate output is absorbed by investment,. This curbs the increase of the flow of opportunity cost of employment $\left(z_{j}\right)$ from increasing, which makes wages even less responsive. Therefore, firms have more incentives to expand employment because wages adjust slowly to the true state of the economy.

However, firms' responses to this shock are not uniform. The most productive firms experience a larger expansion in employment as a consequence of a positive aggregate TFP innovation. Because there is a large expansion in overall employment, there is a large flow of job changers that makes the separation rate increase for low-paying/less-productive firms. Hence, the value of a new hire is affected by two countervailing effects. On the one hand, the productivity increase, combined with sluggish real wages, tends to increase the value of an additional worker for firms in an expansion. On the other hand, an increase in the separation rate reduces the value of an additional worker because firms expect the match to not last as long. Hence, the value of an additional worker should increase more for highly-productive firms. Therefore, they expand employment the most. According to these results, the increase in the separation rate for low-paying firms is so large that they reduce their employment levels, as they are crowded out by the large expansion of highly productive firms. As a result, the differential employment growth rate between high and low paying firms is positive and procyclical, which is consistent with the empirical evidence (e.g. Kahn \& McEntarfer, 2014; Haltiwanger et al., 2015). 
This differential growth rate in employment implies a differential growth in the FOCE $\left(z_{j}\right)$. Because high-paying firms are expanding employment the most, they also experience a larger increase in $z_{j}$, which makes their wages increase more than the wages for low-paying firms. The fact that wages increase more for the most productive firms does not imply that their workers have more or better information than workers employed at low-paying firms. Because workers can perfectly distinguish among firms and they know that highly-productive firms are more sensitive to the business cycle, employees at the most productive firms demand a higher wage than employees at less-productive firms in response to an increase in perceived productivity. Hence, the differential employment growth rate occurs despite the larger adjustment in wages for high-paying firms, which is also consistent with the empirical evidence. Kahn and McEntarfer (2014) do not find that the differential employment growth rate is driven by high-paying firms facing more sluggish wages. In fact, they show that high-paying firms reduce wages in recessions relative to low-paying firms.

These results imply different dynamics for the job-filling rate across firms $\left(\tilde{q}_{j}\right)$. In particular, since low-paying firms rely more on hiring from the pool of unemployment, they experience a large decline in $\tilde{q}_{j}$ because of the decline in unemployment. By contrast, high-paying firms experience an initial decrease in the job-filling rate because of the large increase in the total number of vacancies. But as the pool of employment increases, the job filling rate for the most productive firms goes up because most of their new hires come from other firms.

\subsubsection{Expectations and Responses to Noise Shocks}

Figure 7 plots the evolution of workers' beliefs in response to a 1\% increase in aggregate TFP. Figure 7 depicts the current level of aggregate TFP and unemployment along with worker's forecasts about the unemployment rate 3 and 12 months ahead. As the first panel shows, workers only perceive $40 \%$ of TFP shocks, but as time goes by their perceived productivity increases and converges to the true TFP. Despite this information friction, workers do not have much difficulty inferring the current unemployment rate. Nonetheless, workers have limitations forming expectations about future economic conditions because they are uncertain about the fundamentals of the economy (i.e., $a$ and $n$ ), which prevents their wage demands from increasing in response to a productivity shocks as previously explained.

Noise shocks, however, do not only reduce wage demands through workers' perceived productivity. Given the assumed information friction, workers will partially attribute noise shocks to TFP innovations. Hence, a noise shock will result in higher wage demands and, as a consequence, higher unemployment and lower output as shown in Figure 8. Since workers know that the demanding higher wages in response to noise shocks is not optimal, wage demands will tend to be even lower in response to productivity shocks. In other words, wage demands weight the positive effects of a positive TFP shock and the negative effects of a positive noise shock. 


\subsubsection{Wages and Employment Composition}

The left panels of Figure 9 plot the IRF to a 1\% increase in aggregate TFP for average wages for each type of worker in the model with information frictions (panel 9a) and in the model with full information (panel 9c). Notice that the average wage for new hires, job changers, and new employees has a larger response, soon after the TFP shock, than the average wage for job stayers and all workers. The wage differential between new hires and job stayers is even larger in the model with information frictions. However, these wage differences are driven primarily by heterogeneity across firms. Note that average wages increase for two reasons: (1) because wages within firms increase and (2) because high-wage firms increase employment the most in an expansion. In order to see the importance these two effects, the right panels of Figure 9 plot the average wage for all groups of workers when wages are adjusted for this composition effect. In particular, I follow Horrace and Oaxaga (2001) and define the average wage for group $G$ adjusted for composition effects $\left(\tilde{w}^{G}\right)$ as the average wage for a fixed composition of workers across firms, where the composition of workers is given by the distribution of workers across firms in steady state.

By comparing the left and right panels of Figure 9, we can infer that the initial increase in the wages of new hires, job changers and new employees is due almost entirely to the large increase in employment at high-paying firms. Actually, in the model with information frictions, the average wage response for new employees is lower than the average wage response for job changers, which is slightly lower than the average wage response for job stayers. This is because unemployed workers are more likely to find a job at a low paying firms and then to move up the job ladder (Figure 3f), and low paying firms increase their wages less in booms (Figure 6). This result is in line with previous empirical evidence. For example, using the National Longitudinal Survey of Youth (NLSY) and the Panel Study of Income Dynamics (PSID), Hagedorn and Manovskii (2013) find no significant differences in the cyclicality of wages for job changers and job stayers when they control for match quality. ${ }^{40}$

How does the wage flexibility in my model compare with the data? Citing previous empirical studies, Pissarides (2009) argues that the wage semi-elasticity with respect to the unemployment rate for new hires is around $-3 \%$ compared with $-1 \%$ for job stayers. ${ }^{41}$ According to Pissarides (2009), these numbers indicate a larger wage flexibility for new hires than usually assumed, questioning the importance of wage stickiness to explain the unemployment volatility. Most of the studies cited by Pissarides (2009) estimate this wage semi-elasticity $\left(\beta_{u}\right)$ by fitting the following

\footnotetext{
${ }^{40}$ Gertler et al. (2014) find the same result for a different sample period using the SIPP dataset.

${ }^{41}$ These numbers imply that an increase of one percentage point in unemployment (for example, from $5 \%$ to $6 \%$ ) makes wages for job changers and job stayers decrease by $3 \%$ and $1 \%$ respectively.
} 
equation:

$$
\left(\log \left(w_{t}^{G}\right)-\log \left(w_{t-1}^{G}\right)\right)=\alpha_{0}+\beta_{u} \cdot\left(u r_{t}-u r_{t-1}\right)+e_{t}
$$

where $w_{t}^{G}$ is the average wage (controlling for individual characteristics) for group $G$. $\alpha_{0}$ is a constant, $u r_{t}$ is the unemployment rate at time $t$, and $e_{t}$ is an error term.

Table 6 reports the estimated values for $\beta_{u}$ using the wage series constructed from the CPS and IPUMS-CPS microdata (column 1) along with the theoretical value for that parameter in the model with full information (column 2) and with information frictions (column 3). ${ }^{42}$

Using the wage series constructed from microdata, I get a negative wage semi-elasticity for all group of workers. However, these semi-elasticities are smaller than reported by Pissarides (2009), and only the semi-elasticity for new employees is statistically significant at $10 \%$. On the one hand, the model with full information predicts a wage semi-elasticity of $-1 \%$ for all workers but positive and large semi-elasticities for new employees and job changers. This is because, the largest wage responses are on impact, but the largest unemployment response is not. On the other hand, the model with information frictions generates negative wage semi-elasticities for all groups of workers. The wage semi-elasticity is $-2.93 \%$ for job changers, -2.65 for new employees, and $-1.12 \%$ for all workers in the model with information frictions. It is worth noting that these values are not a target in my calibration. The reason wages for new hires display a higher wage semi-elasticity in the model with information frictions is because the largest changes in wages are more synchronized with the largest changes in the unemployment pool. In the model with information frictions, the largest wage responses are not on impact, and we observe a significant change in the average wage for new hires because high-paying firms expand employment the most in booms (Figure 9), which induces a higher correlation between changes in unemployment and wages for new hires.

Given that most of the wage cyclicality reported in column (3) of Table 6 is driven by the reallocation of workers from low to high paying firms in booms, I asses the employment flows generated by my model in Table 7 . Column (1) of Table 7 reproduces the findings of Haltiwanger, et al (2015) regarding the reallocation of workers from low to high paying firms during the business cycle. As before, columns (2) and (3) report the analog theoretical moments. In particular, Table 7 reports the estimated values of $\beta$ in the following specification:

$$
Y_{t}=\gamma+\pi_{t}+\beta \cdot C Y C_{s t}+\epsilon_{t}
$$

where $Y_{s t}$ is differential net job flows, net poaching flow, and net nonemployment flows between

\footnotetext{
${ }^{42}$ Using my model, I generate artificial series of the same size and frequency as my data (148 monthly observations for the average wage of all and new employees and 88 monthly observations for the average wage of job changer). Using this artificial series, I estimate $\beta_{u}$ by fitting equation (44). I repeat this exercise 10,000 times and get the theoretical value of $\beta_{u}$ by taking the average across the 10,000 simulations.
} 
high and low wage firms. ${ }^{43} \gamma$ is a constant, $\pi$ includes seasonal dummies and a time trend, and $\epsilon$ is an error term. $C Y C$ is a cyclical variable, which can be the HP-filtered unemployment rate or the first different in the unemployment rate.

According to Table 7, both models (full information and information frictions) generate differential employment flows that are consistent with the empirical estimates of Haltiwanger, et al (2015) when I use the HP-filtered unemployment rate as a cyclical indicator. But both models generate little differential employment growth when the first different in the unemployment rate is used as a cyclical indicator. Given that my model does not display a larger differential employment flow than observed in the data, the wage cyclicality reported in Table 6 does not seem to be driven by an excessive reallocation of workers from low to high-paying firms.

\subsubsection{Simulated Business Cycles Statistics}

Table 8 reports the theoretical business cycle statistics predicted by a model in which workers face information frictions, and Table 9 does the same for the model with full information. ${ }^{44}$ In comparison with the U.S. data, my model with information frictions does a good job predicting a high volatility for labor market variables and a low volatility for wages and consumption. This is in part because of the amplifying effect of the information friction. The volatility of $u$, $v$, and $v / u$ are three times larger in the model with information frictions than in the model with full information, but the volatility of consumption and wages is just slightly larger in the former. The autocorrelation predicted by my model are close to the data, and my model is able to display a lower autocorrelation for the average wage of new employees and job changers. Even though the information friction tends to reduce the correlation between the average wage of the economy with other economy variables, those correlations continue to be significantly larger than in the data. Similarly, the correlations between the average wage for new employees and all variables of the economy have a different sign as in the data. ${ }^{45}$

\section{A Simple Test Using Survey Data}

In this section, I test the main implication of my model: Wages should increase when workers are more optimistic about economic conditions. To this end, I re-estimate equation (44) introducing

\footnotetext{
${ }^{43}$ High wage firm indicates that the firm is in the two top quintiles of the wage distribution across firms. Low wage firm indicates that the firm is in the bottom quintile of the wage distribution.

${ }^{44}$ The model was used to generate artificial series of the same length and frequency as in my data. These series were used to compute, in the same way, the same business cycle statistics reported in Table 1. This exercise was repeated 10,000 times. Then, each statistic reported in Tables 8 and 9 is the average of that moment across the 10,000 simulations.

${ }^{45}$ In section 7.4, I compute conditional moments in data and compare them with the conditional moments generated by my model. I find that my model generates conditional moments that are very close to those I compute in the data.
} 
a variable of workers' expectations. Hence, my empirical model takes the following form:

$$
\left(\log \left(w_{t}^{G}\right)-\log \left(w_{t-1}^{G}\right)\right)=\alpha_{0}+\beta_{u} \cdot\left(u r_{t}-u r_{t-1}\right)+\beta_{E} \cdot \Delta E_{t}^{w}+e_{t}
$$

Where variable $\Delta E_{t}^{w}$ is a measure of change in workers expectations. As a proxy of $E_{t}^{w}$, I use the Index of Consumer Sentiments (ICS) of the Surveys of Consumers conducted by the University of Michigan. The ICS is reported monthly and is intended to be a indicator of how consumers view prospects (better or worst) for their own financial situation and for the economy in the near and long term. The ICS is used in because it asks for expected changes instead of expected levels. Also, for an easier interpretation in my estimation, I normalize the ICS such that it has a zero mean and a standard deviation equal to one. Figure 10b plots this index, and the top panel in Table 10 presents the results of estimating equation (46) by OLS. For an easier interpretation, all values in Table 10 are expressed as semi-elasticities. By including a variable of workers expectations, all wage semi-elasticities with respect to the unemployment rate become smaller and statistically insignificant. Also, these results show that wages are positively correlated with workers' expectations, but this coefficient is only statistically significant for the average wage of all workers. A one standard deviation increase in the ICS is associated with a $0.14 \%$ increase in the average wage for all workers.

To see if wages are correlated with other agents' expectations, the bottom panel of Table 10 reports the results of estimating the following equation:

$$
\left(\log \left(w_{t}^{G}\right)-\log \left(w_{t-1}^{G}\right)\right)=\alpha_{0}+\beta_{u} \cdot\left(u r_{t}-u r_{t-1}\right)+\beta_{E} \cdot E_{t}^{w}+\beta_{u e} \cdot u r_{t}^{e}+\beta_{y} \cdot y_{t}^{e} e_{t}
$$

where $u r_{t}^{e}$ is the expected change in the unemployment rate over the next year, and $y_{t}^{e}$ is the expected GDP growth for the following year. $u r_{t}^{e}$ and $y_{t}^{e}$ are taken from the Survey of Professional Forecasters and are available at a quarterly frequency. These results show that workers' expectations are more significantly correlated with wages at a quarterly frequency. A 1 standard deviation increase in the ICS is associated with a $0.35 \%, 0.63 \%$ and $0.48 \%$ increase in the average wage for all workers, new employees and job changers respectively. Also, it is worth noticing that the ICS is the only statistically significant variable in Table 10, suggesting a significant relationship between wages and workers' beliefs.

\section{Robustness and Extensions}

This section addresses the robustness of my results to variations in some of the assumptions that underlie my analysis. I show the following: (1) Assumption 1 holds in my calibration. (2) For this calibration, in equilibrium, firms do not have incentives to pay higher wages. (3) Assuming 
that firms face information frictions can make unemployment responses larger or smaller than in my benchmark model depending on specific assumptions. But wage dynamics will depend on the workers' expectations as long as the workers' information set is a subset of the firms' information set. (4) I estimate that between $60 \%$ and $65 \%$ of overall business cycle volatility in labor market quantities such as unemployment, vacancies, and the vacancy-unemployment ratio and $50 \%$ of overall volatility in wages can be explained by temporary TFP innovations.

\subsection{Checking Assumption 1}

In section 3.5, the equilibrium wage was characterized under the assumption that for all realization of $a$ and $n$, all firms receive a positive payoff by paying workers what they demand. I check that this assumption holds by simulating the economy for 1 million periods and computing, for each period, $m J=\min _{j}\left\{J_{j}\right\}$. Figure 11a plots $m J$ and shows that $m J$ is always positive and never close to zero.

\subsection{Unilateral Deviations in Equilibrium}

Nothing in my model prevents firms from paying a higher wage in equilibrium. Even though higher wages increase firms' payroll, offering a higher wage can reduce the fraction of workers who are poached by other firms, and as a consequence, increase profits. When workers' bargaining power is low, firms incentives to offer higher wages could be large. However, in my calibration with a bargaining power equal to 0.5, no firm has incentives to offer a higher wage. Suppose that firm

$j$ is considering offering a higher wage to its employees in order to reduce its separation rate and increase its profits. Hence, following Moscarini and Postel-Vinay (2013), the problem for firm $j$ would be given by:

$$
\begin{aligned}
\Pi_{j}\left(\omega_{f}, \bar{W}, \Omega\right) & =\max _{v_{j}, k_{j}, w_{j}, W_{j}^{\prime}} e^{a_{j}+a} k_{j}^{\alpha} h_{j}^{1-\alpha}-w_{j} h_{j}-r k_{j}-\frac{\kappa}{1+\chi}\left(\tilde{q}_{j} v_{j}\right)^{1+\chi}+E\left[Q \Pi_{j}\left(\omega_{f}^{\prime}, W_{j}^{\prime}, \Omega^{\prime}\right)\right] \\
\text { s.t. } & h_{j}^{\prime} \\
= & \left(1-\delta_{h}\right)\left(1-\bar{i} q F\left(W_{j}^{\prime}\right)\right) h_{j}+\tilde{q}\left(W_{j}^{\prime}\right) v_{j} \\
E_{\mathcal{I}_{h}}\left[W_{j}\right] & \geq \vartheta \cdot E_{\mathcal{I}_{h}}\left[S_{j}\right] \\
E_{\mathcal{I}_{h}}\left[W_{j}^{\prime}\right] & \geq \vartheta \cdot E_{\mathcal{I}_{h}}\left[S_{j}^{\prime}\right] \\
E_{\mathcal{I}_{h}}\left[W_{j}\right] & \geq \bar{W} \\
\Omega^{\prime} & =\lambda^{f}(\Omega) \\
v_{j}, \quad \geq 0 &
\end{aligned}
$$


where restrictions (50) and (51) imply that the wage offer cannot be lower than what workers would get otherwise, and restriction (52) implies that the continuation value for workers cannot be lower than what was promised at the end of the last period. Given that the optimality conditions for $k_{j}$ and $v_{j}$ do not change, let me concentrate on $W_{j}^{\prime}$. Given that $E_{\mathcal{I}_{h}}\left[W_{j}\right]=\max \left\{\vartheta \cdot E_{\mathcal{I}_{h}}\left[S_{j}\right], \bar{W}\right\}$, the optimality condition for $W_{j}^{\prime}$ is:

$$
E\left[-Q \tilde{q}\left(W_{j}^{\prime}\right) v_{j}+Q J^{\prime}\left(\omega_{f}, W_{j}^{\prime}, \Omega\right) h_{j}\left(1-\delta_{h}\right) \bar{i} q \frac{\partial F\left(W_{j}^{\prime}\right)}{\partial W_{j}^{\prime}}\right] \leq 0
$$

equation (55) holds with equality if $W_{j}^{\prime}>\vartheta \cdot E_{\mathcal{I}_{h}}\left[S_{j}^{\prime}\right]$. If firm $j$ increase its wage in one unit, its wage bill will increase by $\tilde{q}\left(W_{j}^{\prime}\right) v_{j}$ next period, but it will retain an additional fraction $(1-$ $\left.\delta_{h}\right) \bar{i} q \frac{\partial F\left(W_{j}^{\prime}\right)}{\partial W_{j}^{\prime}}$ of its current employees, each one of which will increase firm's profits by $J^{\prime}\left(\omega_{f}, W_{j}^{\prime}, \Omega\right) .{ }^{46}$ Hence, in equilibrium, equation (51) holds with equality if:

$$
\underline{\Pi}_{j}=E\left[-Q \tilde{q}_{j} \frac{v_{j}}{h_{j}}+Q J^{\prime}\left(\omega_{f}, \Omega\right)\left(1-\delta_{h}\right) \bar{i} q \frac{\partial F\left(W_{j}^{\prime}\right)}{\partial W_{j}^{\prime}}\right] \leq 0
$$

Figure $11 \mathrm{~b}$ shows that $\underline{\Pi}_{j}$ is negative for all firms in steady state. Hence, for this particular calibration, firms do not have incentives to unilaterally deviate in equilibrium.

\subsection{Firms Face Information Frictions}

Assuming that firms and workers face information frictions is not a straight forward exercise in my model. Depending on how this new friction is introduced in the benchmark model, hiring decisions and the unemployment response can become larger or smaller. However, as long as workers face information frictions regarding aggregate conditions, and assuming that the workers' information set is always a subset of the firms' information set, wages will have fewer pressures to increase in booms because the value of the outside option (the value of unemployment) is underestimated. Notice that the two equations governing the dynamics of wages and hiring decisions in this model are given by:

$$
\begin{aligned}
E_{\mathcal{I}_{h}}\left[\vec{W}_{j}\left(w_{j}, \omega, \Omega\right)\right] & =\vartheta \cdot E_{\mathcal{I}_{h}}\left[S_{j}\right]+E_{\mathcal{I}_{h}}[U(\omega, \Omega)] \\
\kappa\left(\tilde{q}_{j} v_{j}\right)^{\chi} & =E_{\mathcal{I}_{j}}\left[Q \cdot J_{j}^{\prime}\left(\omega_{f}^{\prime}, \Omega^{\prime}\right)\right]
\end{aligned}
$$

where $\mathcal{I}_{j}$ is the information set of firm $j$. Hence, wages depend on workers' expectations, while hiring decisions depend on firms beliefs.In the benchmark model, workers underestimate changes

\footnotetext{
${ }^{46}$ Moscarini and Postel-Vinay (2013) show that the wage bill effect (the first term in equation (55)) does not depend on the firm's initial size $\left(h_{j}\right)$. This is because firms are indifferent about the timing of wages paid to deliver a utility label $W_{j}=\max \left\{\vartheta \cdot S_{j}, \bar{W}\right\}$, since workers and firms share the same discount factor.
} 
in $S_{j}$ and $U(\omega, \Omega)$ reducing the volatility of wages. This rises the volatility of $J j$, which increases firms' hiring decision. Now let me consider the following three variations of my benchmark model:

Model 2: Firms and workers have the same information set. Aggregate productivity $(a)$ is never observed, and all agents have to form expectations based on the public and aggregate signal $\hat{a}$.

Model 3: Firms and workers have the same information set. Employers and workers at firm $j$ observe their overall productivity $\left(a_{j}+a\right)$ at all times but cannot decompose unexpected changes into aggregate and idiosyncratic shocks.

Model 4: Workers' information set is as described in section 3.4. Firms observe their overall productivity $\left(a_{j}+a\right)$ at all times but cannot decompose unexpected changes into aggregate and idiosyncratic shocks. Firms also observe aggregate public signal $\hat{a}$.

In Models 2 and 4, wages will continue to be very sluggish because workers underestimate the responses of $S_{j}$ and $U(\omega, \Omega)$ to TFP shocks. However, in Model 3, workers' expectations about $S_{j}$ will tend to be more volatile than in the benchmark model while changes in $U(\omega, \Omega)$ will continue to be undervalued. Hence, wages will tend to be more procyclical in Model 3 than in my bench mark model.

When looking at hiring decision in each one of these models, we should observe a lower hiring response to TFP shocks in Model 2 than in my benchmark model, as firms' expectations about $J_{j}\left(\omega_{j}, \Omega\right)$ do not significantly change. Nonetheless, hiring responses in Model 3 should be larger than in Model 2 as firms' expectations regarding the value of an additional worker (equation (58)) become more volatile. In Model 3, firms anticipate a larger productivity in the future but do not expect a significant increase in their separation rate and wages in response to TFP shocks, which makes firms hire more workers in booms. Finally, hiring responses in Model 4 should be even larger than in Model 3. In Model 4, in response to a positive TFP shocks, firms expect a lower change in wages than in model 3 because workers' expectations about $S_{j}$ are lower in Model 4 than in Model 3.

Even though hiring decisions in my benchmark model should be larger than in Model 2 but lower than in Model 4, the relationship between Model 3 and my benchmark model is not clear. In Model 3, firms expect a lower increase in their separation rate but a larger increase in their wages than in my benchmark model. However, both models should display larger unemployment responses than a model with perfect information.

Figure 12 plots the IRFs for unemployment and wages generated by these models. For these responses, I assumed that the persistence of idiosyncratic productivity shocks is equal to $\rho_{a}$. 
As expected, Models 2 and 4 generate smaller and larger unemployment responses, respectively, than the benchmark model. However, for this particular calibration, Model 3 displays smaller unemployment responses to TFP shocks than my benchmark model. In Models 3 and 4 , unemployment peaks earlier and is less persistent than in other models because firms overreact to aggregate shocks, and they compensate for these overreactions in later periods when they have amassed more information. For example, in response to a positive TFP shock, firms post a lot of vacancies on impact, but they reduce the number of vacancies (post less) as they learn about aggregate conditions and realize that the value of an additional worker is not as high as they had thought.

In contrast, wage responses are larger in Models 3 and 4, but lower in Model 2, than in the benchmark model. As long as workers have more information (Model 3) or unemployment is more sensitive to the business cycle (Model 4), workers will demand higher wages in response to TFP shocks. It is worth pointing out that all models with information frictions display hump-shaped wage responses because workers demand higher wages as they learn that the economy is in an expansion and that the value of the outside option is greater than they thought. However, these models tend to generate larger wage semi-elasticities (Table 11) and differential growth rates (Table 12) than my benchmark model (and the data).

\subsection{Conditional Moments}

In contract to the data, there are two sources of aggregate uncertainty in my model : TFP and noise shocks. Because only a fraction of business cycle moments can be accounted by productivity shocks, I follow the literature that investigates the effects of productivity innovations in order to estimate the properties of the business cycle that is driven by TFP shocks. ${ }^{47}$ In particular, for each variable $x$, I estimate the following system of equations:

$$
\begin{aligned}
& a_{t}=\alpha_{a}+\rho_{a} \cdot a_{t-1}+e_{a} \\
& x_{t}=\alpha_{x}+\sum_{i=1}^{p_{x}} \rho_{x}^{i} \cdot x_{t-i}+\sum_{i=0}^{q_{x}} \beta_{x}^{i} \cdot a_{t-i}+e_{x t}
\end{aligned}
$$

In the first equation, I regress TFP $(a)$ on one lag of itself, which is a hypothesis that cannot be rejected. ${ }^{48}$ The second equation regresses each variable $x$ on the current $a, p_{x}$ lags of itself, and $q_{x}$ lags of $a$, where $p_{x}$ and $q_{x}$ are based on the Hannan-Quinn information criterion. Based on these estimations, Figure 13 plots the IRFs of the variables of interest to a $1 \%$ increase in aggregate TFP

\footnotetext{
${ }^{47}$ Examples in this literature are Barnichon (2010b), Basu, Fernald and Kimball (2006), Blanchard and Quah (1989), Christiano, Eichenbaum, and Vigfusson (2003, 2005), Gali (1999) and Shea (1998).

${ }^{48}$ Adding further lags does not improve explanatory power.
} 
(solid black lines). ${ }^{49}$ Given that all of these variables are in logs and HP-filtered, the responses are percentage deviations around a trend and can be interpreted as elasticities. Some results from Figure 13 include the following: (1) Unemployment, vacancies, and the vacancy-unemployment ratio are very sensitive to TFP shocks. In response to a $1 \%$ increase in TFP, unemployment declines $5 \%$ while vacancies rise by $5 \%$, which implies that the vacancy-unemployment ratio increases $10 \%$. (2) Responses are hump-shaped, which means that the largest response of these variables does not occur on impact. (3) Wages, adjusted for individual characteristics, are positively correlated with TFP. (4) The average wage peaks two years (eight quarters) after a TFP shock, in contrast to one year (four quarters) for unemployment and vacancies.

Based on the system of equations (59)-(60), I construct recursively the auxiliary variable $\tilde{x}$, which describes how variable $x$ evolved in response to TFP innovations:

$$
\begin{array}{lr}
\tilde{x}_{t}=x_{t} & t \leq \max \left\{p_{x}, q_{x}\right\} \\
\tilde{x}_{t}=\alpha_{x}+\sum_{i=1}^{p_{x}} \rho_{x}^{i} \cdot \tilde{x}_{t-i}+\sum_{i=0}^{q_{x}} \beta_{x}^{i} \cdot a_{t-i} & t>\max \left\{p_{x}, q_{x}\right\}
\end{array}
$$

Table 13 presents business cycle statistics for these auxiliary variables. As expected, the standard deviations are lower and most of the correlations become stronger. For example, the correlation between unemployment and TFP increases from $-46 \%$ to $-87 \%$. Also, I estimate that $64 \%$ of overall unemployment volatility is due to productivity shocks. Similarly, around $60 \%$ of overall volatility in vacancies and the vacancy-unemployment ratio can be explained by TFP. In contrast, productivity explains an even lower fraction of the observed volatility in wages. On average, productivity explains $50 \%$ of the standard deviation of wages for all groups.

Figure 15 plots the IRF of my model variables when treating my model and data similarly. The dotted lines are the IRF from my calibrated model with Full Information, and the dashed lines are the IRF generated by my benchmark model. Similarly, Table 14 presents the theoretical business cycle statistics when the simulated data are treated the same as the data used in Table 13. According to these results, conditional on TFP shocks, my benchmark model generates business cycle moments and dynamics that are similar to those estimated from the data.

\footnotetext{
${ }^{49}$ I run these bivariate near-VARs, instead of a full VAR because of the smaller sample period for the average wage for job changer. To check how robust these IRFs are to this specification, Figure 14 compares the empirical IRF derived from bivariate near-VARs and a VAR-4 (excluding the average wage for job changer), in which TFP is assumed to be the most exogenous variable.
} 


\section{Conclusion}

I propose a new mechanism for sluggish wages based on workers' noisy information about the state of the economy. In my model, workers receive noisy signals about the current state of the economy and learn slowly about aggregate conditions. Hence, wages do not immediately respond to a positive aggregate shock because workers do not (yet) have enough information to demand higher wages. This delayed adjustment in wages increases firms' incentives to post more vacancies, making unemployment more volatile and sensitive to aggregate shocks. My calibrated model is able to explain $70 \%$ of overall unemployment volatility.

My model is robust to two major critiques of existing theories of sluggish wages and volatile unemployment: the flexibility of wages for new hires and the cyclicality of the opportunity cost of employment. On the one hand, my model predicts a very cyclical opportunity cost of employment, as the value of non-working activities in terms of consumption increases in expansions. On the other hand, my model assumes flexible wages for new hires and generates a wage semi-elasticity with respect to the unemployment rate for new hires and all workers of around $-3 \%$ and $-1 \%$ respectively, which is similar to the estimate of Pissarides (2009) and larger than the estimates of Hagedorn and Manovskii (2013), Gertler et al. (2014) and my own estimations using the CPS and IPUMS-CPS (Flood et al., 2015) microdata (-0.27\% for all workers, $-1.66 \%$ for new employees, and $-0.57 \%$ for job changers).

Consistent with recent empirical evidence (e.g. Kahn \& McEntarfer, 2014; Haltiwanger et al. 2015), my model predicts that high-wage highly productive firms expand employment more than low-wage firms and also exhibit larger wage adjustments in expansions. This differential growth rate implies that the distribution of new hires shifts to the most productive and highest paying firms in response to positive productivity shocks. This has important consequences for new hires, as they find more and better paying jobs in expansions.

I use the University of Michigan Surveys of Consumers and my wage series constructed from the CPS and IPUMS-CPS microdata to test whether wages increase when workers are more optimistic about economic conditions. Even though workers' expectations and wages are positively correlated, this relationship is only statistically significant at quarterly frequencies. I estimate that a 1 standard deviation increase in my measure of workers' expectations is associated with a $0.35 \%$, $0.63 \%$, and $0.48 \%$ increase in the average wage for all workers, new employees and job changers respectively. Also, I find no statistically significant correlation between unemployment and output expectations from the Survey of Professional Forecasters and wages.

In the extensions of the model, I show that wage dynamics will depend on workers' expectations while hiring decisions will depend on firms' beliefs as long as the workers' information set is a subset of the firms' information set. However, assuming that firms face information frictions can make 
unemployment responses larger or smaller than in my benchmark model depending on specific assumptions. I present three variations of my benchmark model that generate very different unemployment dynamics, but in all cases, wages displayed a hump-shaped response because wage demands change as workers learn about aggregate economic conditions.

Finally, I propose a method for solving heterogeneous agents' models with information frictions by combining the Reiter Method (Reiter, 2009) and the Kalman filter and may be of interest in its own right. First, I show that the vector of state variables only needs to include the last $\mathcal{T}$ realization of the aggregate shocks in order to keep track of agents' expectations. Then, the law of motion for the economy (based on which agents form expectations) can be found by slowly adjusting the agents' perceived law of motion and the law of motion that this perception implies.

\section{References}

[1] Abraham, Katherine G., and John C. Haltiwanger (1995) "Real Wages and the Business Cycle." Journal of Economic Literature vol. 33(3), pages: 1215-1264.

[2] Abraham, Katherine G., and Lawrence F. Katz (1986) "Cyclical Unemployment: Sectoral Shifts or Aggregate Disturbances?" Journal of Political Economy vol.94(3), pages: 507-522.

[3] Acharya, Sushant (2014) "Costly information, planning complementarities and the Phillips Curve." Federal Reserve Bank of New York Staff Report \# 698.

[4] Andolfatto, David (1996) "Business Cycles and Labor-Market Search." American Economic Review vol. 86(1), pages: 112-132.

[5] Angeletos, George-Marios, and Jennifer La'O (2012) "Optimal Monetary Policy with Informational Frictions." NBER Working Paper \# 17525.

[6] Barattieri, Alessandro, Susanto Basu, and Peter Gottschalk (2014) "Some Evidence on the Importance of Sticky Wages." American Economic Journal: Macroeconomics vol. 6(1), pages: $70-101$.

[7] Barlevy, Gadi (2001) "Why are the Wages of Job Changers so Procyclical?." Journal of Labor Economics vol. 19(4), pages: 837-878.

[8] Barnichon, Regis (2010) "Building a Composite Help-Wanted Index." Economics Letters vol. 109(3), pages: 175-178.

[9] Barnichon, Regis (2010) "Productivity and Unemployment Over the Business Cycle." Journal of Monetary Economics vol. 57(8), pages 1013-1025. 
[10] Basu, Susanto, John G. Fernald, and Miles S. Kimball (2006) "Are Technology Improvements Contractionary?" American Economic Review vol. 96(5), pages: 1418-1448.

[11] Beaudry, Paul, and John DiNardo (1991) "The Effect of Implicit Contracts on the Movement of Wages Over the Business Cycle: Evidence From Micro Data." Journal of Political Economy vol. 99(4), pages: 665-688.

[12] Bils, Mark J. (1985) "Real Wages Over The Business Cycle: Evidence From Panel Data." Journal of Political Economy vol. 93(4), pages: 666-689.

[13] Bils, Mark J., Yongsung Chang, and Sun-Bin Kim (2014) "How Sticky Wages In Existing Jobs Can Affect Hiring." NBER Working Paper \# 19821.

[14] Blanchard, Oliver J., and Jordi Galı(2010) "Labor Markets and Monetary Policy: A New Keynesian Model With Unemployment." American Economic Journal: Macroeconomics vol. 2(2), pages: $1-30$.

[15] Blanchard, Oliver J., and Danny Quah (1989) "The Dynamic Effects of Aggregate Demand and Supply Disturbances." American Economic Review vol. 79(4), pages: 655-673.

[16] Branch, William A. (2004) "The Theory of Rationally Heterogeneous Expectations: Evidence from Survey Data on Inflation Expectations." The Economic Journal vol. 114(497), pages: 592-621.

[17] Brown, Charles, and James Medoff (1989) "The Employer Size-Wage Effect." Journal of Political Economy vol. 97(5), pages: 1027-1059.

[18] Brugemann, Bjorn, and Giuseppe Moscarini (2010) "Rent Rigidity, Asymmetric Information, And Volatility Bounds in Labor Markets." Review of Economic Dynamics vol. 13(3), pages: $575-596$.

[19] Carlsson, Mikael \& Andreas Westermark (2015) "Endogenous Separations, Wage Rigidities and Employment Volatility." MIMEO, Uppsala University.

[20] Carroll, Christopher D. (2003) "Macroeconomic Expectations of Househlds and Professional Forecasters." Quarterly Journal of Economics vol. 118(1), pages: 269-298.

[21] Chodorow-Reich, Gabriel, and Loukas Karabarbounis (2014) "The Cyclicality of The Opportunity Cost of Employment." NBER Working Paper \# 19678.

[22] Christiano, Lawrence J., Martin Eichenbaum, and Charles L. Evans (2005) "Noinal Rigidities And The Dynamic Effects of a Shock to Monetary Policy." Journal of Political Economy vol. 113 (1), pages: 1-45. 
[23] Christiano, Lawrence J., Martin S. Eichenbaum, and Mathias Trabandt (2013) "Unemployment and Business Cycles." NBER Working Paper \# 19265.

[24] Christiano, Lawrence J., Martin S. Eichenbaum, and Mathias Trabandt (2016) "Unemployment and Business Cycles." Econometrica vol. 84 (4), pages: 1523-1569.

[25] Christiano, Lawrence J., Martin Eichenbaum, and Robert Vigfusson (2003) "Waht Happens After a Technology Shock?" International Finance Discussion Papers \# 768.

[26] Christiano, Lawrence J., Martin Eichenbaum, and Robert Vigfusson (2005) "Alternative Procedures For Estimating Vector Autoregressions Identified With Long-Run Restrictions." International Finance Discussion Papers \# 842.

[27] Coibion, Olivier, and Yuriy Gorodnichenko (2012) "What Can Survey Forecasts Tell Us About Information Rigidities?" Journal of Political Economy vol. 120(1), pages 116-159.

[28] Costain, James S., and Michael Reiter (2008) "Business Cycles, Unemployment Insurance, And The Calibration of Matching Models." Journal of Economic Dynamics and Control vol. 32(4), pages: 1120-1155.

[29] Costain, James S., and Anton Nakov (2011) "Distributional Dynamics under Smoothly StateDependent Pricing." Journal of Monetary Economics vol. 58(6), pages: 646-665.

[30] Davis, Steven J., R. Jason Faberman, and John C. Haltiwanger (2013) "The EstablishmentLevel Behavior of Vacancies And Hiring." The Quarterly Journal of Economics vol. 128(2), pages: $581-622$.

[31] Davis, Steve J., and John C. Haltiwanger (1991) "Wage Dispersion Between And Within U.S. Manufacturing Plants, 1963-86." Brookings Papers on Economic Activity, Microeconomics 1991, pages: 115-200.

[32] den Haan, Wouter J., Garey Ramey, and Joel Watson (2000) "Job Destruction and Propagation of Shocks." American Economic Review vol. 90(3), pages 482-498.

[33] Elsby, Michael W.L. (2009) "Evaluating The Economic Significance of Downward Noinal Wage Rigidity." Journal of Monetary Economics vol. 56(2), pages: 154-169.

[34] Fallick, Bruce, and Charles A. Fleischman (2004) "Employer-to-Employer Flows in the U.S. Labor Market: The Complete Picture of Gross Worker Flows" Finance and Economics Discussion Series \# 2004-34. 
[35] Fort, Teresa C., John C. Haltiwanger, Ron S. Jarmin, and Javier Miranda (2013) "How Firms Respond to Business Cycles: The Role of Firm Age and Firm Size." IMF Economic Review vol. 61(3), pages: 520-559.

[36] Flood, Sarah, Miriam King, Steven Ruggles, and J. Robert Warren (2015) "Integrated Public Use Microdata Series, Current Population Survey: Version 4.0. [dataset]." Minneapolis: University of Minnesota. http://doi.org/10.18128/D030.V4.0.

[37] Gali, Jordi (1999) "Technology, Employment, and the Business Cycle: Do Technology Shocks Explain Aggregate Fluctuations?" American Economic Review vol. 89(1), pages: 249-271.

[38] Gertler, Mark, Chris Huckfeldt, and Antonella Trigari (2014) "Unemployment Fluctuations, Match Quality, and The Wage Cyclicality of New Hires.” MIMEO New York University.

[39] Gertler, Mark, and Antonella Trigari (2009) "Unemployment Fluctuations With Staggered Nash Wage Bargaining." Journal of Political Economy vol. 117(1), pages: 38-85.

[40] Haefke, Christian, Marcus Sonntag, and Thijs van Rens (2013) "Wage Rigidity And Job Creation." Journal of Monetary Economics vol. 60(8), pages: 887-899.

[41] Hagedorn, Marcus, and Iourii Manovskii (2008) "The Cyclical Behavior of Equilibrium Unemployment And Vacancies Revisited." American Economic Review vol. 98(4), pages: 16921706.

[42] Hagedorn, Marcus, and Iourii Manovskii (2013) "Job Selection and Wages over the Business Cycle." American Economic Review vol. 103(2), pages: 771-803.

[43] Haisken-DeNew, John P., and Christoph M. Schmidt (1997) "Interindustry and Interregion Differentials: Mechanics And Interpretation." The Review of Economics And Statistics vol. 79(3), pages: 516- 521 .

[44] Hall, Robert E. (2005) "Employment Fluctuations with Equilibrium Wage Stickiness." American Economic Review vol. 95(1), pages: 50-65.

[45] Hall, Robert E., and Paul R. Milgrom (2008) "The Limited Influence of Unemployment on The Wage Bargain." American Economic Review vol. 98(4), pages: 1653-1674.

[46] Haltiwanger, John C., Henry Hyatt, and Erika McEntarfer (2015) "Cyclical Reallocation of Workers Across Employers by Firm Size and Firm Wage.” MIMEO, University of Maryland.

[47] Haltiwanger, John C., Ron S. Jarmin, and Javier Miranda (2013) "Who Creates Jobs? Small Versus Large Versus Young." The Review of Economics and Statistics vol. 95(2), pages: 347361. 
[48] Hines, James R., Hilary Hoynes, and Alan B. Krueger (2001) "Another Look at Whether a Rising Tide Lifts All Boats." In: Alan B. Krueger and Robert Solow (Ed.), The Roaring Nineties: Can Full Employment Be Sustained? (pp. 493-537). New York, NY: Russell Sage Foundation.

[49] Horrace, William C., and Ronald L. Oaxaga (2001) "Inter-Industry Wage Differentials And The Gender Wage GAP: an Identification Problem." Industrial And Labor Relations Review vol. 54(3), pages: 611-618.

[50] Juhn, Chinhui, Kevin M. Murphy, and Brooks Pierce (1993) "Wage Inequality And The Rise in Returns to Skill." Journal of Political Economy vol. 101(3), pages: 410-442.

[51] Kahn, Shulamit (1997) "Evidence of Nominal Wage Stickiness from Microdata." American Economic Review vol. 87(5), pages: 993-1008.

[52] Kahn, Lisa and Lisa McEntarfer (2014) "Employment Cyclicality and Firm Quality." NBER Working Paper \# 20698.

[53] Kennan, John (2009) "Private Information, Wage Bargaining and Employment Fluctuations." Review of Economic Studies vol. 77(2), pages: 633-664.

[54] Klein, Paul (2000) "Using the Generalized Schur form to Solve a Multivariate Linear Rational Expectations Model." Journal of Economic Dynamics and Control vol. 24(10), pages: 14051423.

[55] Krueger, Alan B., and Lawrence H. Summers (1988) "Efficiency Wages And The InterIndustry Wage Structure." Econometrica vol. 56(2), pages: 259-293.

[56] Le Bihan, Herve, Jeremi Montornes, and Thomas Heckel (2012) "Sticky Wages: Evidence from Quarterly Microeconomic Data." American Economic Journal: Macroeconomics vol. 4(3), pages: $1-32$.

[57] Long, Mark C., Kristin M. Dziczek, Daniel D. Luria, and Edith A. Wiarda (2008) "Wage and Productivity Stability in U.S. Manufacturing Plants." Monthly Labor Review May 2008, pages: $24-36$.

[58] Lucas, Robert E. (1972) "Expectations and the Neutrality of Money." Journal of Economic Theory vol. 4(2), pages: 103-124.

[59] Lunnemann, Patrick, and Ladislav Wintr (2009) "Wages Are Flexible, Aren't They? Evidence From Monthly Micro Wage Data." European Central Bank Working Paper Series \# 1074. 
[60] Mackowiak, Bartosz, and Mirko Wiederholt (2009) "Optimal Sticky Prices Under Rational Innattention." American Economic Review vol. 99(3), pages: 769-803.

[61] Matejka, Filip, and Alisdair McKay (2012) "Simple Market Equilibria with Rationally Inattentive Consumer." American Economic Review: Papers 6 Proceedings vol. 102(3), pages: 24-29.

[62] McLaughlin, Kenneth J., and Mark Bils (2001) "Interindustry Mobility and the Cyclical Upgrading of Labor." Journal of Labor Economics vol. 19(1), pages: 94-135.

[63] Menzio, Guido (2005) "High-Frequency Wage Rigidity." MIMEO, University of Philadelphia.

[64] Menzio, Guido and Shouyong Shi (2011) "Efficient Search on the Job and the Business Cycle." Journal of Political Economy vol. 119(3), pages: 468-510.

[65] Merz, Monika (1995) "Search in The Labor Market And The Real Business Cycle." Journal of Monetary Economics vol. 36(2), pages: 269-300.

[66] Mortensen, Dale T., and Christopher A. Pissarides (1994) "Job Creation and Job Destruction in the Theory of Unemployment." Review of Economic Studies vol. 61(3), pages: 397-415.

[67] Mortensen, Dale T., and Éva Nagyál (2007) "More on Unemployment And Vacancy Fluctuations." Review of Economic Dynamics vol. 10(3), pages: 327-347.

[68] Moscarini, Giuseppe, and Fabien Postel-Vinay (2008) "The Timing of Labor Market Expansions: New Facts And a New Hypothesis." in NBER Macroeconomics Annual 2008, Volumne 23 ed. by D. Acemoglu, K. Rogoff, and M. Woodford. University of Chicago Press.

[69] Moscarini, Giuseppe, and Fabien Postel-Vinay (2012) "The Contribution of Large and Small Employers to Job Creation in Times of High and Low Unemployment." American Economic Review vol. 102(6), pages: 2509-2539.

[70] Moscarini, Giuseppe, and Fabien Postel-Vinay (2013) "Stochastic Search Equilibrium." Review of Economic Studies vol. 80(4), pages: 1545-1581.

[71] Moscarini, Giuseppe, and Fabien Postel-Vinay (2015) "Did the Job Ladder Fail After the Great Recession?" Journal of Labor Economics (forthcoming).

[72] Muller, Andreas I. (2012) "Separations, Sorting And Cyclical Unemployment." IZA Discussion Paper \# 6849.

[73] Okun, Arthur M. (1973) "Upward Mobility in a High Pressure Economy." Brookings Papers on Economic Activity vol. 4(1), pages: 207-262. 
[74] Peterman, William B. (2012) "Reconciling Micro and Macro Estimates of the Frisch Labor Supply Elasticity." Finance and Economics Discussion Series \# 2012-75.

[75] Pissarides, Christopher A. (2009) "The Unemployment Volatility Puzzle: Is Wage Stickiness The Answer?." Econometrica vol. 77(5), pages: 1339-1369.

[76] Reilly, Kevin T., and Luisa Zanchi (2003) "Industry Wage Differentials: How Many, Big And Significant Are They?." International Journal of Manpower vol. 24(4), pages: 367-398.

[77] Reiter, Michael (2009) "Solving heterogeneous-agent models by projection and perturbation." Journal of Economics Dynamics and Control vol 33 (3), pages: 649-665.

[78] Reis, Ricardo (2006) "Inattentive Producers." Review of Economic Studies vol. 73(3), pages: 793-821.

[79] Reis, Ricardo (2006) "Inattentive Consumers." Journal of Monetary Economics vol. 53(8), pages: $1761-1800$.

[80] Roberts, John M. (1998) "Inflation Expectations and the Transmission of Monetary Policy." Federal Reserve Board FEDS working paper \# 1998-43.

[81] Rogerson, Richard and Robert Shimer (2010) "Search in Macroeconomic Models of the Labor Market." In: D. Card and O. Ashenfelter (Ed.), Handbook of Labor Economics, Volume 4 a (pp. 619-700). Elsevier.

[82] Rudanko, Leena (2009) "Labor Market Dynamics Under Long-Term Wage Contracting." Journal of Monetary Economics vol. 56(2), pages: 170-183.

[83] Shea, John (1998) "What do Technology Shocks do?" NBER Working Paper \# 6632.

[84] Shimer, Robert (2005) "The Cyclical Behavior of Equilibrium Unemployment and Vacancies." American Economic Review vol. 95(1), pages: 25-49.

[85] Rubinstein, Ariel (1982) "Perfect Equilibrium in a Bargaining Model." Econometrica vol. 50(1), pages: 97-109.

[86] Schoefer, Benjamin (2015) "The Financial Channel of Wage Rigidity." MIMEO University of California, Berkeley.

[87] Schmitt, John (2003) "Creating a Consistent Hourly Wage Series From The Current Population Survey's Outgoing Rotation Group, 1979-2002." Unpublished Manuscript. Center for Economic and Policy Research. 
[88] Shin, Donggyun (1994) "Cyclicality of Real Wages Among Young Men." Economic Letters vol. 46(2), pages: 137-142.

[89] Sigurdsson, Josef, and Rannveig Sigurdardottir (2011) "Evidence of Nominal Wage Rigidity and Wage Setting from Icelandic Microdata." Working Paper Central Bank of Iceland \# 55.

[90] Sims, Christopher A. (2003) "Implications of Rational Inattention." Journal of Monetary Economics vol 50(3), pages: 665-690.

[91] Sims, Christopher A. (2002) "Solving Linear Rational Expectations Models." Computational Economics vol. 20(1-2), pages: 1-20.

[92] Smets, Frank and Rafel Wouters (2007) "Shocks And Frictions in US Business Cycles: A Bayesian DSGE Approach." American Economic Review vol. 97(3), pages: 586-606.

[93] Solon, Gary, Robert Barsky, and Jonathan A. Parker (1994) "Measuring The Cyclicality of Real Wages: How Important Is Composition Bias?" Quarterly Journal of Economics vol. 109(1), pages: 1-25.

[94] Venkateswaran, Venky (2013) "Heterogeneous Information and Labor Market Fluctuations." MIMEO, Penn State University. 


\section{A Figures}

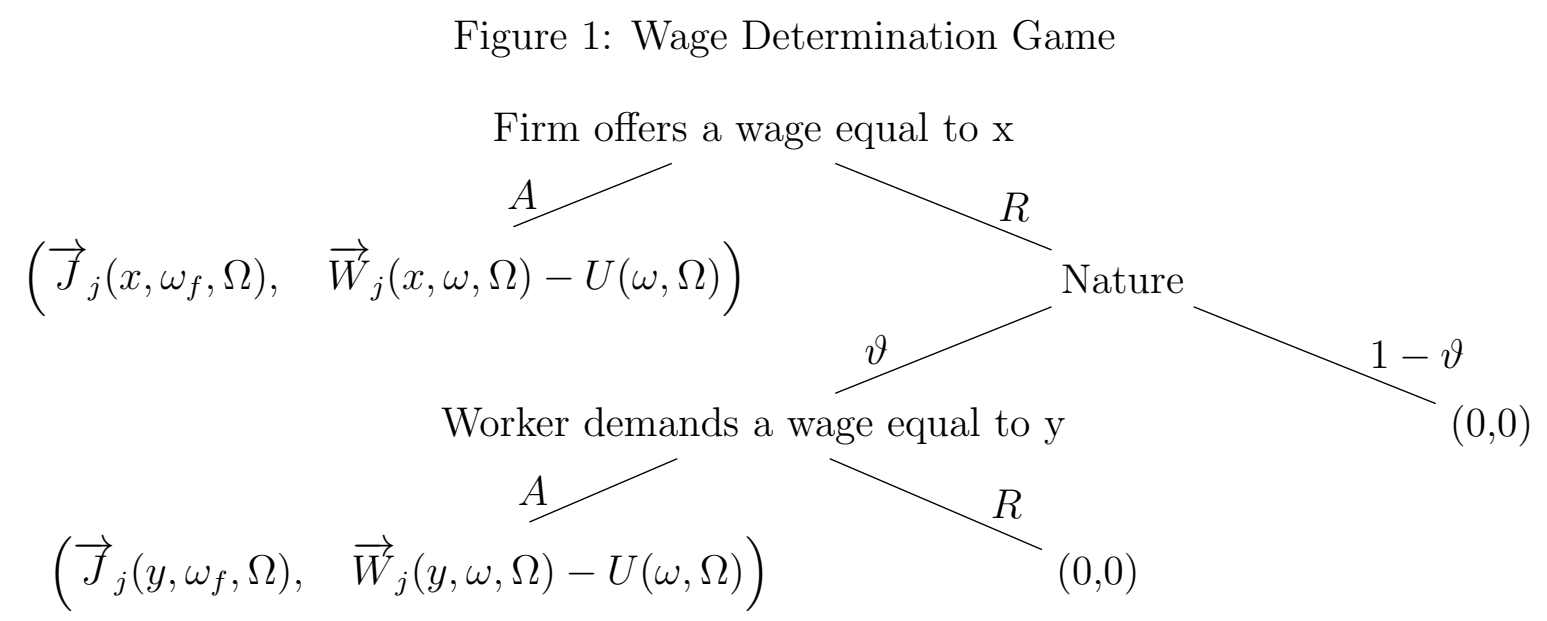

Note: This figure shows the extensive-form representation of the wage determination game. Firms and workers bargain over the match surplus $\left(S_{j}\right)$ by making wage offers/demands. Details are provided in the text. 
Figure 2: Wage and Size Distribution in Steady State: Model vs. Data

(a) Wage Distribution

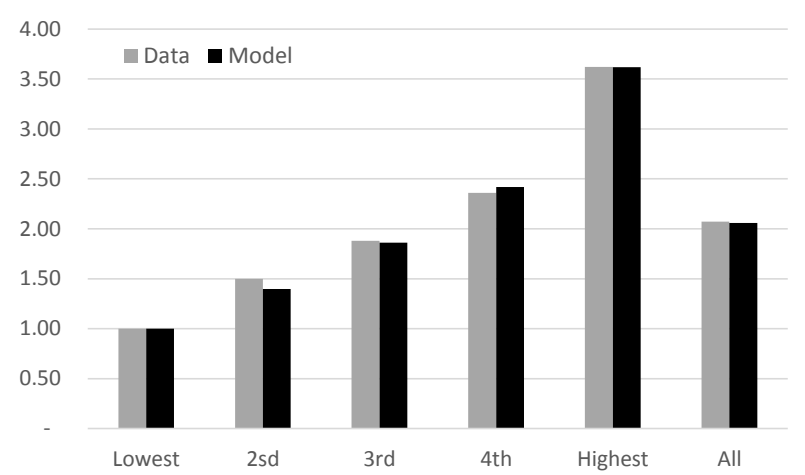

(b) Size Distribution

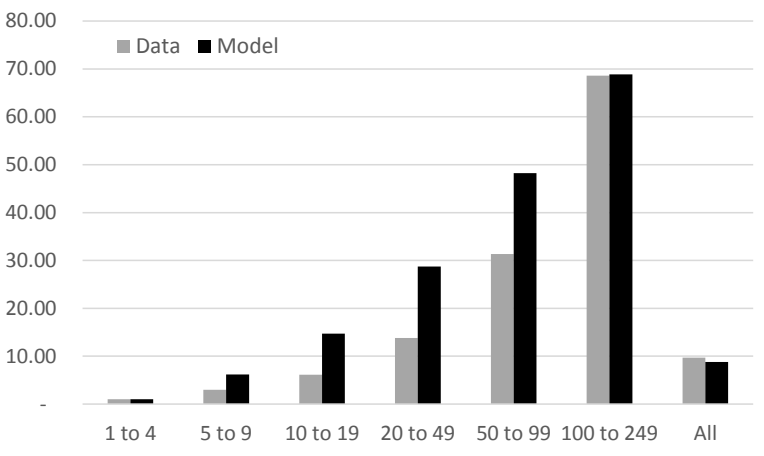

Note: This figure plots the distributions of employment (panel 2b) and wages (panel 2a). Gray bars plot the model distribution in steady state, while the black bars represent the distribution for the United States. Firms with more than 250 employees are excluded in panel $2 \mathrm{~b}$ to preserve the scale. 
Figure 3: Firm and Employment Distribution in Steady State

(a) $p_{j}$ vs. $a_{j}$

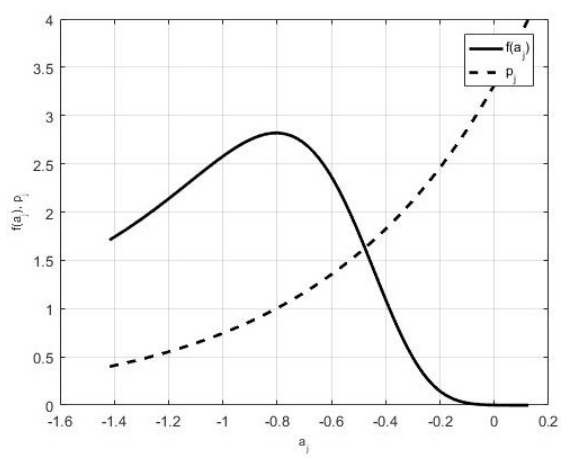

(d) $\delta_{h j}$ vs. $\tilde{q}_{j}$

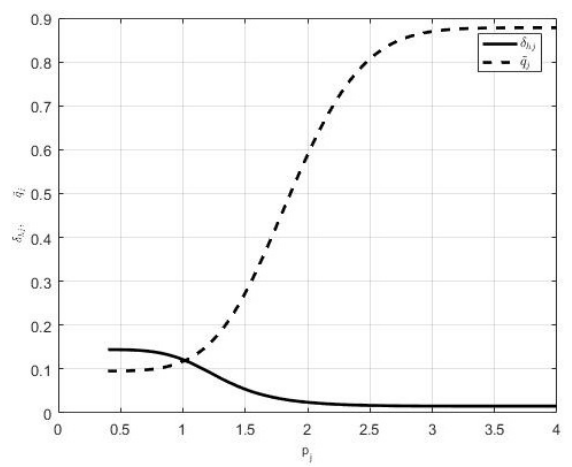

(b) $w_{j}$ vs. $F_{j}$

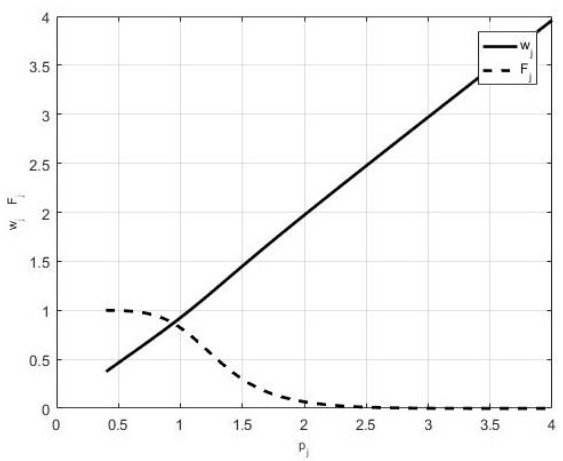

(e) Distribution of New Hires

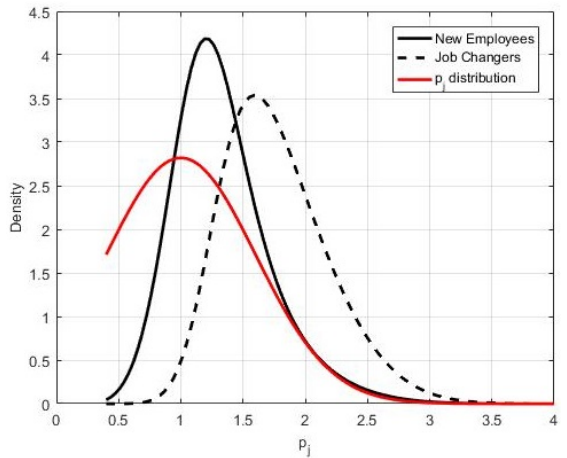

(c) Firm Size and Employment

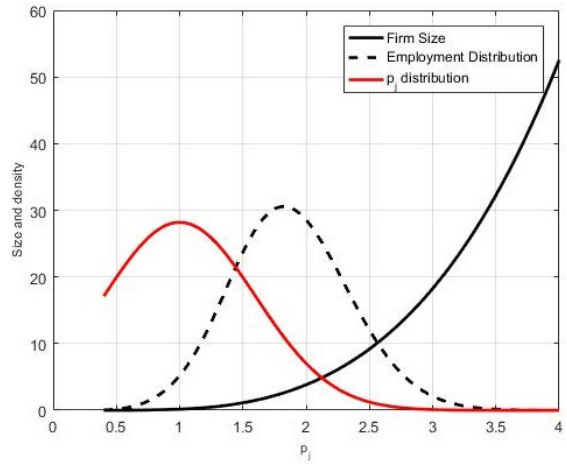

(f) Distributin of Workers

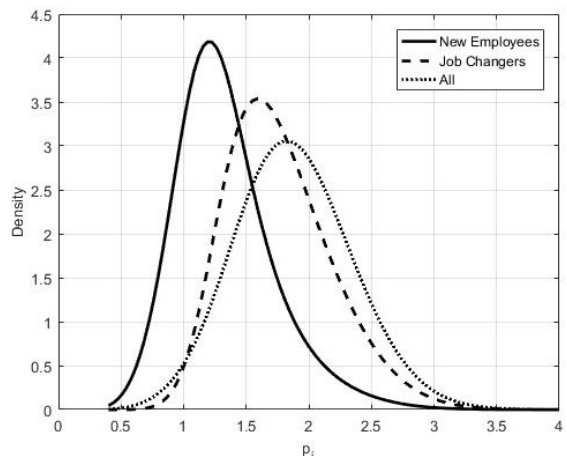

Note: This figure plots the distributions of employment and productivity across firms in steady state along with the separation rate, job filling rate, and wage associated with each firm. 
Figure 4: Impulse Response Function to a 1\% Increase in Aggregate Productivity
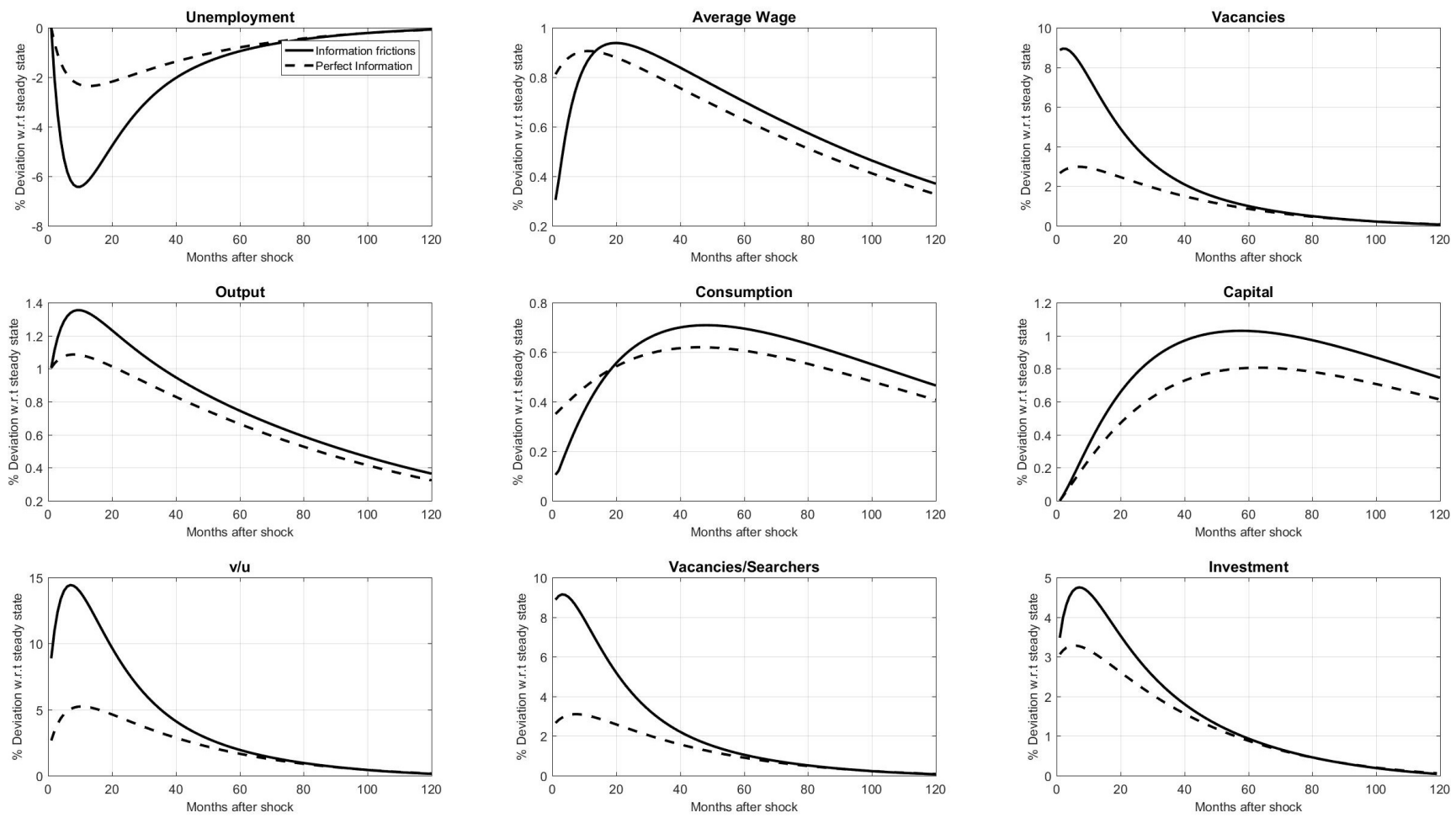

Note: This figure plots model Impulse Response Functions (IRFs) to a $1 \%$ increase in aggregate TFP. Solid black lines are the IRFs for a model in which workers face information frictions, and dashedlines are the IRFs generated by a model in which all agents have perfect information. 
Figure 5: Impulse Response Function to a 1\% Increase in Aggregate Productivity
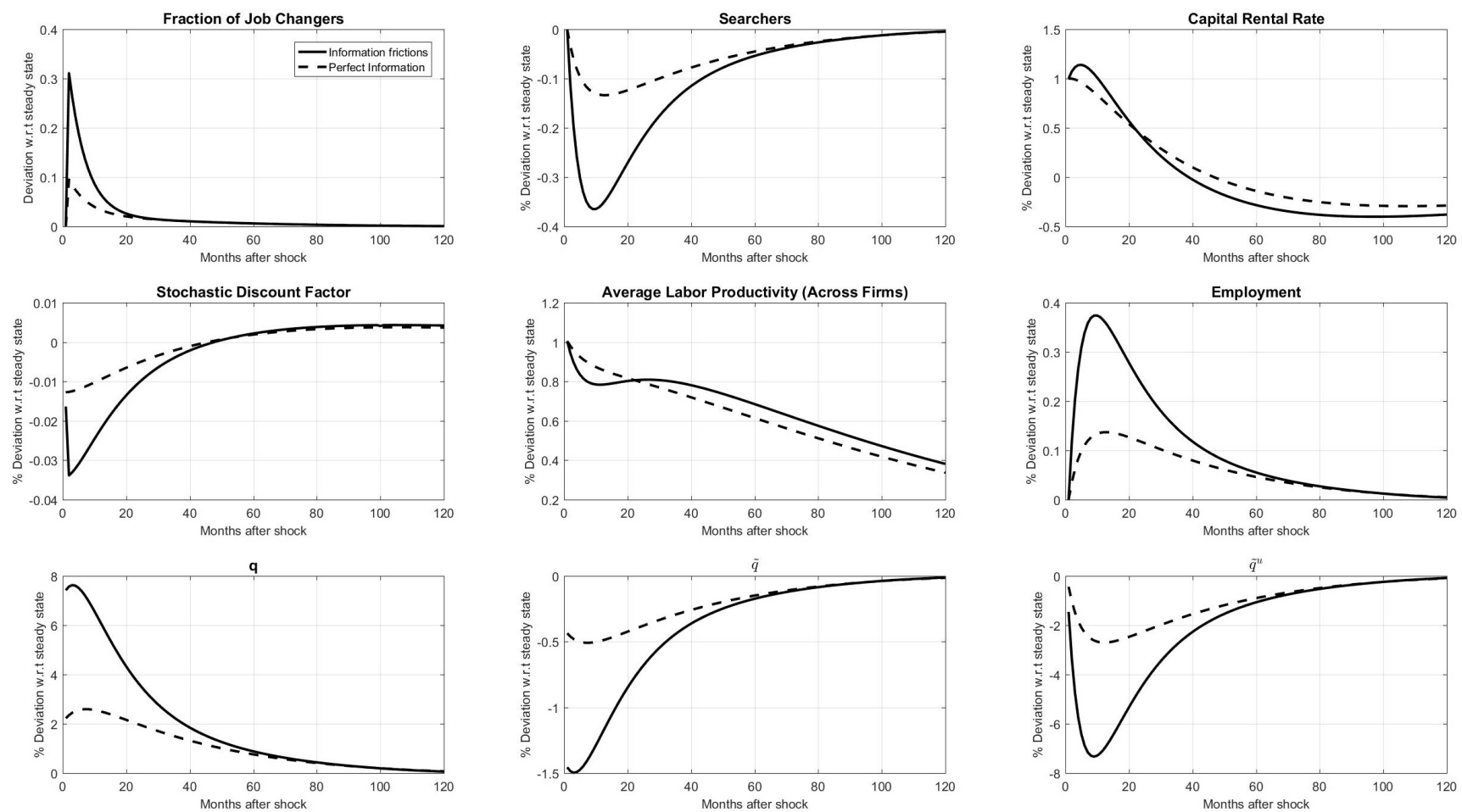

Note: This figure plots model Impulse Response Functions (IRFs) to a 1\% increase in aggregate TFP. Solid black lines are the IRFs of a model in which workers face information frictions, and dashed lines are the IRFs generated by a model in which all agents have perfect information. $q, \tilde{q}$, and $\tilde{q}^{u}$ denote the job finding rate, the probability that a vacancy is matched with a worker, and the job filling rate (from unemployment), respectively. 
Figure 6: Distributional Dynamics to a 1\% Increase in Aggregate Productivity
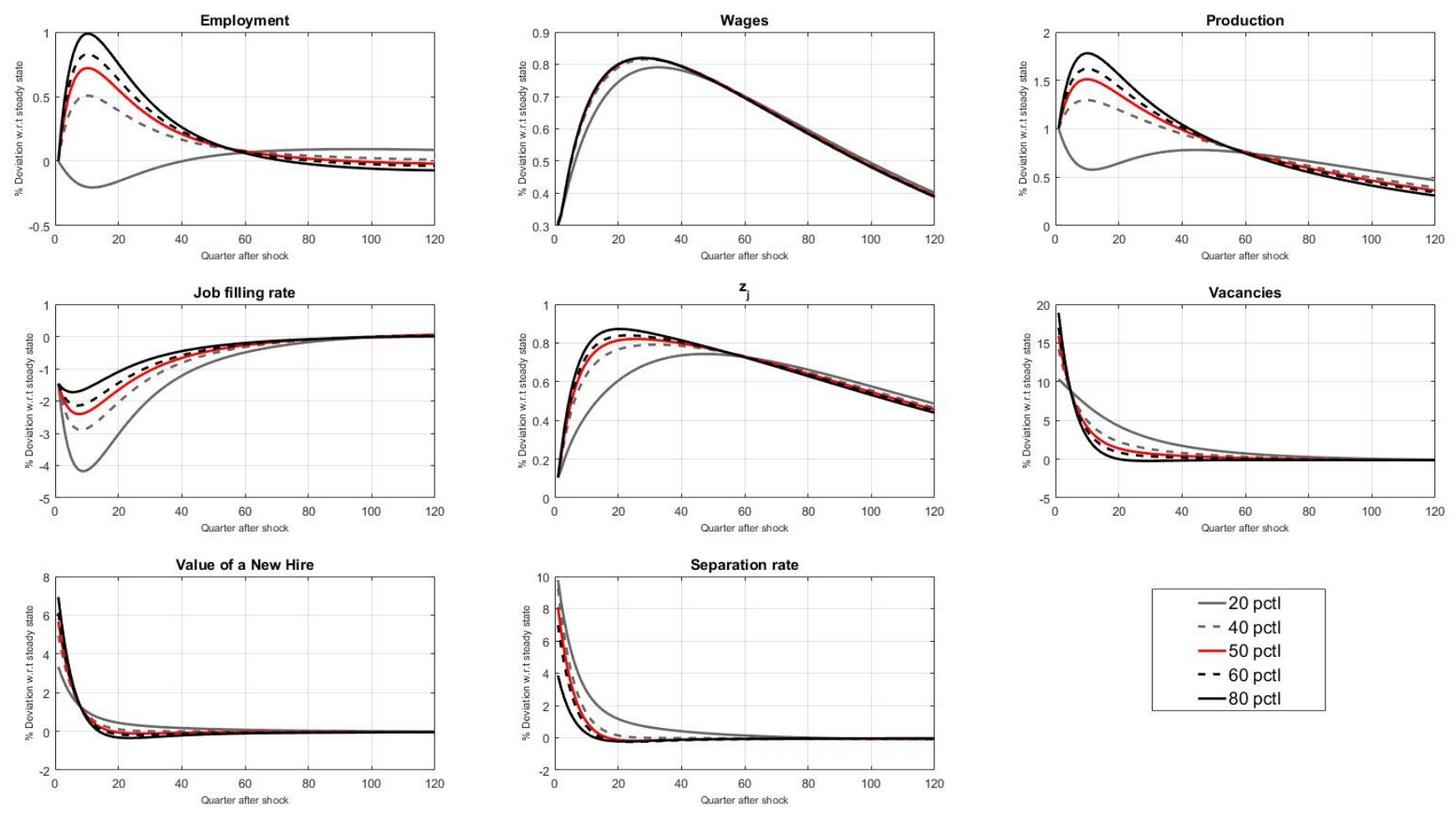

Note: This figure plots the Impulse Response Functions (IRFs) for a model with information frictions for different firms to a $1 \%$ increase in aggregate TFP. Solid gray lines are the IRFs for firms at the 20th percentile of wage distribution weighted by employment. The dashed-gray lines are the IRFs for firms at the 40th percentile. The solid red lines are the IRF for the median firm. The dashed black lines are the IRF for firms at the 60th percentile, and the solid black lines are the IRFs for firms at the 80th percentile. $z_{j}$ denotes the flow opportunity cost of employment for firm $j$. 
Figure 7: Evolution of Workers' Beliefs

Dynamics in Response to a $1 \%$ Increase in Aggregate TFP
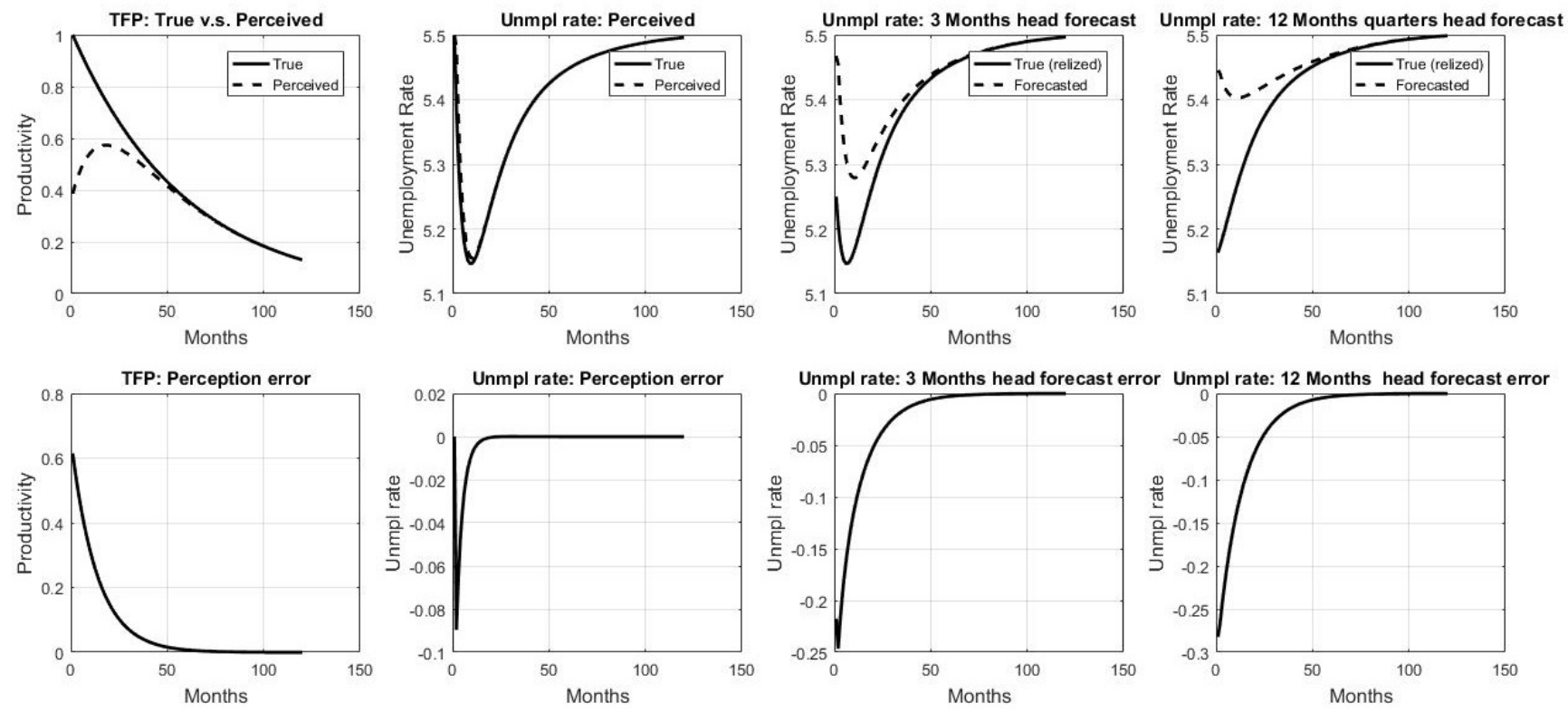

Note: This figure plots the evolution of workers' beliefs and expectations in response to a $1 \%$ increase in aggregate productivity. In the top panels, solid black lines represent the true evolution of each variable, and dashed black lines depict workers' expectations about those variables. The bottom panels plot the difference between the true realization and the workers' expectations. 
Figure 8: Unemployment and Wage Responses to a $1 \%$ increase in Noise Shock

(a) Unemployment

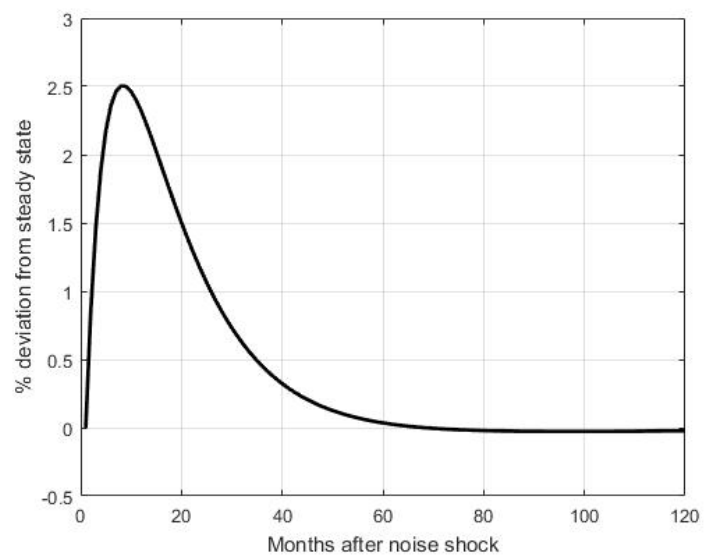

(b) Average Wage

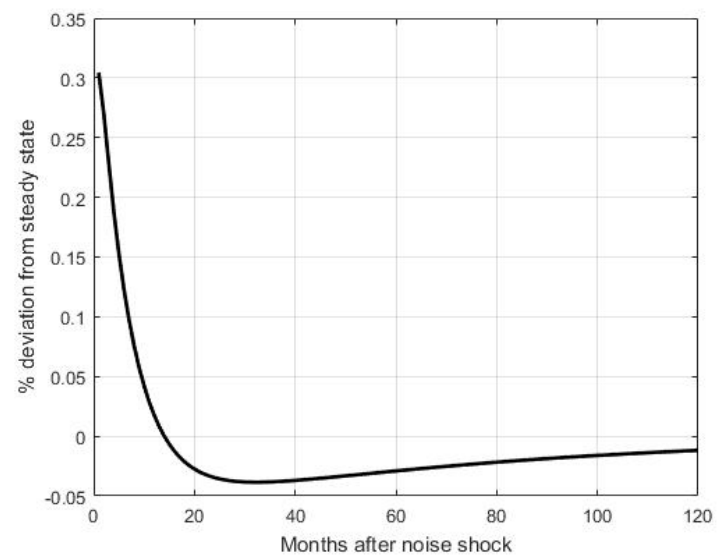

Note: This figure plots the Impulse Response Functions to a $1 \%$ increase in the signal noise $(n)$. Lines represent \% deviation with respect to its steady state value. 
Figure 9: Wages Responses to a 1\% Increase in Aggregate Productivity

(a) Information Frictions Model Simple Average

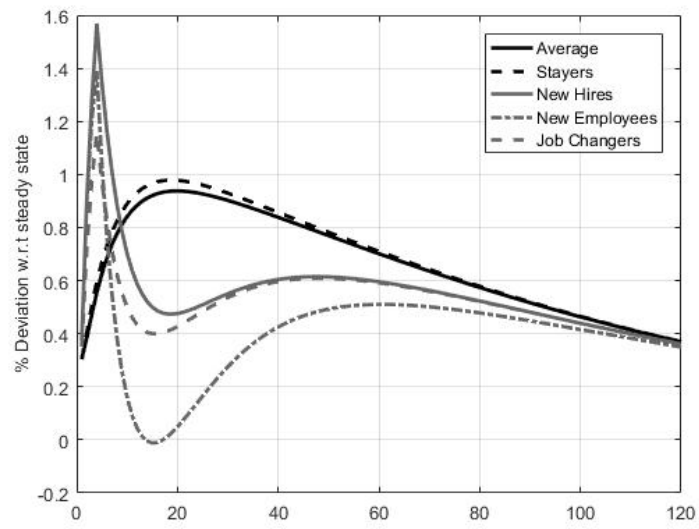

(c) Full Information Model

Simple Average

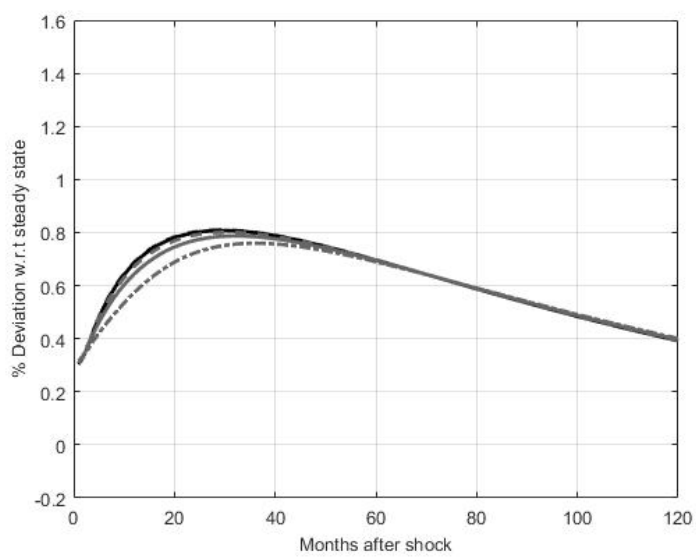

(b) Information Frictions Model Composition Adjusted

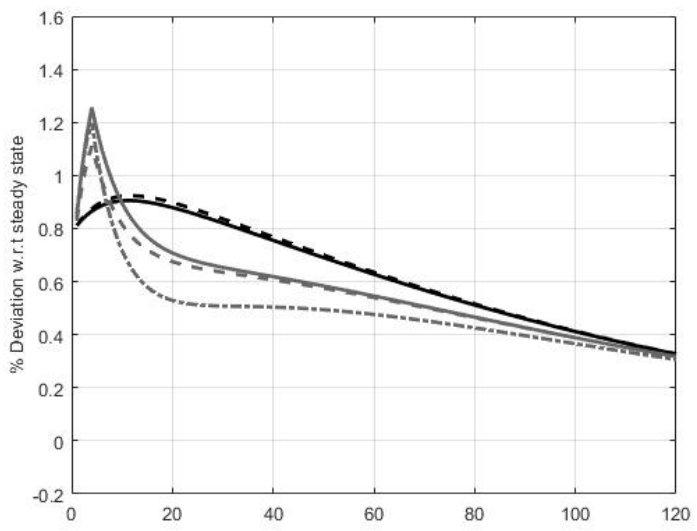

(d) Full Information Model Composition Adjusted

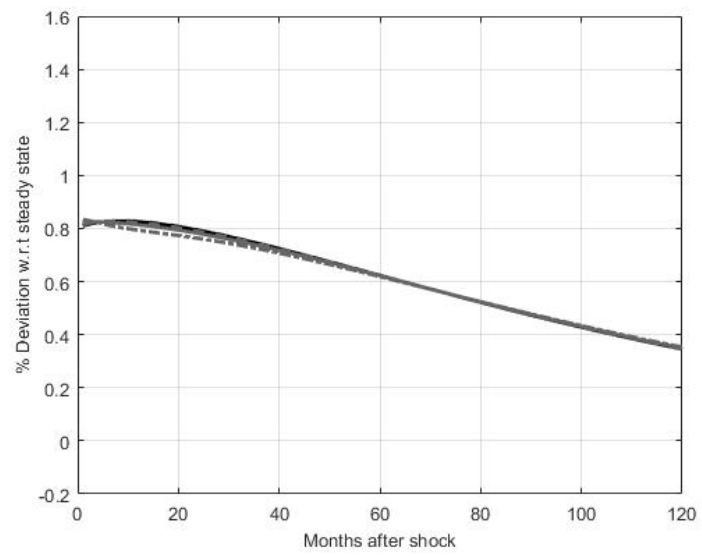

Note: This figure plots the evolution of the average wage for different groups of workers in response to a $1 \%$ increase in aggregate productivity. Panels 9a and 9c plot the evolution of average wages not adjusted for composition effects. Panels $9 \mathrm{~b}$ and $9 \mathrm{~d}$ plot the evolution of average wages adjusted for composition effects as proposed by Horrace and Oaxaga (2001). 
Figure 10: Real Wages and Index of Consumer Sentiment

(a) Average (Log) Real Hourly Wages

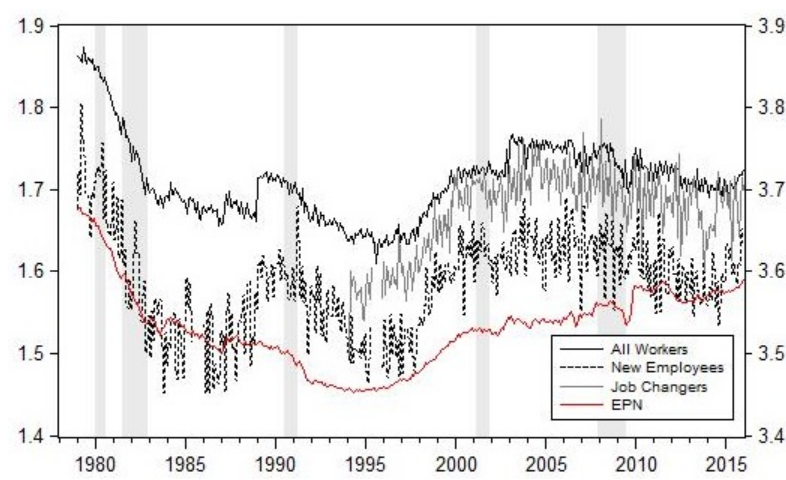

(b) Index of Consumer Sentiment

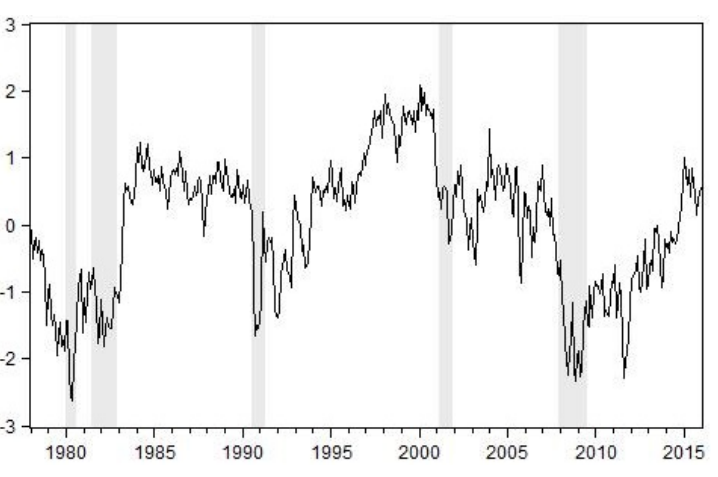

Note: Panel 10a plots the average log real hourly wages for all workers (solid black line), new employees (dashed-black lines), and job changers (solid gray line). The red line (left axis) is the log real average hourly earnings of production and nonsupervisory employees. These series are the coefficient of time fixed effect in a Mincer equation using CPS and IPUMS-CPS microdata. Details of these series are provided in Appendix F. All wages are deflated by CPI. Shadow areas represent NBER recession dates. Panel 10b plots the Index of Consumer Sentiment (ICS) from the University of Michigan Surveys of Consumers. The ICS is re-scaled such that it has a 0 mean and a standard deviation equal to 1 . Shadow areas represent NBER recession dates. The sample period is January 1979 to December 2015. 
Figure 11: Evoluation of $m J$ over 1 Million Simulations and $\underline{\Pi}_{j}$ in Steady State

(a) Simulated $m J=\min _{j}\left\{J_{j}\right\}$

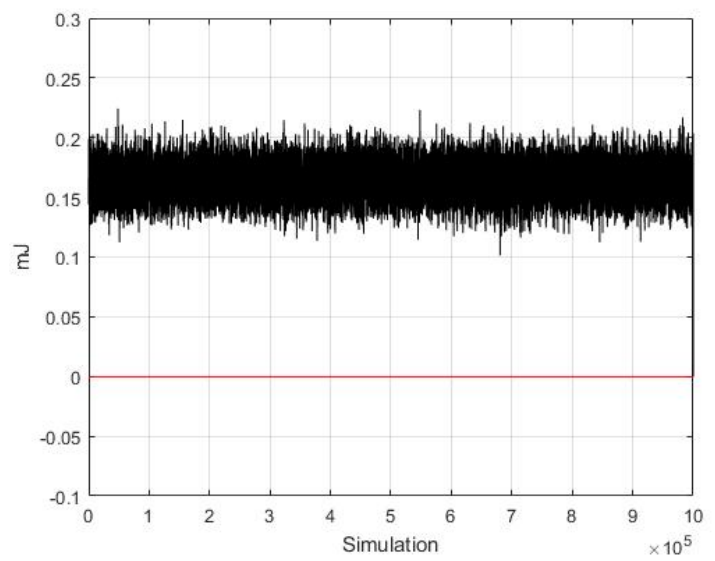

(b) $\underline{\Pi}_{j}$ For All Firms in Steady State

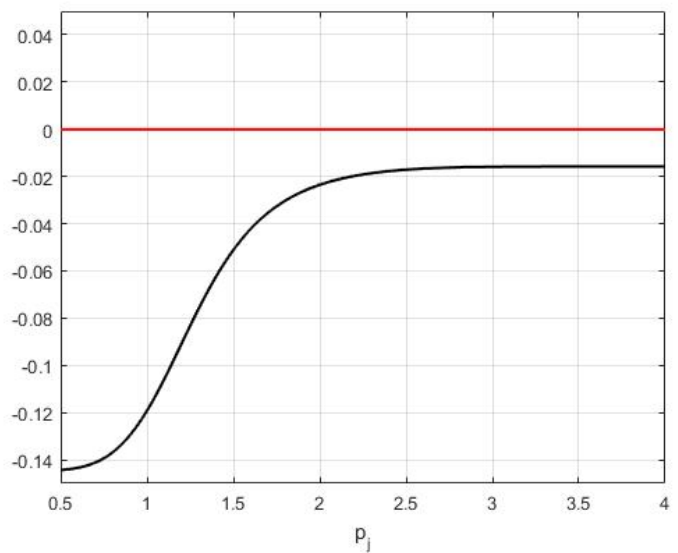

Note: Panel 11a plots the evolution of $\operatorname{mJ}=\min _{j}\left\{J_{j}\right\}$ indicating that Assumption 1 is never violated. Panel $11 \mathrm{~b}$ plots the value of $\underline{\Pi}_{j}$ for all firms in steady state. 
Figure 12: Impulse Response Functions to a 1\% Increase in Aggregate Productivity Comparing Different Information Structures

(a) Unemployment

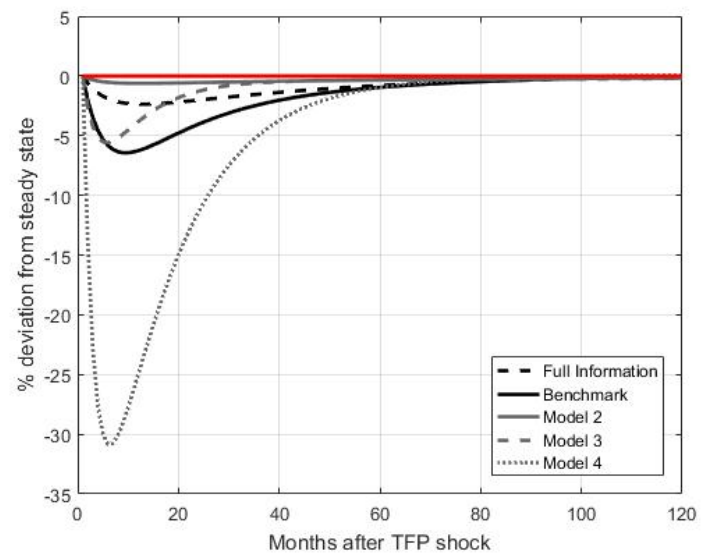

(c) Average Wage New Employees

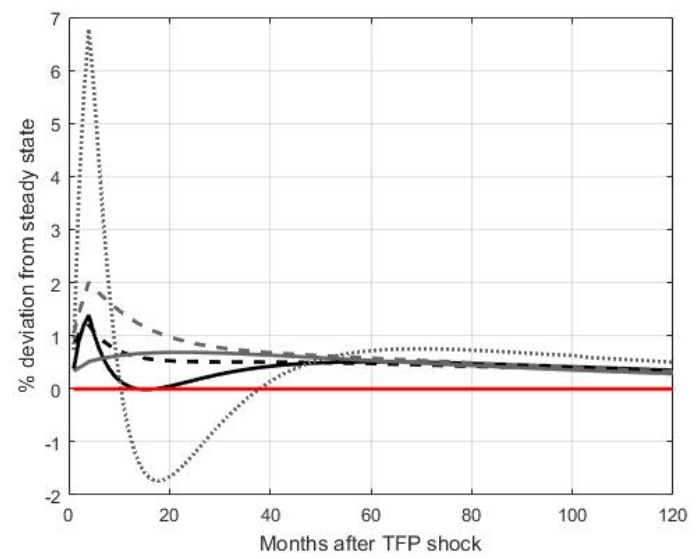

(b) Average Wage All Workers

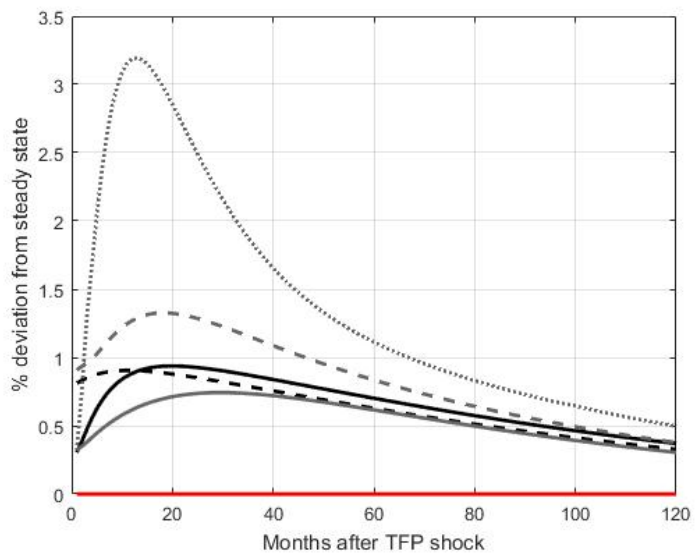

(d) Average Wage Job Changers

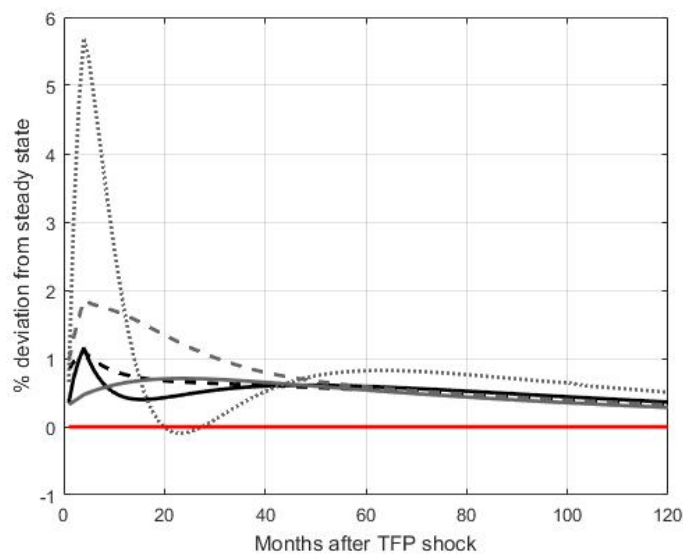

Note: This figure plots the Impulse Response Function of unemployment and wages to a $1 \%$ increase in aggregate TFP. Solid black lines are the IRFs of a model in wihch workers face information frictions and firms have perfect information. Dashed black lines are the IRFs generated by a model in which all agents have perfect information. Models 2 (solid gray lines), 3 (dashed gray lines), and 4 (dotted gray lines) assume that firms and workers face information frictions as described in section 7.3. 


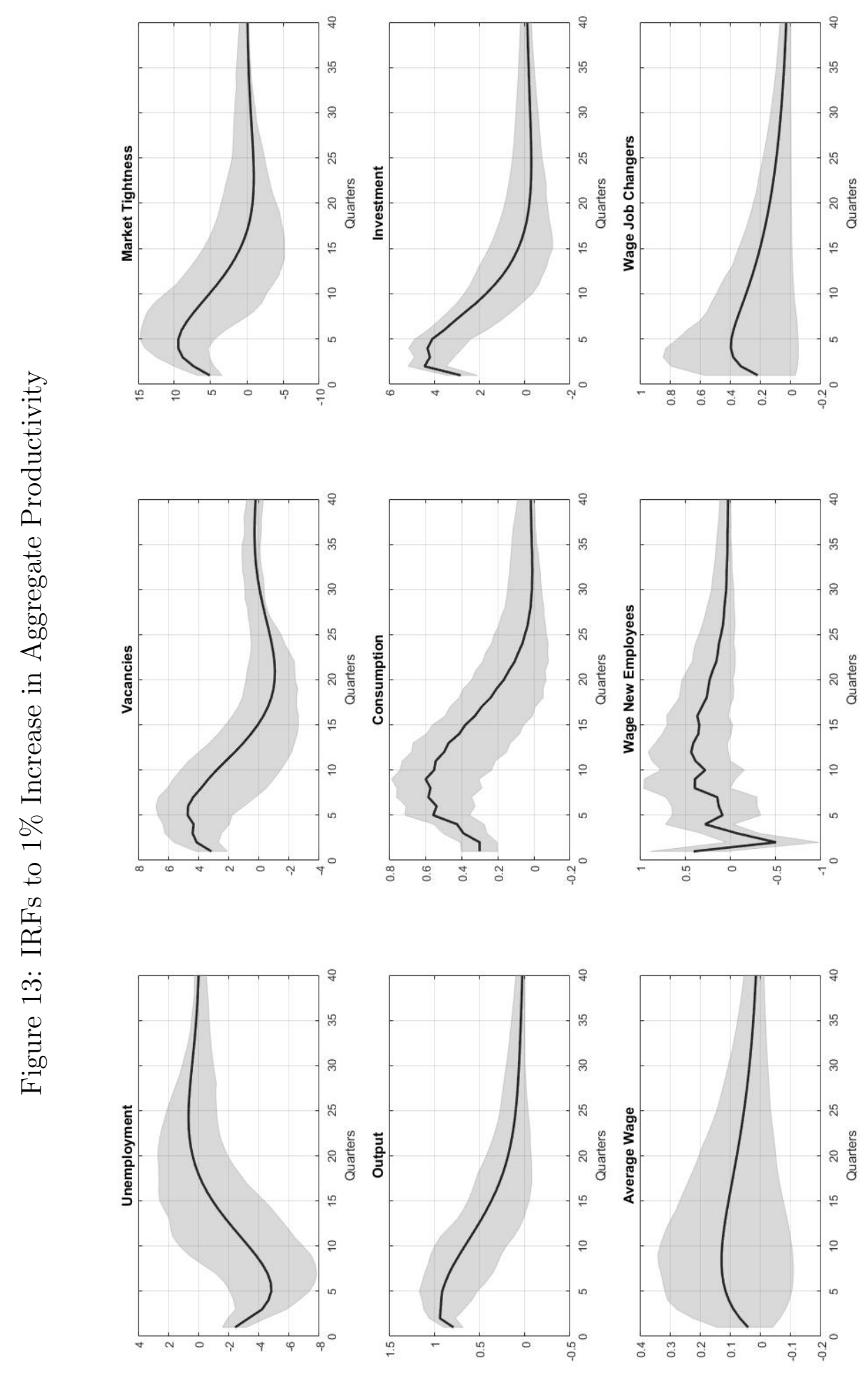

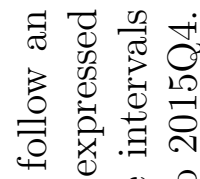

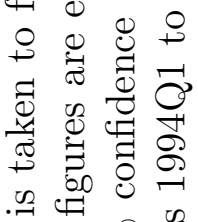

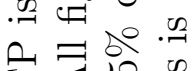

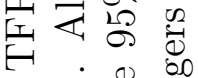
웡ำ 궁용

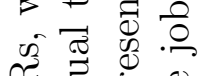

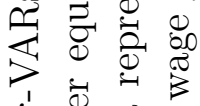

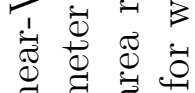
䨌 굴

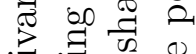

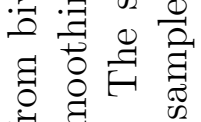
औ 在 $\infty 000$ $\exists$ : 0 क 15 政 00

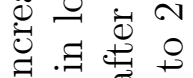
웜

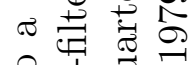
요. 光

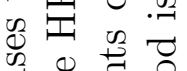

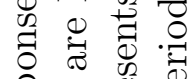
की की

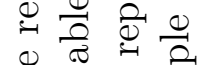

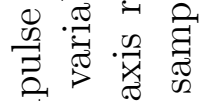
寻击

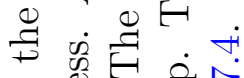

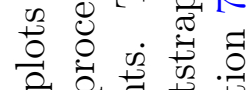

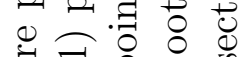

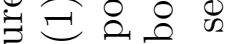
की

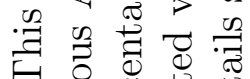

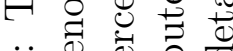

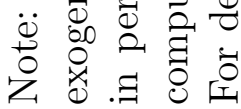




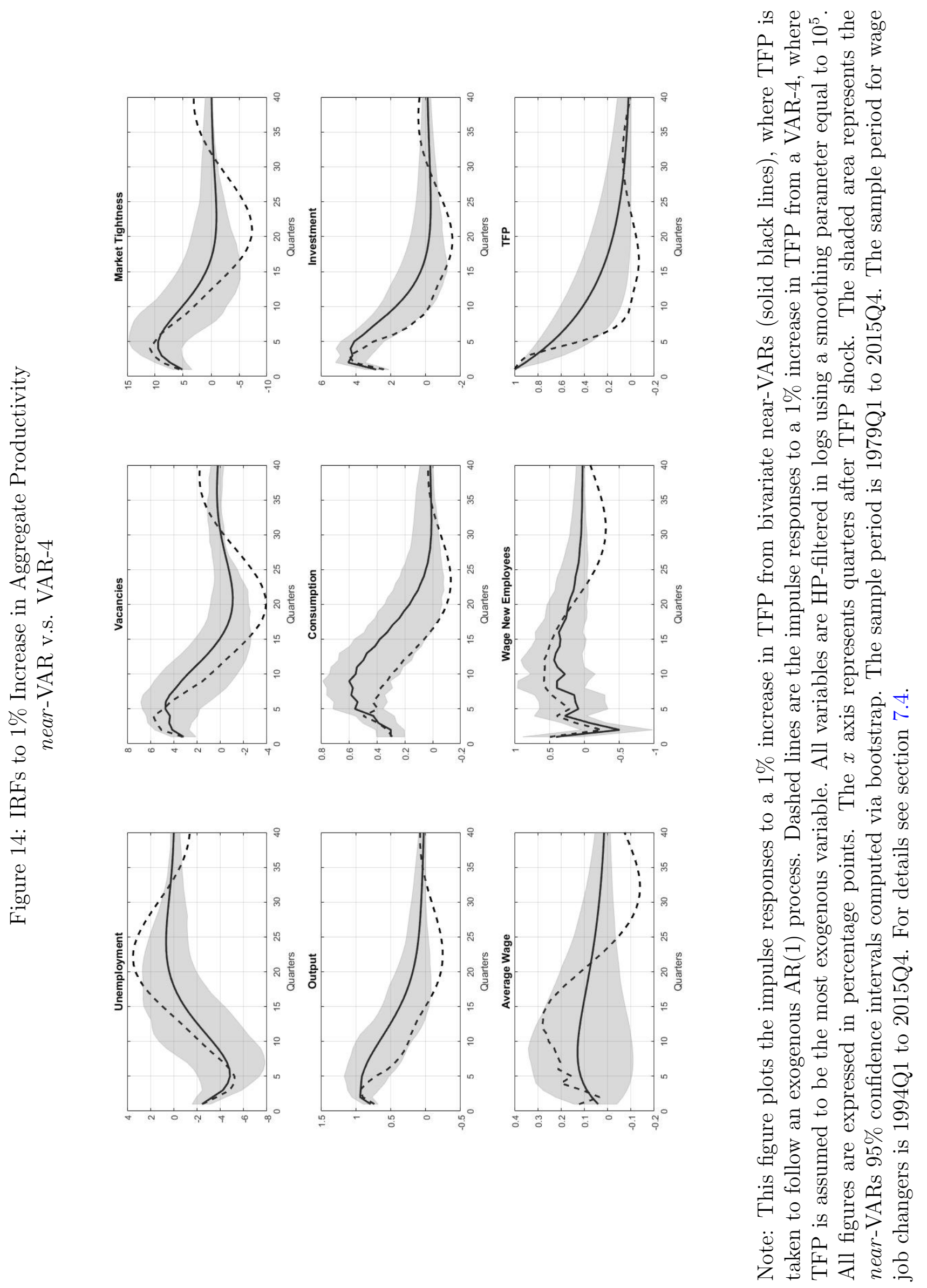




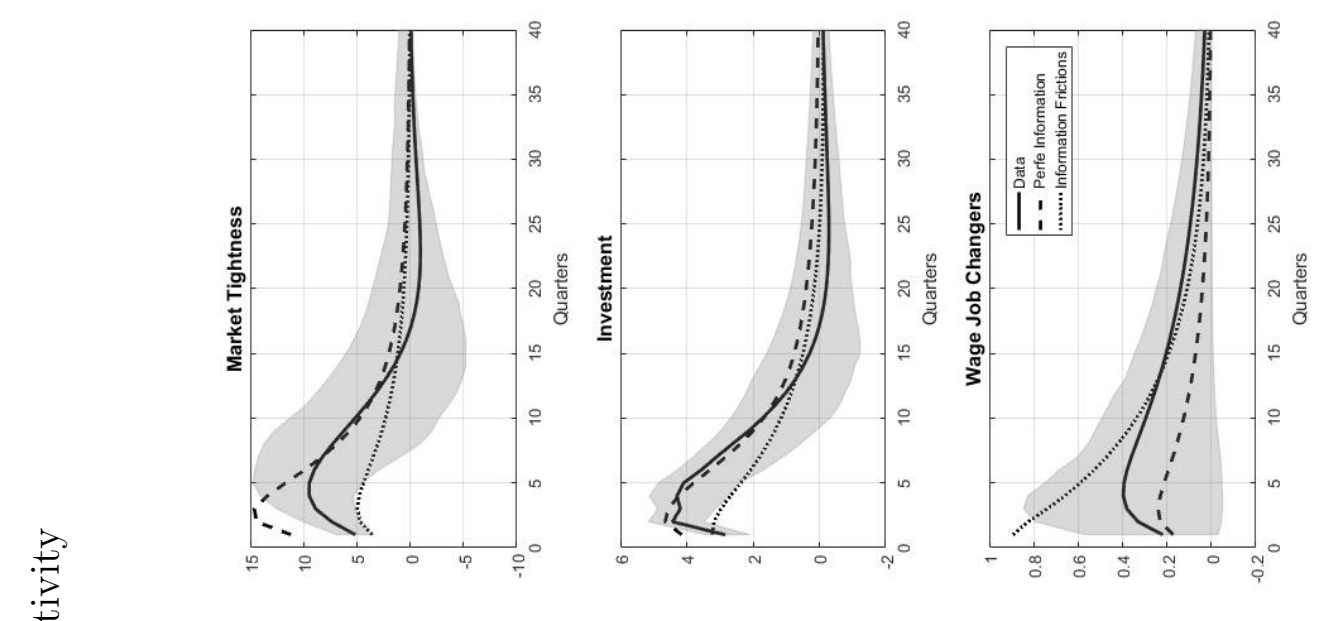

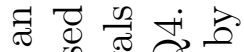

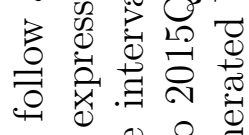

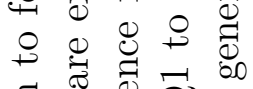

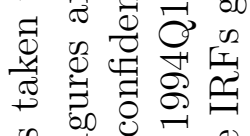

.

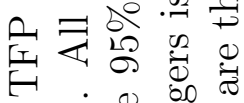

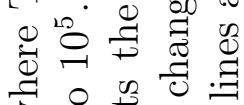

s.

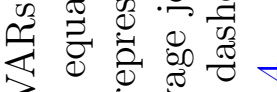

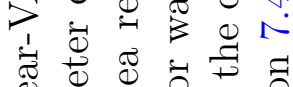

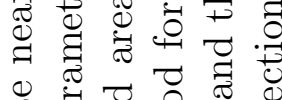

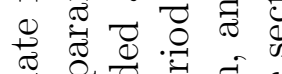

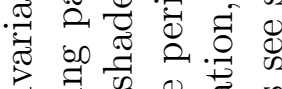

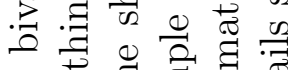

엽 윱

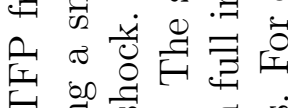

$\forall . \exists$

. $:$ 可

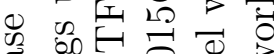

过 0.40

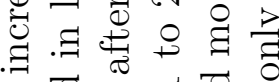

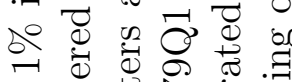

๙

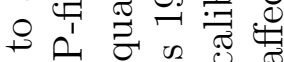

पु

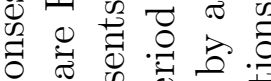

की

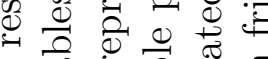

谒

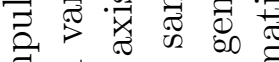

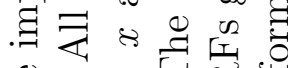

过出品

㔯造

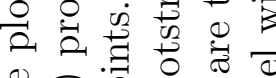

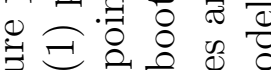

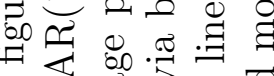

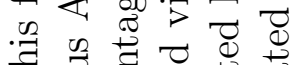

E

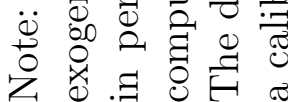




\section{B Tables}

Table 1: Business Cycle Statistics: U.S. Economy 1979:Q1 to 2015:Q4

\begin{tabular}{|c|c|c|c|c|c|c|c|c|c|c|c|}
\hline & & $u$ & $v$ & $v / u$ & $y$ & $c$ & Inv & $w^{a}$ & $w^{u}$ & $w^{c}$ & $a$ \\
\hline \multicolumn{2}{|l|}{$\begin{array}{l}\text { Standard deviation } \\
\text { Autocorrelation }\end{array}$} & $\begin{array}{l}0.19 \\
0.97\end{array}$ & $\begin{array}{l}0.19 \\
0.96\end{array}$ & $\begin{array}{l}0.38 \\
0.97\end{array}$ & $\begin{array}{l}0.02 \\
0.95\end{array}$ & $\begin{array}{l}0.02 \\
0.96\end{array}$ & $\begin{array}{c}0.1 \\
0.94\end{array}$ & $\begin{array}{c}0.02 \\
0.9\end{array}$ & $\begin{array}{l}0.03 \\
0.69\end{array}$ & $\begin{array}{l}0.02 \\
0.65\end{array}$ & $\begin{array}{l}0.02 \\
0.91\end{array}$ \\
\hline \multirow{10}{*}{ Correlation Matrix } & $u$ & 1 & -0.92 & -0.98 & -0.80 & -0.63 & -0.82 & -0.22 & -0.21 & -0.13 & -0.47 \\
\hline & $v$ & & 1 & 0.98 & 0.76 & 0.56 & 0.85 & 0.06 & 0.01 & 0.01 & 0.50 \\
\hline & $v / u$ & & & 1 & 0.79 & 0.6 & 0.86 & 0.14 & 0.11 & 0.07 & 0.49 \\
\hline & $y$ & & & & 1 & 0.91 & 0.82 & 0.54 & 0.40 & 0.49 & 0.81 \\
\hline & $c$ & & & & & 1 & 0.61 & 0.62 & 0.47 & 0.55 & 0.76 \\
\hline & $\operatorname{Inv}$ & & & & & & 1 & 0.22 & 0.07 & 0.25 & 0.67 \\
\hline & $w^{a}$ & & & & & & & 1 & 0.79 & 0.78 & 0.51 \\
\hline & $w^{u}$ & & & & & & & & 1 & 0.71 & 0.32 \\
\hline & $w^{c}$ & & & & & & & & & 1 & 0.45 \\
\hline & $a$ & & & & & & & & & & 1 \\
\hline
\end{tabular}

Note: Statistics for the U.S. economy are based on: $u$ : Unemployment level. $v$ : Help-wanted index (Barnichon, 2010a). $v / u$ : Vancancy-unemployment ratio. $y$ : Real output in the nonfarm business sector. $c$ : Consumption of non-durable goods and services. Inv: Real private domestic investment. $w^{a}$ : Average wage in the economy. $w^{u}$ : Average wage for new employees. $w^{c}$ : Average wage for job changers. a: Solow residual. All series are seasonally adjusted, logged, and detrended via the HP filter with a smoothing parameter of 100,000 . 
Table 2: Wage Distribution

\begin{tabular}{lcccc}
\hline \hline Wage Quintile & $\begin{array}{c}\text { Fraction } \\
\text { of Firms }\end{array}$ & $\begin{array}{c}\text { Monthly } \\
\text { Earnings }\end{array}$ & \multicolumn{2}{c}{ Earnings (\% of Lowest) } \\
\cline { 2 - 4 } & & & & Data \\
Lowest & $20 \%$ & $1,842.16$ & 1.00 & 1.00 \\
$2^{\text {sd }}$ & $20 \%$ & $2,754.87$ & 1.50 & 1.40 \\
$3^{\text {rd }}$ & $20 \%$ & $3,458.19$ & 1.88 & 1.86 \\
$4^{\text {th }}$ & $20 \%$ & $4,354.70$ & 2.36 & 2.42 \\
Highest & $20 \%$ & $6,665.13$ & 3.62 & 3.62 \\
& & & & \\
All & $100 \%$ & $3,815.01$ & 2.07 & 2.06 \\
\hline \hline
\end{tabular}

Note: This table reports average monthly earnings by pay quintile. Average earnings are weighted by employment. Data source is Kahn and McEntarfer (2014). 
Table 3: Firm Size Distribution

\begin{tabular}{|c|c|c|c|c|}
\hline \multirow{2}{*}{ Firm Size } & \multirow{2}{*}{$\begin{array}{l}\text { Fraction } \\
\text { of Firms }\end{array}$} & \multirow{2}{*}{$\begin{array}{c}\text { Average } \\
\text { Size }\end{array}$} & \multicolumn{2}{|c|}{ Size (\% of Smallest) } \\
\hline & & & Data & Model \\
\hline 1 to 4 & $55.1 \%$ & 2.23 & 1.00 & 1.00 \\
\hline 5 to 9 & $21.1 \%$ & 6.66 & 2.99 & 6.21 \\
\hline 10 to 19 & $12.2 \%$ & 13.70 & 6.15 & 14.73 \\
\hline 20 to 49 & $7.4 \%$ & 30.75 & 13.81 & 28.74 \\
\hline 50 to 99 & $2.3 \%$ & 69.85 & 31.37 & 48.24 \\
\hline 100 to 249 & $1.2 \%$ & 152.78 & 68.62 & 68.87 \\
\hline $250+$ & $0.7 \%$ & $1,648.26$ & 740.34 & 117.00 \\
\hline All & $100.0 \%$ & 21.64 & 9.72 & 8.79 \\
\hline
\end{tabular}

Note: This table reports firm size statistics for the United States. for the period 1977 to 2014. Firm size is defined as number of employees per firm. Average size is computed as total number of employees over total number of firms. Data source is Business Dynamics Statistics. 


\section{Externally Calibrated}
Parameter Value
Description

\begin{tabular}{|c|c|c|c|}
\hline$\sigma$ & 1 & \multicolumn{2}{|c|}{ Intertemporal elasticity of substitution } \\
\hline$\xi$ & 0.5 & \multicolumn{2}{|l|}{ Inverse of Frisch elasticity } \\
\hline$\alpha$ & 0.33 & \multicolumn{2}{|c|}{ Labor share in production function } \\
\hline$\rho_{a}$ & $0.95^{1 / 3}$ & \multicolumn{2}{|c|}{ Persistence of productivity shocks } \\
\hline$\vartheta$ & 0.5 & \multicolumn{2}{|c|}{ Workers' bargaining power in steady state } \\
\hline \multicolumn{4}{|c|}{ Internally Calibrated } \\
\hline Parameter & Value & Description & Target \\
\hline$a_{j}$ & & $\begin{array}{l}\text { Idiosyncratic TFP distribu- } \\
\text { tion }\end{array}$ & $\begin{array}{l}\text { Marginal labor productivity dis- } \\
\text { tributed truncated normal with } \\
\text { mean } 1 \text {, standard deviation } 0.6 \text { and } \\
\text { truncated range }[0.4, \infty) \text {. }\end{array}$ \\
\hline$\varsigma_{a}$ & 0.0052 & $\begin{array}{l}\text { Standard deviation of pro- } \\
\text { ductivity shocks }\end{array}$ & $\begin{array}{l}\text { Quarterly standard deviation of fil- } \\
\text { tered TFP equal to } 0.016 \text { (Table } 1 \text { ) }\end{array}$ \\
\hline$\varsigma_{n}$ & $2 \cdot \varsigma_{a}$ & $\begin{array}{l}\text { Standard deviation of noise } \\
\text { shocks }\end{array}$ & Weight on new information $=20 \%$. \\
\hline$\rho_{n}$ & 0.841 & Persistence of noise shocks & $\begin{array}{l}\text { Quarterly persistence of perception } \\
\text { error }=0.80 \text {. }\end{array}$ \\
\hline$\delta_{h}$ & 0.015 & Exogenous separation rate & Unemployment rate $=5.5 \%$ \\
\hline$\Psi$ & 1.158 & $\begin{array}{l}\text { Desutility of labor parame- } \\
\text { ter }\end{array}$ & Average $\frac{z_{j}}{p_{j}}$ equal to 0.72 \\
\hline$b$ & 0.041 & Unemployment benefits & $\begin{array}{l}\text { Fraction of } b \text { over modal (marginal) } \\
\text { labor productivity }=0.041 .\end{array}$ \\
\hline$l$ & 1.3806 & $\begin{array}{l}\text { Matching function parame- } \\
\text { ter }\end{array}$ & $\begin{array}{l}\text { Unemployment duration } \approx 15 \text { weeks } \\
(q=0.27) .\end{array}$ \\
\hline $\bar{i}$ & 0.485 & $\begin{array}{l}\text { Relative search intensity of } \\
\text { employed workers }\end{array}$ & Fraction of job changers $=2.5 \%$ \\
\hline$\beta$ & 0.996 & Discount factor & Annual interest rate $=5 \%$ \\
\hline$\xi$ & 0.2922 & $\begin{array}{l}\text { Elasticity of substitution } \\
\text { between jobs }\end{array}$ & $\begin{array}{l}\text { Relative wage of firms in the highest } \\
\text { wage quintile }=3.62 \text {. }\end{array}$ \\
\hline$\chi$ & 0.3225 & $\begin{array}{l}\text { Hiring cost function convex- } \\
\text { ity }\end{array}$ & $\begin{array}{l}\text { Relative size of firms with } 100 \text { to } 249 \\
\text { employees }=68.62\end{array}$ \\
\hline$\delta_{k}$ & 0.0087 & Capital depreciation rate & Annual depreciation rate $=10 \%$ \\
\hline
\end{tabular}

Note: This table summarizes the parameterization of the model. Details are reported in section 5.1. 
Table 5: Average Wages in Steady State

\begin{tabular}{ccccc}
\hline \hline All workers & Job Stayers & New Hires & Job Changers & New Employees \\
\hline \multirow{2}{*}{1.0000} & 1.0128 & 0.8495 & 0.9416 & 0.7010 \\
\hline \hline
\end{tabular}

Note: This table reports the average wage for different groups of workers in steady state. 
Table 6: Wage Semi-Elasticities with Respect to the Unemployment Rate

\begin{tabular}{lcccc}
\hline \hline & Current Population Survey & \multicolumn{2}{c}{ Model Simulated Data } \\
& $(1)$ & & $(2)$ & $(3)$ \\
\cline { 2 - 2 } All Workers & -0.27 & -1.01 & -1.12 \\
New Employees & $(0.27)$ & & & \\
& $-1.66^{*}$ & & 3.98 & -2.65 \\
Job Changerm & $(0.99)$ & & -2.93 \\
& -0.57 & 3.42 & \\
\hline \hline
\end{tabular}

Note: Column 1 presents the estimated wage semi-elasticities with respect to the unemployment rate for each group of workers using the wage series constructed from the CPS and IMPUS-CPS microdata. Each specification includes monthly dummies and a lag of the independent variable. Robust standard error in parenthesis. ${ }^{*},{ }^{* *},{ }^{* * *}$ indicate statistically significance at $10 \%, 5 \%$, and $1 \%$ respectively. Sample period for all and new employees is January 1979 to December 2015 and for job changers is January 1994 to December 2015. Columns 2 and 3 reports the theoretical semi-elasticities predicted by a model with full information and with information frictions, respectively. 
Table 7: Differential Net Flows, Coefficient on Cyclical Variable High Wage minus Low Wage

\begin{tabular}{|c|c|c|c|}
\hline \multirow[b]{3}{*}{$\begin{array}{l}\text { Net Job Flows } \\
\text { Net Poaching Flows } \\
\text { Net Nonemployment } \\
\text { Flows }\end{array}$} & $\begin{array}{l}\text { Data } \\
(1)\end{array}$ & $\begin{array}{r}\text { Model } \mathrm{S} \\
\text { Full Information } \\
(2)\end{array}$ & $\begin{array}{l}\text { mulated Data } \\
\text { Information Frictions } \\
\qquad(3)\end{array}$ \\
\hline & \multicolumn{3}{|c|}{ Deviation from HP Trend } \\
\hline & $\begin{array}{l}-0.269 \\
-0.253 \\
-0.016\end{array}$ & $\begin{array}{c}-0.210 \\
-0.252 \\
0.042\end{array}$ & $\begin{array}{c}-0.257 \\
-0.292 \\
0.035\end{array}$ \\
\hline & \multicolumn{3}{|c|}{ First Difference } \\
\hline $\begin{array}{l}\text { Net Job Flows } \\
\text { Net Poaching Flows } \\
\text { Net Nonemployment } \\
\text { Flows }\end{array}$ & $\begin{array}{l}-0.557 \\
-1.460 \\
-0.903\end{array}$ & $\begin{array}{l}0.007 \\
0.004 \\
0.003\end{array}$ & $\begin{array}{l}0.018 \\
0.013 \\
0.005\end{array}$ \\
\hline
\end{tabular}

Note: Data for the first column are from Haltiwanger, Hyatt, and McEntarfer (2015) Table 1. Each model was used to generate artificial data over a time horizon of 55 quarters, which is consistent with the sample size of Haltiwanger, et al. (2015). Each model was simulated 10,000 times. The coefficient on the cyclical variable was computed for each artificial series, and the theoretical coefficient was estimated by averaging across the 10,000 simulations. 
Table 8: Simulated Business Cycle

Workers Face Information Frictions

\begin{tabular}{|c|c|c|c|c|c|c|c|c|c|c|c|}
\hline & & $\bar{u}$ & $\bar{v}$ & $\bar{v} v / u$ & $\bar{y}$ & $\overline{c c}$ & $\overline{I n v}$ & $\overline{w^{a}}$ & $\bar{w}^{u}$ & $\overline{w^{c}}$ & $\bar{a}$ \\
\hline Standard deviation & & $\begin{array}{l}0.14 \\
0.93\end{array}$ & $\begin{array}{l}0.18 \\
0.87\end{array}$ & $\begin{array}{l}0.31 \\
0.91\end{array}$ & $\begin{array}{l}0.03 \\
0.93\end{array}$ & $\begin{array}{l}0.01 \\
0.97\end{array}$ & $\begin{array}{l}0.09 \\
0.92\end{array}$ & $\begin{array}{l}0.02 \\
0.94\end{array}$ & $\begin{array}{l}0.02 \\
0.76\end{array}$ & $\begin{array}{l}0.01 \\
0.74\end{array}$ & $\begin{array}{l}0.02 \\
089\end{array}$ \\
\hline \multirow{10}{*}{ Correlation Matrix } & $u$ & 1 & -0.89 & -0.97 & -0.83 & -0.24 & -0.91 & -0.56 & 0.47 & 0.08 & -0.72 \\
\hline & $v$ & & 1 & 0.98 & 0.78 & 0.07 & 0.90 & 0.39 & -0.21 & 0.11 & 0.75 \\
\hline & $v / u$ & & & 1 & 0.83 & 0.15 & 0.93 & 0.48 & -0.34 & 0.03 & 0.76 \\
\hline & $y$ & & & & 1 & 0.61 & 0.94 & 0.86 & -0.01 & 0.40 & 0.96 \\
\hline & $c$ & & & & & 1 & 0.32 & 0.83 & 0.21 & 0.45 & 0.50 \\
\hline & $\operatorname{Inv}$ & & & & & & 1 & 0.69 & -0.13 & 0.26 & 0.93 \\
\hline & $w^{a}$ & & & & & & & 1 & 0.08 & 0.44 & 0.80 \\
\hline & $w^{u}$ & & & & & & & & 1 & 0.87 & 0.18 \\
\hline & $w^{c}$ & & & & & & & & & 1 & 0.54 \\
\hline & $a$ & & & & & & & & & & 1 \\
\hline
\end{tabular}

Note: Statistics for the simulated economy under information frictions: $u$ : Unemployment level. $v$ : Vacancies $v / u$ : Vancancy-unemployment ratio. $y$ : Output. $c$ : Consumption. Inv: Investment. $w^{a}$ : Average wage in the economy. $w^{u}$ : Average wage for new employees. $w^{c}$ : Average wage for job changers. $a$ : Aggregate TFP. All series are seasonally adjusted, logged, and detrended with the HP filter with a smoothing parameter of 100,000 . 
Table 9: Simulated Business Cycle Model with Full Information

\begin{tabular}{|c|c|c|c|c|c|c|c|c|c|c|c|}
\hline & & $u$ & $v$ & $v / u$ & $y$ & $c$ & $\operatorname{Inv}$ & $w^{a}$ & $w^{u}$ & $w^{c}$ & $a$ \\
\hline \multirow{2}{*}{\multicolumn{2}{|c|}{$\begin{array}{l}\text { Standard deviation } \\
\text { Autocorrelation }\end{array}$}} & 0.04 & 0.06 & 0.10 & 0.02 & 0.01 & 0.06 & 0.02 & 0.01 & 0.01 & 0.02 \\
\hline & & 0.95 & 0.92 & 0.95 & 0.92 & 0.96 & 0.91 & 0.92 & 0.77 & 0.82 & 0.89 \\
\hline \multirow{10}{*}{ Correlation Matrix } & $u$ & 1 & -0.93 & -0.98 & -0.93 & -0.76 & -0.92 & -0.9 & -0.7 & -0.74 & -0.9 \\
\hline & $v$ & & 1 & 0.99 & 0.96 & 0.71 & 1.00 & 0.92 & 0.87 & 0.88 & 0.99 \\
\hline & $v / u$ & & & 1 & 0.96 & 0.74 & 0.98 & 0.93 & 0.81 & 0.83 & 0.97 \\
\hline & $y$ & & & & 1 & 0.87 & 0.96 & 0.98 & 0.9 & 0.91 & 0.98 \\
\hline & $c$ & & & & & 1 & 0.69 & 0.88 & 0.74 & 0.77 & 0.75 \\
\hline & $\operatorname{Inv}$ & & & & & & 1 & 0.92 & 0.88 & 0.88 & 0.99 \\
\hline & $w^{a}$ & & & & & & & 1 & 0.87 & 0.89 & 0.94 \\
\hline & $w^{u}$ & & & & & & & & 1 & 0.96 & 0.93 \\
\hline & $w^{c}$ & & & & & & & & & 1 & 0.92 \\
\hline & $a$ & & & & & & & & & & 1 \\
\hline
\end{tabular}

Note: Statistics for the simulated economy under perfect information: $u$ : Unemployment level. $v$ : Vacancies $v / u$ : Vancancy-unemployment ratio. $y$ : Output. $c$ : Consumption. Inv: Investment. $w^{a}$ : Average wage in the economy. $w^{u}$ : Average wage for new employees. $w^{c}$ : Average wage for job changers. a: Aggregate TFP. All series are seasonally adjusted, logged, and detrended with the HP filter with a smoothing parameter of 100,000. 
Table 10: Wage Growth vs. Expectations

\begin{tabular}{cccc}
\hline \hline & All Workers & New Employees & Job Changers \\
\cline { 2 - 4 } & \multicolumn{3}{c}{ Monthly Frequency } \\
$\beta_{u}$ & -0.03 & -1.51 & -0.42 \\
& $(0.28)$ & $(1.02)$ & $(1.28)$ \\
$\beta_{E}$ & $0.14^{* * *}$ & 0.08 & 0.10 \\
& $(0.05)$ & $(0.18)$ & $(0.21)$ \\
& & & \\
$R^{2}$ & 0.21 & 0.27 & 0.26 \\
$N$ & 442 & 426 & 253 \\
& & & \\
\hline
\end{tabular}

Quarterly Frequency

\begin{tabular}{lccc}
$\beta_{u}$ & -0.31 & -0.23 & 0.87 \\
& $(0.28)$ & $(0.94)$ & $(0.98)$ \\
$\beta_{E}$ & $0.35^{* * *}$ & $0.63^{* *}$ & $0.48^{* * *}$ \\
& $(0.11)$ & $(0.27)$ & $(0.24)$ \\
$\beta_{u e}$ & -0.07 & -0.12 & -0.71 \\
& $(0.33)$ & $(0.92)$ & $(1.00)$ \\
$\beta_{y}$ & -0.25 & -0.49 & -0.05 \\
& $(0.20)$ & $(0.42)$ & $(0.50)$ \\
$R^{2}$ & 0.17 & 0.33 & 0.15 \\
$N$ & 146 & 139 & 83 \\
\hline \hline
\end{tabular}

Note: This table reports the estimated coefficient on the unemployment rate $\left(\beta_{u}\right)$, workers' expectations $\left(\beta_{E}\right)$, expected change in the unemployment rate over the next year $\left(\beta_{u e}\right)$, and expected GDP growth for the following year $\left(\beta_{y}\right)$ for each group of workers using the wage series constructed from the CPS and IMPUS-CPS microdata (equations (46) and (47)). Each specification includes monthly (quarterly) dummies and a lag of the independent variable. Robust standard errors in parentheses. ${ }^{*},{ }^{* *},{ }^{* *}$ indicate statistically significance at $10 \%, 5 \%$, and $1 \%$ respectively. Sample period for all and new employees is January 1979 to December 2015 and for job changers is January 1994 to December 2015. Workers' expectations are measured by the Index of Consumer Sentiment from the University of Michigan Surveys of Consumers, and unemployment and GDP expectations are taken form the Survey of Professional Forecasters. 
Table 11: Wage Semi-Elasticities with Respect to the Unemployment Rate Model Simulated Data

\begin{tabular}{lcccc}
\hline \hline & Benchmark & Model 2 & Model 3 & Model 4 \\
\cline { 2 - 4 } All Workers & -1.12 & 0.32 & -0.02 & -0.72 \\
New Employees & -2.65 & 3.49 & -4.77 & -7.15 \\
Job Changers & -2.93 & 1.69 & -6.05 & -8.81 \\
\hline \hline
\end{tabular}

Note: This table reports the theoretical wage semi-elasticities with respect to the unemployment rate based on equation (46). In the benchmark model only workers face information frictions. In models 2,3 , and 4 firms and workers face information frictions as described in Section 7.3. 
Table 12: Differential Net Flows, Coefficient on Cyclical Variable High Wage minus Low Wage. Model Simulated Data

\begin{tabular}{lcccc}
\hline \hline & Benchmark & Model 2 & Model 3 & Model 4 \\
\cline { 2 - 5 } & \multicolumn{5}{c}{ Deviation from HP Trend } \\
Net Job Flows & -0.257 & -0.696 & -0.728 & -0.538 \\
Net Poaching Flows & -0.292 & -0.502 & -0.652 & -0.503 \\
Net Nonemployment & 0.035 & -0.036 & -0.075 & -0.034 \\
Flows & & & & \\
\end{tabular}

First Difference

$\begin{array}{lllll}\text { Net Job Flows } & 0.018 & -0.035 & 0.009 & 0.012 \\ \text { Net Poaching Flows } & 0.013 & -0.030 & 0.007 & 0.009 \\ \text { Net Nonemployment } & 0.005 & -0.005 & 0.002 & 0.003\end{array}$

Flows

Note: This table reports the theoretical differential net job flows as discuss in the paper. In the benchmark model only workers face information frictions. In models 2, 3 and 4 firms and workers face information frictions as described in Section 7.3. 
Table 13: Business Cycle Statistics Driven by TFP: U.S. Economy 1979:Q1 to 2015:Q4

\begin{tabular}{|c|c|c|c|c|c|c|c|c|c|c|c|}
\hline & & $u$ & $v$ & $v / u$ & $y$ & c c & $\operatorname{Inv}$ & $w^{a}$ & $w^{u}$ & $w^{c}$ & $a$ \\
\hline \multirow{2}{*}{\multicolumn{2}{|c|}{$\begin{array}{l}\text { Standard deviation } \\
\text { Autocorrelation }\end{array}$}} & 0.12 & 0.12 & 0.22 & 0.02 & 0.01 & 0.09 & 0.01 & 0.02 & 0.01 & 0.02 \\
\hline & & 0.98 & 0.97 & 0.97 & 0.96 & 0.98 & 0.96 & 1.00 & 0.73 & 0.96 & 0.91 \\
\hline \multirow{10}{*}{ Correlation Matrix } & $u$ & 1 & -0.96 & -0.99 & -0.95 & -0.89 & -0.92 & -0.47 & -0.51 & -0.85 & -0.87 \\
\hline & $v$ & & 1 & 0.97 & 0.90 & 0.77 & 0.95 & 0.34 & 0.33 & 0.79 & 0.86 \\
\hline & $v / u$ & & & 1 & 0.95 & 0.84 & 0.95 & 0.47 & 0.45 & 0.85 & 0.90 \\
\hline & $y$ & & & & 1 & 0.93 & 0.92 & 0.46 & 0.50 & 0.90 & 0.96 \\
\hline & $c$ & & & & & 1 & 0.76 & 0.45 & 0.61 & 0.84 & 0.82 \\
\hline & $\operatorname{Inv}$ & & & & & & 1 & 0.22 & 0.23 & 0.85 & 0.93 \\
\hline & $w^{a}$ & & & & & & & 1 & 0.78 & 0.75 & 0.35 \\
\hline & $w^{u}$ & & & & & & & & 1 & 0.50 & 0.37 \\
\hline & $w^{c}$ & & & & & & & & & 1 & 0.89 \\
\hline & $w^{a}$ & & & & & & & & & & 1 \\
\hline
\end{tabular}

Notes: Statistics for the U.S. economy are based on: $u$ : Unemployment level. $v$ : Help-wanted index (Barnichon, 2010a). $v / u$ : Vancancy-unemployment ratio. $y$ : Real output in the nonfarm business sector. $c$ : Consumption of non-durable goods and services. Inv: Real private domestic investment. $w^{a}$ : Average wage in the economy. $w^{u}$ : Average wage for new employees. $w^{c}$ : Average wage for job changers.a: Solow residual. All series are seasonally adjusted, logged, and detrended via the HP filter with a smoothing parameter of 100,000 . These are the business cycle statistics that can be accounted for TFP shocks, as described in section 7.4. 
Table 14: Simulated Business Cycle Statistics Driven by TFP

Benchmark Model with Information Frictions

\begin{tabular}{|c|c|c|c|c|c|c|c|c|c|c|c|}
\hline & & $\bar{u}$ & $v$ & $v / u$ & $y$ & c c & Inv & $w^{a}$ & $w^{u}$ & $w^{c}$ & $\bar{a}$ \\
\hline $\begin{array}{l}\text { Standard deviation } \\
\text { Autocorrelation }\end{array}$ & & $\begin{array}{l}0.11 \\
0.95\end{array}$ & $\begin{array}{l}0.15 \\
0.88\end{array}$ & $\begin{array}{l}0.26 \\
0.92\end{array}$ & $\begin{array}{l}0.03 \\
0.93\end{array}$ & $\begin{array}{l}0.01 \\
0.99\end{array}$ & $\begin{array}{l}0.09 \\
0.92\end{array}$ & $\begin{array}{l}0.02 \\
0.97\end{array}$ & $\begin{array}{l}0.01 \\
0.67\end{array}$ & $\begin{array}{l}0.01 \\
0.95\end{array}$ & $\begin{array}{l}0.02 \\
0.89\end{array}$ \\
\hline \multirow{10}{*}{ Correlation Matrix } & $u$ & 1 & -0.84 & -0.92 & -0.96 & -0.62 & -0.95 & -0.93 & -0.19 & -0.89 & -0.92 \\
\hline & $v$ & & 1 & 0.98 & 0.86 & 0.24 & 0.95 & 0.66 & 0.55 & 0.71 & 0.91 \\
\hline & $v / u$ & & & 1 & 0.91 & 0.35 & 0.98 & 0.76 & 0.42 & 0.79 & 0.93 \\
\hline & $y$ & & & & 1 & 0.66 & 0.97 & 0.94 & 0.35 & 0.89 & 0.98 \\
\hline & $c$ & & & & & 1 & 0.47 & 0.81 & -0.08 & 0.67 & 0.55 \\
\hline & $\operatorname{Inv}$ & & & & & & 1 & 0.85 & 0.43 & 0.84 & 0.98 \\
\hline & $w^{a}$ & & & & & & & 1 & 0.12 & 0.89 & 0.87 \\
\hline & $w^{u}$ & & & & & & & & 1 & 0.23 & 0.50 \\
\hline & $w^{c}$ & & & & & & & & & 1 & 0.85 \\
\hline & $a$ & & & & & & & & & & 1 \\
\hline
\end{tabular}

Notes: Simulated statistics treating simulated data as data reported in Table 14. $u$ : Unemployment level. $v$ : Vacancies $v / u$ : Vancancy-unemployment ratio. $y$ : Output. $c$ : Consumption. Inv: Investment. $w^{a}$ : Average wage in the economy. $w^{u}$ : Average wage for new employees. $w^{c}$ : Average wage for job changers. a: Aggregate TFP. All series are seasonally adjusted, logged, and detrended with the HP filter with a smoothing parameter of 100,000 . These are the business cycle statistics that can be accounted for TFP shocks, as described in section 7.4. 


\section{Proofs}

\section{C.1 Proof of Lemma 1}

If all agents in the economy have complete and perfect information, the following strategy profiles constitute the unique sub-game perfect Nash equilibrium of this game:

- For the worker:

- To accept only wage offers greater than or equal to $x^{*}$ where $\vec{W}_{j}\left(x^{*}, \omega, \Omega\right)-U(\omega, \Omega)=$ $\vartheta \cdot S_{j}$

- To demand a wage equal to $y^{*}$ such that $\vec{W}_{j}\left(y^{*}, \omega, \Omega\right)-U(\omega, \Omega)=S_{j}$ and $\vec{J}_{j}\left(y^{*}, \omega_{f}, \Omega\right)=$ 0.

- For the firm:

- To offer $x^{*}$.

- To accept only wage demands that are less than or equal to $y^{*}$.

Proof. I begin at the third stage of the game (i.e. when the worker makes an offer). At this stage, the firm will accept any wage demand $y$ as long as $\vec{J}_{j}\left(y, h_{j}, \Omega\right) \geq 0$. Hence, the worker will demand a wage $y^{*}$ such that $\vec{J}_{j}\left(y^{*}, h_{j}, \Omega\right)=0$ and she keeps all the match surplus. Thus, at the second stage (i.e. when the worker has to accept or reject the firm's offer), the worker knows that if she rejects this offer, her expected payoff at the third stage will be $\vartheta \cdot S_{j}$. Therefore, she will only accept wage offers that are greater than or equal to $x^{*}$ where $\vec{W}_{j}\left(x^{*}, \omega, \Omega\right)-U=\vartheta \cdot S_{j}$. Finally, at the first stage of the game (i.e. when the firm makes an initial offer), the firm anticipates a payoff of zero if it makes an offer less than $x^{*}$ and a payoff of $\vec{J}_{j}\left(x, h_{j}, \Omega\right)$ if $x \geq x^{*}$. Hence, the firm offers exactly $x^{*}$ to the worker and she accepts it.

\section{C.2 Proof of Lemma 2}

Suppose that agents are information-constrained as described in section 3.4. If there is an equilibrium in which firms' strategy is to reveal the aggregate state of the economy, the best strategy for firms is the same strategy described in Lemma 1.

Proof. As we are considering the equilibrium of the game, if firms are following a revealing strategy, workers know it and behave rationally. As a consequence, workers can perfectly infer the current state of the economy based on the firm's wage offer.

Hence, a worker knows that she will receive, in expectation, $\vartheta \cdot S_{j}$ if she rejects a firm's offer. Therefore, the optimal strategy for workers is the following: 
- To infer the current level of the aggregate productivity based on firm's offer $x: a=x^{-1}(a)$

- To accept only wage offers greater than or equal to $x^{*}$ where:

$$
\begin{aligned}
\vec{W}_{j}\left(x^{*}, \omega, \Omega\right)-U & =\vartheta \cdot S_{j} \\
\vec{J}_{j}\left(x^{*}, \omega, \Omega\right) & =0
\end{aligned}
$$

- To demand a wage equal to $y^{*}$ if she has the chance such that:

$$
\vec{W}_{j}\left(y^{*}, \omega, \Omega\right)-U=S_{j}
$$

Now, given the workers' strategy, the firm anticipates a payoff of zero if it makes an offer less

than $x^{*}$ and a payoff of $\vec{J}_{j}\left(x, h_{j}, \Omega\right)-U$ if $x \geq x^{*}$. Given that $\vec{J}_{j}\left(x, h_{j}, \Omega\right)$ is strictly decreasing in $x$, the optimal strategy for firms, assuming that they follow a revealing strategy is the following:

- To offer $x^{*}$.

- To accept only wage demands that are less than or equal to $y^{*}$.

As a consequence, if there exists an equilibrium in which firms reveal the true state of the economy, in equilibrium firms offer exactly $x^{*}$ and workers will accept it. In other words, workers rationally believe that if a firm extends a wage offer $x$, it has to be the case that $x=x^{*}$.

\section{C.3 Proof of Lemma 3}

If agents in the economy are information-constrained as described in section 3.4, then in equilibrium, firms do not follow a strategy in which they perfectly reveal the true state of the economy.

Proof. Suppose not. By Lemma C.2, if there is an equilibrium in which firms reveal the true state of the economy, firms always offer $x=x^{*}$ and workers accept all wage offers $(x)$ because they rationally believe that $x$ is always equal to $x^{*}$. However, in order for these strategies to be an equilibrium, firms cannot have incentives to deviate.

Suppose that firms deviate to a strategy in which they offer $\tilde{x}=0.5 x^{*}$. Workers will accept this offer because they believe $\tilde{x}=x^{*}$, and firms will be better off because $J_{j}(\tilde{x})>J_{j}\left(x^{*}\right)$. Therefore, there is not an equilibrium in which firms reveal the true state of the economy.

\section{C.4 Proof of Lemma 4}

If agents in the economy are information-constrained as described in section 3.4, the following strategy profiles constitute a Perfect Bayesian Nash equilibrium that satisfies the intuitive criterion: 
- For the worker:

- To accept only wage offers greater than or equal to $x^{* *}$ where:

$$
E_{\mathcal{I}_{h}}\left[\vec{W}_{j}\left(x^{* *}, \omega, \Omega\right)-U(\omega, \Omega)\right]=\vartheta \cdot E_{\mathcal{I}_{h}}\left[S_{j}\right]
$$

- To demand a wage equal to $y^{* *}$ such that:

$$
E_{\mathcal{I}_{h}}\left[\vec{W}_{j}\left(y^{* *}, \omega, \Omega\right)-U(\omega, \Omega)\right]=E_{\mathcal{I}_{h}}\left[S_{j}\right]
$$

- For the firm:

- To offer $x^{* *}$.

- To accept only wage demands that are less than or equal to $\tilde{y}^{* *}$ such that $\vec{J}_{j}\left(\tilde{y}^{* *}, \omega_{f}, \Omega\right)=$ 0.

Proof. I begin at the third stage of the game (i.e. when the worker gets to make an offer). At this stage, the firm will accept any wage demand $y$ as long as its expected value is greater than or equal to zero. Given the firm's strategy, the firm's offer does not reveal its information. Therefore, the worker will demand a wage $y^{* *}$ such that, given her information set, the firm's value is zero. Thus, at the second stage (i.e. when the worker has to accept or reject the firm's offer), the worker knows that if she rejects this offer, her expected payoff at the third stage will be $\vartheta \cdot E_{\mathcal{I}_{h}}\left[S_{j}\right]$. Therefore, she will only accept wage offers that are greater than or equal to $x^{* *}$. Finally, at the first stage of the game (i.e. when the firm makes an offer), the firm anticipates a payoff of zero if it makes an offer less than $x^{* *}$ and a payoff of $\vec{J}_{j}\left(x, h_{j}, \Omega\right) \geq 0$ if $x \geq x^{* *}$. Hence, the firm offers exactly $x^{* *}$ to the worker and she accepts it.

To prove that this equilibrium satisfies the intuitive criterion, define $\Theta$ as the set of all possible realizations of $\{a, n\}$. Then, for a given information set $\mathcal{I}_{h}$, define $\hat{\Theta}(w) \subseteq \Theta$ as the set of pairs $\{a, n\}$ for which a wage offer $w$ is not equilibrium dominated for firm $j$. Hence:

$$
\begin{aligned}
& \hat{\Theta}\left(w>x^{* *}\right)=\emptyset \\
& \hat{\Theta}\left(w<x^{* *}\right)=\Theta
\end{aligned}
$$

Any wage offer above the equilibrium wage $x^{* *}$ is always equilibrium dominated. Given that a worker is willing to work for a wage $x^{* *}$, offering a higher wage will only reduce the firm's profits.

However, wage offers below the equilibrium wage are not equilibrium dominated for any realization of $\{a, n\}$ because firm's profits will increase if a worker is willing to work for a lower wage. As a consequence, if a worker receives a wage offer below the equilibrium wage, she cannot extract 
more information from that offer. Regardless of the realization of $a$ and $n$, offering a lower wage could always be a profitable deviation for firms. Formally:

$$
\begin{aligned}
\operatorname{Pr}\left(a=x \mid \mathcal{I}_{h}, w<x^{* *}\right) & =\operatorname{Pr}\left(a=x \mid \mathcal{I}_{h}\right) \quad \forall \quad x \in \Theta \\
E\left[a \mid \mathcal{I}_{h}, w<x^{* *}\right] & =E\left[a \mid \mathcal{I}_{h}\right]
\end{aligned}
$$

Conditional on receiving a wage offer below the equilibrium wage, the worker's expectations do not change. 


\section{Detailed Household's Problem}

This appendix presents the household's problem in recursive form and the complete derivation of the employment and unemployment functions. The household's utility function is given by:

$$
\mathbb{U}(\omega, \Omega)=\frac{c^{1-\sigma}}{1-\sigma}-\Psi \frac{\tilde{h}^{1+\eta}}{1+\eta}+\beta E\left[\mathbb{U}\left(\omega^{\prime}, \Omega^{\prime}\right)\right]
$$

Hence, the household's problem is:

$$
\max _{c, k^{\prime},\left\{h_{j}^{\prime}\right\}_{j=0}^{1}} E_{\mathcal{I}_{h}}\{\mathbb{U}(\omega, \Omega)\}
$$

subject to the budget constraint, the law of motion of labor, and the perceived law of motion of the economy:

$$
\begin{aligned}
c+k^{\prime} & =\left(r+1-\delta_{k}\right) k+\int_{0}^{1} w_{j} h_{j} d j+\int_{0}^{1} \pi_{j} d j+b \cdot u-T \\
h_{j}^{\prime} & =\left(1-\delta_{h}\right)\left(1-q \bar{i} F_{j}\right) h_{j}+q\left(\frac{v_{j}}{v}\right) u+\int_{0}^{j} q \bar{i}\left(\frac{v_{j}}{v}\right)\left(1-\delta_{h}\right) h_{x} d x \\
\tilde{h} & =\left(\int_{0}^{1} h_{j}^{1+\xi} d j\right)^{\frac{1}{1+\xi}} \\
u & =\int_{0}^{1}\left(1-h_{j}\right) d j \\
\Omega^{\prime} & =\lambda^{h}(\Omega)
\end{aligned}
$$

where $E_{\mathcal{I}_{h}}[\cdot]$ is the expectation conditional on the household information set $\mathcal{I}_{h} . \omega=\left\{k,\left\{h_{j}\right\}, \mathcal{I}_{h}\right\}$ is the vector of state variables for household, and $\Omega$ is a vector that summarizes the aggregate state of the economy. Letting $\phi_{c}$ and $\phi_{j}$ denote the Lagrange multipliers for equations (69) and (70), the first order conditions are given by:

$$
\begin{aligned}
& c: E_{\mathcal{I}_{h}}\left\{c^{-\sigma}-\phi_{c}\right\} \quad=0 \\
& k^{\prime}: E_{\mathcal{I}_{h}}\left\{-\phi_{c}+\beta \phi_{c}^{\prime}\left(r^{\prime}+1-\delta_{k}\right)\right\} \quad=0 \\
& h_{j}^{\prime}: \quad E_{\mathcal{I}_{h}}\left\{-\phi_{j}-E\left\{\beta \Psi \tilde{h}^{\prime} \eta-\xi h_{j}^{\prime \xi}+\beta \phi_{c}^{\prime}\left(w_{j}^{\prime}-b\right)\right.\right. \\
& +\left(1-\delta_{h}\right)\left(1-q^{\prime} i F_{j}^{\prime}\right) \beta \phi_{j}^{\prime}-q^{\prime} \int_{0}^{1} \beta \phi_{x}^{\prime}\left(\frac{v_{x}^{\prime}}{v^{\prime}}\right) d x \\
& \left.\left.+\left(1-\delta_{h}\right) q^{\prime} i \int_{j}^{1} \beta \phi_{x}^{\prime}\left(\frac{v_{x}^{\prime}}{v}\right) d x\right\}\right\}
\end{aligned}
$$


Hence, combining (74) and (76) and lagging one period:

$$
\begin{aligned}
E_{\mathcal{I}_{h}}\left\{\left(W_{j}(\omega, \Omega)-U(\omega, \Omega)\right)\right\}= & E_{\mathcal{I}_{h}}\left\{w_{j}-z_{j}\right. \\
& +E\left\{Q \left(\left(1-\delta_{h}\right)\left(1-q \bar{i} F_{j}\right)\left(W_{j}\left(\omega^{\prime}, \Omega^{\prime}\right)-U\left(\omega^{\prime}, \Omega^{\prime}\right)\right)\right.\right. \\
& +\left(1-\delta_{h}\right) q \bar{i} F_{j}\left(\tilde{W}_{j}\left(\omega^{\prime}, \Omega^{\prime}\right)-U\left(\omega^{\prime}, \Omega^{\prime}\right)\right) \\
& \left.\left.\left.-q\left(\bar{W}\left(\omega^{\prime}, \Omega^{\prime}\right)-U\left(\omega^{\prime}, \Omega^{\prime}\right)\right)\right)\right\}\right\}
\end{aligned}
$$

where:

$$
\left(W_{j}\left(\omega^{\prime}, \Omega^{\prime}\right)-U\left(\omega^{\prime}, \Omega^{\prime}\right)\right)=\frac{\phi_{j}}{\beta \phi_{c}^{\prime}}
$$

Also from the first order conditions, we can verify that the optimality conditions for $c$ is given by:

$$
c^{-\sigma}=\beta E_{\mathcal{I}_{h}}\left[\left(1-\delta+r^{\prime}\right) c^{\prime-\sigma}\right]
$$




\section{E Recursive Competitive Equilibrium (Equations)}

This appendix presents the equations that characterize the recursive competitive equilibrium.

$$
\begin{aligned}
& c^{-\sigma}=\beta E_{\mathcal{I}_{h}}\left[\left(1-\delta+r^{\prime}\right) c^{\prime-\sigma}\right] \\
& \kappa_{v}\left(\tilde{q}_{j} v_{j}\right)=E\left[\cdot Q \cdot J_{j}^{\prime}\left(\omega_{f}^{\prime}, \Omega^{\prime}\right)\right] \\
& r=p_{j}\left(\frac{h_{j}}{k_{j}}\right)\left(\frac{\alpha}{1-\alpha}\right) \\
& h_{j}^{\prime}=\left(1-\delta_{h}\right)\left(1-\bar{i} q F_{j}\right) h_{j}+\tilde{q}_{j} v_{j} \\
& c+k^{\prime}=\left(r+1-\delta_{k}\right) k+\int_{0}^{1}\left[w_{j} h_{j}+\pi_{j}\right] d j \\
& z_{j}=b+\Psi c^{\sigma} \tilde{h}_{j}^{\eta} h_{j}^{\xi} \\
& \pi_{j}=y_{j}-w_{j} h_{j}-r k_{j}-\kappa\left(\tilde{q}_{j} v_{j}\right) \\
& Q=\beta\left(\frac{c^{\prime}}{c}\right)^{-\sigma} \\
& \theta=\left(\frac{v}{s}\right) \\
& y_{j}=e^{a_{j}+a} k_{j}^{\alpha} h_{j}^{1-\alpha} \\
& F_{j}=\int_{j}^{1} \frac{v_{x}}{v} d x \\
& \tilde{q}_{j}=\tilde{q}^{u}+\tilde{q}_{j}^{c} \\
& \tilde{q}^{u}=\tilde{q} \cdot\left(\frac{u}{s}\right) \\
& \tilde{q}_{j}^{c}=\tilde{q} \cdot\left(\int_{0}^{j} \frac{\left(1-\delta_{h}\right) \bar{i} h_{x}}{s} d x\right) \\
& q=m(v, s) / s \\
& v=\int_{0}^{1} v_{j}\left(\omega_{f}, \Omega\right) d j \\
& y=\int_{0}^{1} y_{j}\left(\omega_{f}, \Omega\right) d j \\
& s=u+\int_{0}^{1} \bar{i} h_{j}\left(\omega_{f}, \Omega\right) d j \\
& u=\int_{0}^{1}\left(1-h_{j}\left(\omega_{f}, \Omega\right)\right) d j
\end{aligned}
$$




$$
\begin{aligned}
& k=\int_{0}^{1} k_{j}\left(\omega_{f}, \Omega\right) d j \\
& \vartheta \cdot E_{\mathcal{I}_{h}}\left[S_{j}\right]=E_{\mathcal{I}_{h}}\left[\vec{W}_{j}\left(w_{j}, \omega, \Omega\right)-U(\omega, \Omega)\right] \\
& \mathbb{U}(\omega, \Omega)=\frac{c^{1-\sigma}}{1-\sigma}-\Psi \frac{\tilde{h}^{1+\eta}}{1+\eta}+\beta E\left[\mathbb{U}\left(\omega^{\prime}, \Omega^{\prime}\right)\right] \\
& \tilde{h}=\left(\int_{0}^{1} h_{j}^{1+\xi} d j\right)^{\frac{1}{1+\xi}} \\
& U(\omega, \Omega)=b+E\left\{Q\left((1-q) \cdot U\left(\omega^{\prime}, \Omega^{\prime}\right)+q \cdot \int_{0}^{1} W_{x}\left(\omega^{\prime}, \Omega^{\prime}\right) \frac{v_{x}}{v} d x\right)\right\} \\
& \left(W_{j}(\omega, \Omega)-U(\omega, \Omega)\right)=w_{j}-z_{j} \\
& +E\left\{Q \left(\left(1-\delta_{h}\right)\left(1-q \bar{i} F_{j}\right)\left(W_{j}\left(\omega^{\prime}, \Omega^{\prime}\right)-U\left(\omega^{\prime}, \Omega^{\prime}\right)\right)\right.\right. \\
& +\left(1-\delta_{h}\right) q \bar{i} F_{j}\left(\tilde{W}_{j}\left(\omega^{\prime}, \Omega^{\prime}\right)-U\left(\omega^{\prime}, \Omega^{\prime}\right)\right) \\
& \left.\left.-q\left(\bar{W}\left(\omega^{\prime}, \Omega^{\prime}\right)-U\left(\omega^{\prime}, \Omega^{\prime}\right)\right)\right)\right\} \\
& \tilde{W}_{j}\left(\omega^{\prime}, \Omega^{\prime}\right)=\int_{j}^{1} W_{x}\left(\omega^{\prime}, \Omega^{\prime}\right) \frac{v_{x}}{v_{t}} \cdot F_{j}^{-1} d x \\
& \bar{W}\left(\omega^{\prime}, \Omega^{\prime}\right)=\int_{0}^{1} W_{x}\left(\omega^{\prime}, \Omega^{\prime}\right) \frac{v_{x}}{v} d x \\
& \Pi_{j}\left(\omega_{f}, \Omega\right)=\pi_{j}+E\left[Q \Pi_{j}\left(\omega_{f}^{\prime},, \Omega^{\prime}\right)\right] \\
& J_{j}\left(\omega_{f}, \Omega\right)=p_{j}-w_{j}+E\left[Q \cdot\left(1-\delta_{h}\right)\left(1-\bar{i} q F_{j}\right) \cdot J_{j}\left(\omega_{f}^{\prime}, \Omega^{\prime}\right)\right] \\
& S_{j}=J_{j}\left(\omega_{f}, \Omega\right)+W_{j}(\omega, \Omega)-U(\omega, \Omega) \\
& \hat{a}=a+n \\
& a^{\prime}=\rho_{a} \cdot a+e_{a}^{\prime} \\
& n^{\prime}=\rho_{n} \cdot n+e_{n}^{\prime}
\end{aligned}
$$




\section{F Wages from CPS and IPUMS-CPS}

I use the Current Population Survey (CPS) and IPUMS-CPS (Flood, Kind, Ruggles \& Warren, 2015) microdata to construct wage series adjusted for workers characteristics. The CPS is the main labor force survey for the United State, and it is the primary source of labor force statistics such as the national unemployment rate. The CPS consists of a rotating panel where households and their members are surveyed for four consecutive months, not surveyed for the following eight months, and interviewed again for another four consecutive months. The CPS includes individual information such as employment status, sex, education, race, and state. However, individual earnings and hours worked are collected only in the fourth and eighth interviews. In addition, since 1994, individuals have been asked if they still work in the same job reported in the previous month, making it possible to identify job changers. IPUMS-CPS is a project from the University of Minnesota that integrates, disseminates and harmonizes CPS microdata. IPUMS-CPS is free and includes, among many other variables, harmonized series for education, occupation and industry and a unique person and household ID, which makes it easier to link individuals across samples and facilitates data analysis.

Following Muller (2012) and Haefke, Sonntag and van Rens (2013), my empirical model is based on the following MINCER equation for the wage of individual $i$ at time $t\left(w_{i t}\right)$ :

$$
\log \left(w_{i t}\right)=x_{i t}^{\prime} \beta_{x}+\left(\sum_{j=1}^{T} \alpha_{j}^{a} \cdot D_{j}+\alpha_{j}^{n h u} \cdot D_{j} \cdot D_{i t, n h u}+\alpha_{j}^{n h c} \cdot D_{j} \cdot D_{i t, n h c}\right)+e_{i t}
$$

$x_{i t}$ is a vector of individual characteristics, and $\beta_{x},\left\{\alpha_{j}^{a}, \alpha_{j}^{n h u}, \alpha_{j}^{n h c}\right\}_{j=1}^{T}$ are coefficients. $D_{j}$ is a time dummy equal to 1 if $j=t$ and 0 otherwise. $D_{i t, n h u}$ is a dummy variable equal to 1 if worker $i$ spent time in unemployment during the past three months and 0 otherwise. $D_{i t, n h c}$ is a dummy variable equal to 1 if worker $i$ was previously employed at another firm during the past three months and has not been unemployed while switching jobs. Hence, the average (log) wage for all workers $\left(w^{a}\right)$, new employees $\left(w^{u}\right)$ and job changers $\left(w^{c}\right)$ are given by:

$$
\begin{aligned}
& w_{t}^{a}=\alpha_{t} \\
& w_{t}^{u}=\alpha_{t}+\alpha_{t}^{n h u} \\
& w_{t}^{c}=\alpha_{t}+\alpha_{t}^{n h c}
\end{aligned}
$$

The hourly wage rate is constructed by dividing weekly earnings by weekly hours. Following Schmitt (2003), top-coded weekly earnings are imputed assuming a log-normal cross-sectional distribution for earnings. Following Haefke et al. (2013) I drop hourly wage rates below the 0.25th and above the 99.75th percentiles each month. In order to uniquely identify workers in the CPS 
files, I use the IMPUMS-CPS ID variables: CPSID and CPSIDP. ${ }^{50}$

Vector $x_{i t}$ includes a fourth order polynomial in experience, gender, race, marital status, state, 10 occupation dummies, and 14 industry dummies. For occupation, industry and education, I use harmonized variables OCC1950, IND1950, and EDUC provided by IPUMS-CPS. Experience is defined as age minus years of education minus 6. Following the literature, individual $i$ 's weight is the product of the individual's weight reported by the BLS and hours worked.

Due to sample design, it is not possible to match individuals between July 1985 and December 1985 and between June 1995 and November 1995. Hence, with the exception of the average wage for all workers, wage series have a missing value in those months. To compute business cycle statistics for these wage series, I compute the quarterly average wage and impute the missing quarters using the average wage for all workers.

\footnotetext{
${ }^{50}$ I follow IPUMS-CPS recommendations, and I drop a few observations for which changes in sex or race are reported and for individuals whose age changes more than 2 years between samples
} 


\section{G Computational Method: Computing Expectations}

In this appendix, I show how to compute workers expectations given a vector of state variables $\Omega=\left\{k,\left\{h_{j}\right\}_{j=0}^{1}, a^{\mathcal{T}}, n^{\mathcal{T}}\right\}$, and a linear law of motion for the economy as in (40) and (41). Reiter (2009) shows how to find the aggregate law of motion for the economy for heterogeneous agent models. In this appendix, I focus on how to compute workers' expectations, which is the novel part of my paper. In particular, I show that we only need to keep track of the last $\mathcal{T}$ realization of the exogenous state variables in order to compute expectations. Therefore, we do not need to include as a state variable agents' beliefs or the realization of vector $\Omega, \mathcal{T}$ periods ago. This represents a significant gain in efficiency because the dimensionality of the problem does not significantly increase. Solving numerically this model, I found that setting $\mathcal{T}=100$ was more than enough, meaning that a value of $\tilde{\mathcal{T}}>>\mathcal{T}$ did not represent any significant difference. However, the optimal value for $\mathcal{T}$ is a function of how informative the signal is. For example, when $\rho_{a}$ and $\rho_{n}$ are close, it becomes more difficult to distinguish between TFP and noise shocks. Agents' expectations take longer to converge to the true values, and a larger value of $\mathcal{T}$ is needed.

This note is based on the Kalman filter and follows the notation of Hamilton (1994). I start with some definitions. Then, I show how to compute expectations regarding the vector of state variables. I conclude by computing expectations about endogenous variables and forecasting economic conditions.

\section{G.1 Preliminary Definitions}

Define $e_{t}=\left[\begin{array}{ll}a_{t} & n_{t}\end{array}\right]^{\prime}$ as the vector of exogenous state variables, which evolves according to:

$$
\begin{aligned}
e_{t+1} & =\mathcal{F} e_{t}+\mathcal{V}_{t} \\
\mathcal{F} & =\left[\begin{array}{cc}
\rho_{a} & 0 \\
0 & \rho_{n}
\end{array}\right] \\
E\left[\mathcal{V}_{t} \mathcal{V}_{t}^{\prime}\right] & =\mathcal{Q} \\
& =\left[\begin{array}{ll}
\varsigma_{a} & 0 \\
0 & \varsigma_{n}
\end{array}\right]
\end{aligned}
$$

The vector of states variables $\Omega$ can be partitioned as $\Omega_{t}=\left[\begin{array}{ll}\Omega_{t} & e_{t}\end{array}\right]^{\prime}$ where $\tilde{\Omega}$ is the vector of endogenous predetermined state variables. Then, the dynamics for $\Omega$ and $\Upsilon$ (vector of non- 
predetermined variables) are given by:

$$
\begin{aligned}
\Omega_{t+1} & =\mathbb{F} \Omega_{t}+\mathbb{E}_{t} \\
\Upsilon_{t} & =\mathbb{J} \Omega_{t} \\
\mathbb{E}_{t} & =\left[\begin{array}{ll}
\varnothing & \mathcal{V}_{t}
\end{array}\right] \\
\mathbb{F} & =\left[\begin{array}{cc}
\mathbb{F}_{\tilde{\Omega}} & \mathbb{F}_{e} \\
\varnothing & \mathcal{F}
\end{array}\right] \\
E\left[\mathbb{E}_{t} \mathbb{E}_{t}^{\prime}\right] & =\mathcal{R} \\
& =\left[\begin{array}{ll}
\varnothing & \varnothing \\
\varnothing & \mathcal{Q}
\end{array}\right]
\end{aligned}
$$

Hence, assuming that vector $\Omega$ was perfectly observed at time $t-\mathcal{T}$, we only need to from expectations about $e$ to infer agents' beliefs regarding other variables in the economy.

\section{G.2 Computing Expectations about $e$}

Forming beliefs about $e$ is a classic signal extraction problem. In this section, I show that the expectation of $e_{t}$ conditional on information available at time $x$, which is denoted by $e_{t \mid x}$ can be expressed as a linear combination of the last $\mathcal{T}-1$ shocks.

In this case, the signal is given by $\hat{a}=a+n$, and the evolution of conditional expectations $\left(e_{t \mid x}\right.$ is given by:

$$
\begin{aligned}
a_{t} & =H^{\prime} e_{t} \\
e_{t \mid t} & =\mathcal{F} e_{t \mid t-1}+B_{t}\left(a_{t}-H^{\prime} \mathcal{F} e_{t \mid t-1}\right)
\end{aligned}
$$

where matrices $H$ and $B_{t}$ :

$$
\begin{aligned}
H & =\left[\begin{array}{ll}
1 & 1
\end{array}\right]^{\prime} \\
B_{t} & =P_{t \mid t-1} H\left(H^{\prime} P_{t \mid t-1} H\right)^{-1} \\
P_{t \mid t-1} & =\mathcal{F} P_{t \mid t} \mathcal{F}^{\prime}+\mathcal{Q} \\
P_{t \mid t} & =P_{t \mid t-1}-P_{t \mid t-1} H\left(H^{\prime} P_{t \mid t-1} H\right)^{-1} P_{t \mid t-1} \\
P_{t-\mathcal{T} \mid t-\mathcal{T}} & =\varnothing
\end{aligned}
$$


It can be verified that:

$$
\begin{aligned}
e_{t \mid t} & =e_{t}+\sum_{j=0}^{\mathcal{T}-1} C_{t-j} \mathcal{V}_{t-j} \\
C_{t} & =\left(B_{t} H^{\prime}-I\right) \\
C_{t-j} & =-C_{t-j+1} \mathcal{F}\left(B_{t-j} H^{\prime}-I\right) \quad 0<j<=\mathcal{T}
\end{aligned}
$$

\section{G.3 Computing Expectations about $\tilde{\Omega}$}

We can rewrite the law of motion for $\tilde{\Omega}_{t}$ as follows:

$$
\begin{aligned}
\tilde{\Omega}_{t} & =\mathbb{F}_{\tilde{\Omega}} \tilde{\Omega}_{t-1}+\mathbb{F}_{e} e_{t-1} \\
& =\mathbb{F}_{\tilde{\Omega}}^{\mathcal{T}} \tilde{\Omega}_{t-\mathcal{T}}+\mathbb{F}_{\tilde{\Omega}}^{\mathcal{T}-1} \mathbb{F}_{e} e_{t-\mathcal{T}}+\sum_{j=0}^{\mathcal{T}-2} \mathbb{F}_{\tilde{\Omega}}^{j} \mathbb{F}_{e} e_{t-1-j}
\end{aligned}
$$

Given that workers perfectly know $\tilde{\Omega}_{t-\mathcal{T}}$ and $e_{t-\mathcal{T}}$, the expected value of $\tilde{\Omega}$ given information available at time $t$ is given by:

$$
\tilde{\Omega}_{t \mid t}=\mathbb{F}_{\tilde{\Omega}}^{\mathcal{T}} \tilde{\Omega}_{t-\mathcal{T}}+\mathbb{F}_{\tilde{\Omega}}^{\mathcal{T}-1} \mathbb{F}_{e} e_{t-\mathcal{T}}+\sum_{j=0}^{\mathcal{T}-2} \mathbb{F}_{\tilde{\Omega}}^{j} \mathbb{F}_{e} e_{t-1-j \mid t-1-j}
$$

Combining, (138), (139), and (134), we get:

$$
\begin{aligned}
\tilde{\Omega}_{t \mid t} & =\tilde{\Omega}_{t}+\sum_{j=0}^{\mathcal{T}-2} \mathbb{F}_{\tilde{\Omega}}^{j} \mathbb{F}_{e} \tilde{\mathcal{V}}^{t-1-j} \\
\tilde{\mathcal{V}}^{t-1-j} & =\sum_{i=0}^{\mathcal{T}} C_{t-1-j-i} \mathcal{V}_{t-1-j-i}
\end{aligned}
$$

According to (134) and (141), I only need to keep track of the last $\mathcal{T}$ realization of $e$ instead of keeping track of the whole vector of expectations $\tilde{\Omega}_{t \mid t}$ and $e_{t \mid t}$ to compute workers expectations. ${ }^{51}$

\section{G.4 Expectations about $\Upsilon$ and Forecast}

It is now straight forward to define the expectations of $\Upsilon$ given information available at time $t$.

$$
\begin{aligned}
& \Upsilon_{t \mid t}=\mathbb{G} \Omega_{t \mid t} \\
& \Omega_{t \mid t}=\left[\begin{array}{ll}
\tilde{\Omega}_{t \mid t} & e_{t \mid t}
\end{array}\right]^{\prime}
\end{aligned}
$$

\footnotetext{
${ }^{51}$ Notice that you can also keep track of $\mathcal{V}$ directly.
} 
Hence, partitioning matrix $\mathbb{G}=\left[\begin{array}{ll}\mathbb{G}_{\tilde{\Omega}} & \mathbb{G}_{e}\end{array}\right]$, the forecast $f$ periods ahead is given by:

$$
\left[\begin{array}{c}
\tilde{\Omega}_{t+f \mid t} \\
e_{t+f \mid t} \\
\Upsilon_{t+f \mid t}
\end{array}\right]=\left[\begin{array}{ccc}
\mathbb{F}_{\tilde{\Omega}} & \mathbb{F}_{e} & \varnothing \\
\varnothing & \mathcal{F} & \varnothing \\
\mathbb{G}_{\tilde{\Omega}} & \mathbb{G}_{e} & \varnothing
\end{array}\right]^{f}\left[\begin{array}{c}
\tilde{\Omega}_{t \mid t} \\
e_{t \mid t} \\
\Upsilon_{t \mid t}
\end{array}\right]
$$

